\title{
Daughters caring for elderly parents
}

Citation for published version (APA):

Dautzenberg, M. G. H. (2000). Daughters caring for elderly parents. [Doctoral Thesis, Maastricht University]. Datawyse / Universitaire Pers Maastricht. https://doi.org/10.26481/dis.20001124md

Document status and date:

Published: 01/01/2000

DOI:

10.26481/dis.20001124md

Document Version:

Publisher's PDF, also known as Version of record

\section{Please check the document version of this publication:}

- A submitted manuscript is the version of the article upon submission and before peer-review. There can be important differences between the submitted version and the official published version of record.

People interested in the research are advised to contact the author for the final version of the publication, or visit the DOI to the publisher's website.

- The final author version and the galley proof are versions of the publication after peer review.

- The final published version features the final layout of the paper including the volume, issue and page numbers.

Link to publication

\footnotetext{
General rights rights.

- You may freely distribute the URL identifying the publication in the public portal. please follow below link for the End User Agreement:

www.umlib.nl/taverne-license

Take down policy

If you believe that this document breaches copyright please contact us at:

repository@maastrichtuniversity.nl

providing details and we will investigate your claim.
}

Copyright and moral rights for the publications made accessible in the public portal are retained by the authors and/or other copyright owners and it is a condition of accessing publications that users recognise and abide by the legal requirements associated with these

- Users may download and print one copy of any publication from the public portal for the purpose of private study or research.

- You may not further distribute the material or use it for any profit-making activity or commercial gain

If the publication is distributed under the terms of Article $25 \mathrm{fa}$ of the Dutch Copyright Act, indicated by the "Taverne" license above, 


\section{DAUGHTERS CARING FOR ELDERLY PARENTS}


Hendrik Nicolas Werkman (1882-1945) is een Groningse kunstenaar die deel witmaakre van 'De Ploeg'. De meeste werken die hier zijn afgebeeld hangen in her Gemeentemuseum van Den Haag, ze zijn gemaakr tussen 1941 en 1944. Het zijn afdrukken warbij gebruik is gemaakt wan sjablonen en stempels. De centrale figur op de prenten symboliseert de dochter die haar ouders helpt, de andere figuren de diverse rollen en weranrwoordelijkheden die ze heeft woor de mensen om haar been.

Hendrik Nicolaas Werkman (1882-1945) is a Durch artist who lived and worked in Groningen, where he was parr of De Ploeg'. De various figures on the prints symbolise the diversity of roles and responsibilities that daughters of elderly parents may have.

9 Dautzenberg Marike GH, Maastricht 2000

ISBN $905278292 X$

Vormgeving en druk:

Datawyse/Uniwersitaire Pers Maastricht

Hiustratie omslag:

Metre de Groot, Groningen 


\section{DAUGHTERS CARING FOR ELDERLY PARENTS}

\section{Proefschrift}

ter verkriging van de graad van doctor aan de Universiteit Maastricht, op gezag van de Rector Magnificus,

Prof. dr. A.C. Nieuwenhuijzen Kruseman, volgens het besluit van het College van Decanen, in het openbaai te verdedigen op vrijdag 24 november 2000 om 14.00 uur door

\section{Maria Gerarda Hubertina Dautzenberg}

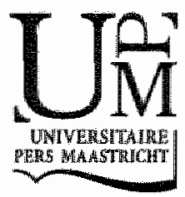




\section{Promotor:}

Prof. dr. H.Philipsen

\section{Co-promotor:}

Dr. J.P.M. Diederiks

\section{Beoordelingscommissie:}

Prof. dr. H.F.J.M. Crebolder (voorzitter)

Prof. dr. W.J.A. van den Heuvel

Prof. dr. C.M.A. Frederiks

Dr. J.F.B.M. Fiolet

Dr. C.W. Bosch 
For my mother

who made the unbearable

always light 


\section{TABLE OF CONTENTS}

CHAPTER 1

Overview and general discussion 9

CHAPTER 2

Women of a middle generation and parent care

CHAPTER 3

Multigenerational caregiving and well-being; Distress and burden

of middle-aged daughters providing assistance to elderly parents

CHAPTER 4

The competing demands of paid work and parent care

CHAPTER 5

Multiple roles of women as determinants of the caregiving responsibility; Why some daughters become primary helpers of

elderly parents and others secondary helpers

CHAPTER 6

Stability and change in caregiving; A longitudinal study on the impact of women's multiple roles on continuation and cessation of caregiving

Summary

Samenvatting

Acknowledgements 
CHAPTER 1

Overview and general discussion

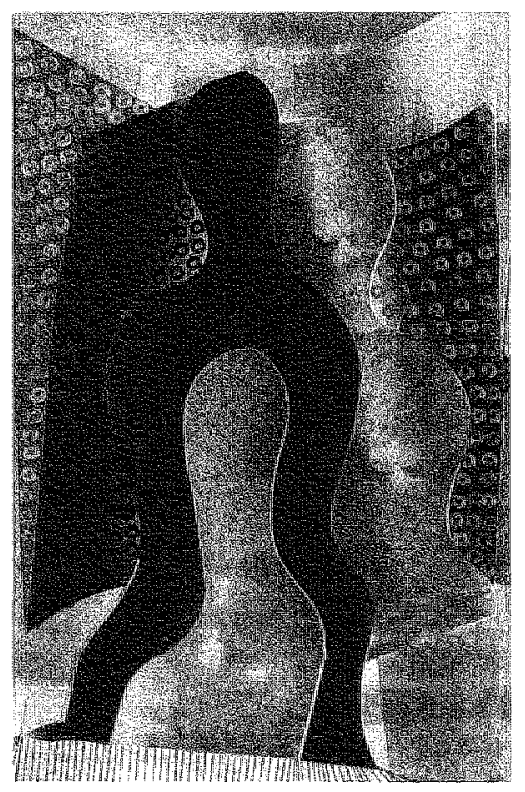


10 Chapter

$I k$ zoek je nog steeds en bid

om nog wat tijd.

Ik ben bang

dat je weggaat zonder dat ik je kende.

Tanita Buizer 
This dissertation addresses one of the most prominent social issues of our times - the support that older people receive from younger generations. Demographic trends show that the proportion of old people in the population is growing dramatically. More people are growing old, chronic diseases are replacing acute diseases, and people are living longer with more severe and more complex disabilities. The proportion of people over 65 years is expected to increase in the Netherlands from $13 \%$ in 2000 to $20 \%$ by 2025 , with the absolute number of elderly people almost doubling in that same period, in particular of the so-called 'old old' (Central Bureau of Staristics, 1999).

When elder care is needed, the family is still considered as the first port of call; families have been reported to provide over $80 \%$ of the care received by the elderly in the community (Merrill, 1997). Close relatives of frail elderly are assisting in myriad ways, probably providing more elaborate care for longer periods of time than ever before. In this context, Brody (1985) has described parent care as a "normative experience". Almost any adult will be involved in the care for a frail parent at some stage of her or his life - "expectable, though usually unexpected" (Brody, 1985:21).

Not every adult child gets equally involved in parent care. Family care for the old usually means that the women of the family are held responsible. In particular when a parent's spouse is no longer available, daughters are the main providers of help for elderly parents. Policy makers have expressed concern that the principal role of women in parent care might change. Shifting social values and life styles, and in particular the rapid entry of middle-aged women into the labor force during the past decades, have raised questions on how these developments might affect women's involvement in care roles such as parent care. Terms such as "women-in-the-middle", "the sandwich generation" and "the double burden" are used, suggesting that women might get "caught" or "sandwiched" in the middle of multiple claims on their time and energy. They might either decide to withdraw from caregiving or continue to do so at the cost of their own health. Relatively few studies have subjected these assumptions to empirical proof. Do we face a social problem, now or in the near future, and to what extent is it an issue of major concern? Is parent care negatively affected when women have other roles as well? To what extent does women's involvement in parent care -when combined with other responsibilities-enhance or reduce, their wellbeing? These are the issues that we focus on in this dissertation. 


\section{Women as caregivers}

In this dissertation, the universe of discourse is women and in particular female caregivers. From a sociological and theoretical point of view, family care is a strongly gendered institution since it is almost the exclusive domain of women. In socialization processes, girls are taught from early childhood onwards to be sensitive to other people's needs and feelings. As a consequence, women have developed an inclination to experience other people's needs as if they were their own (Brody, 1990). This attitude makes women very susceptible to assume caregiving tasks and to become the nurturers and the "kinkeepers" of the family. In this context the term "labor of love" has been used, referring to the fact that, for women, caring about -love- and caring for -labor-are often considered as almost identical (Gilligan, 1982, cired in Lewis and Meredith, 1988). Women's inclination to care characterizes their atritude towards elderly parents and other frail relatives.

The empirical consequence of women's dominance in the institution of family care is that the majority of helpers of elderly parents are women. Daughters have been reported in the US to outnumber sons in ratios of four to one (Brody, 1990) and in the Netherlands in ratios of nine to one (Janssen, 1991). When sons are the primary caregivers, their wives, i.e. the daughters-in-law, usually provide most of the hands-on care (Brody, 1990). In astudy like that described in this dissertation, use was made of a population-based sample, i.e. including respondents that were not involved in parent care. A very large sample would have been required to find a sample of male respondents large enough for perform statistical analyses on. Hence, we only included women in the sample of our study.

This dissertation does not only focus on women, but narrows the study population further down to middle-aged women. Middle-aged women stand 'in the middle' in various ways. They are in their middle years, perhaps facing the first signs and symptoms of declining health. They may also stand in the middle of conflicting values. Women have been raised with the traditional value that care of older people is their responsibility. At the same time they are expecred to pursue other interests outside their homes, in particular employment. Further, they may feel that they are emorionally in the middle between the needs of elderly parents and their own families at home, both rivaling for her attention and rime.

In this dissertation, we do not question this predominance of women in parent care. We consider it as an established fact from which we have started our investigation. One nuance has to be made. The principal role of women in parent care should not conceal the efforts of sons and sons-in-law. Sons also behave as caring and responsible helpers for their parents, in particular when daughters are not available. 


\section{Sample}

As cited above, use was made of a population-based probability sample among women of the birth cohort 1940-1954. We selected this group of middle-aged women - 40 to 54 years at that time - because these women were most likely to be simultaneously involved in multigenerational caregiving and out-of-home employment. Women younger than 40 are less likely to have a parent that is frail. Women older than 54 are less likely to have children at home -the mean age of women when children leave the parental home is 52 years (Cörvers, 1979). Moreover, these women are more likely to already have left the labor force.

A random sample was drawn from the population registration offices of the municipality offices in Heerlen and Landgraaf. Heerlen is a city about 30 kilometers from Maastricht University and Landgraaf is a conglomerate of villages and semi-urbanized quarters bordering Heerlen. Together, Heerlen and Landgraaf are known as Parkstad Limburg, their population being over 120,000. The registration offices of Parkstad Limburg provided names and addresses, the telephone offices provided the telephone numbers. Telephone coverage in the Netherlands is over $99 \%$ and the proportion of households with unlisted number is less than $10 \%$. Data were collected by a telephone survey by a team of professionall interviewers of the Medical Information Center (MEMIC) of Maastricht University. The study relied completely on self-reported data.

Data collection took place in two waves with an interval of 25 months. The first wave was in 1994 and the second wave in 1996. In 1994, 1260 women were approached by telephone, with 934 completing the questionnaire (response rate $79 \%$ ); in 1996,843 women could be traced again with 743 completing the questionnaire (response rate $80 \%$ ). The overall response rate of the two waves was $62 \%$. The non-response analysis of the women not willing to participate in the study, as well the description of measurements, are provided in the various chapters of this dissertation.

In addition to the telephone survey, a series of in-depth interviews took place with a limited number of respondents. Informants were selected on the basis of the telephone survey data, with a focus on women who could be described as "women-in-the-middle'. They helped parents at least 3 hours per week, and combined this help with a family of their own, an (almost) full-time job, or both. A comparison group of women who only helped a parent was included. Both primary and secondary helpers were interviewed, as well as another relative involved in the care for the parent (if applicable). Although we do not report the findings of the in-depth study in this dissertation, the information provided by the informants $(n=78)$ added to the researchers ${ }^{*}$ understanding of the so-called 'internals' of caregiving and the context in which help to parents took place. 


\section{Topics}

In this dissertation, first, the prominence of the phenomenon 'women-in-the-middle' or the 'sandwich generation' has been described by determining the proportion of women that actually have multiple roles and responsibilities, i.e. combining regular assistance to parents (caregiver role) with paid work (role of employee), child rearing responsibilities (role of mother), having a spouse (spousal roles), and other social activities. The present state of literature and the terminology suggests that large groups of middle-aged women might be juggling conflicting demands on their time and energy, or whole generations getting caught in the middle of claims from younger and older generations. In Chapter 1 we tested these assumptions empirically and indicated the magnitude of the phenomenon that has been labeled as 'women-in-the-middle".

Second, we examined whether women's other responsibilities affect the amount of help they give to parents. Dowomen with families of their own, or employed women, spend less time on helping parents? Are these women more likely to withdraw from caregiving? The consequences of women's multiple roles for parent care are described in various chapters. In Chapter 2 , we describe briefly whether women with families of their own provide less help to ellderly parents. In Chapter 3 we examined whether multigenerarional caregiving and women's multiple roles reduce, or enhance their wellbeing. Chapter 5 describes how women's other roles affect the level of responsibiliry women are able to assume in parent care, i.e. whether they become primary caregivers or only will be helping as secondary caregivers. In Chapter 6 we examine wherher women's multiple roles affect in particular decisions regarding withdrawal from caregiving.

Third, we investigated the determinants of the amount of parent care when daughters or daughters-in-law help frail parents. In multivariate analyses, we compared the relative importance of women's social roles to the impact of various other factors, in particular geographical distance, the type of impairment of the parent, the quality of the relationship with the parent and filial obligation. Is the nearest living daughter always helping the parent or the daughrer that feels most strongly obliged to the parent? What is the (relative) importance of structural, situational factors as compared to personal idiosyncratic factors, in particular the quality of the relationship with the elder and feelings of obligation towards the parent? The results of these analyses are found in the Chapters 2, 3, 4 and 5.

Fourth, this dissertation examines the impact of women's multiple roles on their wellbeing and subjective burden of care. Do women whose life is filled with various responsibilities become more distressed when they take on the caregiver role? Or does the opposite occur, with caregivers faring better when they have multiple social roles because it may support, buffer or compensate for any strains emanating from parent care? The answers these questions are mainly presented in Chapter 3. In addition, in Chap- 
ter 2 we examined whether the combination of having a job and providing assistance to elderly parents makes women feel conflicted, increases their absenteeism at work and forces women to quit their jobs.

Fifth, we examined the motives for helping parents. Why do some daughters devote part of their lives to the care of elderly parents? Moreover, why do others provide no help at all? It is common sense that the emotional bond between parent and child is natural and that children are driven by affection when helping their parents. However, little is known about what motivates adult children to help parents and why some choose not to get involved. Is it love and affection that inspires them? Or do they mainly feel obliged to help their parents? To what exrent is this type of moral commitment waning? What explanations are being used when daughters do give help and when they don't? The answers to these questions are found in Chapters 5 and 6.

Before we turn to the findings, we will briefly elaborate the theoretical foundations of this dissertation and the hypotheses that have been tested empirically on our data-set.

\section{THEORETICAL FRAMEWORK}

\section{Role theory}

Assumptions of either a positive or negative impact of women's involvement in various social roles, and the assumed incompatibility - for women - of work and family roles, originate mainly from role theory. Role theory is based on the general view that societies consist of institutions and that institutions are made up of social roles. The concept of social roles is instrumental for empirical research because it links the more abstract and hence less observable sociological notions of 'social structures' and 'social institutions' to a more easily empirically observable phenomenon, that is the social behavior of individuals (Goode, 1960). Social roles refer to a set of obligations that individuals are expected to fulfil and a common set of values and agreements that usually go with it. In this dissertation, social roles of women refer mainly to the role of employee, i.e. women's involvement in paid work, the role of mother, referring to child-rearing responsibilities, and the spousal role, referring to living together with a partner.

Role theory assumes that social roles have a dual function. On the one hand, social roles provide individuals with rights, privileges, and hence self-fulfillment and life satisfaction. On the other hand, social roles induce role strain because the so-called 'role incumbents' often have difficulty in fulfilling all role obligations. Regarding the balance between those two mechanisms, i.e. the net outcome of role strains and role privileges, three different hypotheses have been formulated, labeled as the role scarcity hy- 
pothesis (Goode, 1960, Marks, 1977), the role expansion hypothesis (Marks, 1977) and the role accumulation hypothesis (Sieber, 1974). This dissertation relies mainly on notions derived from role theory, that is the role scarcity, the role accumulation and the tole expansion hypothesis.

\section{Role scarcity bypothesis}

The role scarcity hypothesis of William Goode (1960) assumes that individuals are limited in their time and energy, in other words, that there is a scarcity in time and energy to be allocated to various roles and obligations. One of the basic assumptions of the role scarcity hypothesis is that individuals generally make their lives full and 'busy'. In the terminology of fole theory, they tend to accumulate roles until the total role system is overdemanding, with role strain automatically resulting from that. One source of strain is the fact that some social roles may require inconsistent or incompatible demands. Another source of strain is role overload, referring to the process through which role obligations become too overwhelming in time and energy. Obligations within roles, or berween various roles, may also conflict in time or in the allocation of resources. Regarding multiple roles, Goode (1960) states that, when individuals start to accumulate social roles, after an initial decrease, role strain will increase more rapidly than the corresponding rewards do. The individual's main problem is to make the total role system manageable and to keep role strain within bearable limits.

Several techniques exist to teduce role strain. Roles can be eliminated, although curtailment is one of the most difficult things to do. Another technique is 'compartmentalization', referring to the demarcation of obligations, for example to ser time limits to specific tasks or roles. Even the extension of roles may reduce role strain because adding another role may function as an excuse to reduce the more extensive claims from another role. In short, the scarcity hypothesis assumes that the occupancy of multiple roles usually is conflicting and stressful.

\section{Role accumulation bypothesis}

In contrast to the scarciry hypothesis with its focus on role strain, role overload and role conflicts, the role accumulation bypothesis of Sam Sieber (1974) emphasizes the positive effects that multiple roles can have on people. According to this hypothesis, the one-sided stress on negative results is misplaced because it overlooks the merits and rewards that originate from role accumulation. Sieber (1977) classified role rewards into four categories: (1) role privileges, (2) status security, (3) resources for status enhancement and role performance, and, (4) personality enrichment and ego gratification. 
With regard to role privileges, Sieber states that every role carries with it duties and rights, but that there is a tendency of a net result of rights over duties. Starus security refers to the notion that multiple roles provide people with multiple nerworks and, hence, with possibilities to compensate the strains that result from one role, by the gratification and satisfaction from other roles. Examples are primary relationships, such as one's family or spouse, and secondary relationships, such as co-workers, that may function as buffers and contribute to the individual's stability and security. Multiple roles may also provide with additional resources for status enthancement, another type of reward, relating in particular to non-institutionalized by-products of social relarions. Examples are connections and the emoluments that often become available by sheer occupancy of certain positions, such as access to additional sources of information, social gatherings or free meals. The occupancy of multiple roles often has a multiplier effect because it gives access to more networks that give access again to orher nerworks securing the individual's possibilities to remain influential and embedded in social networks. Role performance may also enhance someone's self-esteem and self-fulfillment, reducing boredom and providing access to more sources of information. All of these factors contribute to the mental health and wellbeing of an individual. In short, the role accumulation hypothesis believes that multiple roles are more gratifying than stressful.

\section{Role expansion bypothesis}

The third hypothesis, formulated by Steven Marks, is the role expansion bypothesis, occupying a middle position between the role scarcity and the rolle accumulation hypotheses. It assumes that people's energy and role systems are neirher scarce or limited and inexhaustible. Marks (1977) thought in terms of reserves of energy, assuming that people always withold some energy and free these reserves only for the most valued or most sanctioned obligations. Hence, people consciously manipulate their energy system and prevent its full flow into one single role or into the total (multiple) role system. In this line of thought, the crucial mediating concept is 'commitment'. Individuals have ample energy for activities and roles they feel committed to, and may even feel more energetic when fulfilling obligations to which they feel, in Marks' terms, overcommitted. In contrast, individuals easily feel exhausted and drained when they perform tasks that they feel uncommitted, or undercommitted, to. Social and cultural norms and walues determine to which types of roles people feel committed. As described before, women are more inclined to feel committed to care roles such as child care and parent care and are to a lesser extent expected to be committed to paid work. Marks (1977) suggests that the popular appeals to a lack of time that are so often heard in contemporary societies actually are statements that are used by individuals to hide their undercommitment and the lack of priorities given to certain roles or obligations. 
An example is that as men usually are being excused from the caregiving role when they" are employed while employed women are not. In short, according to the expansion view, the addition of another role to a multiple role set only increases distress when individuals feel committed to that role.

In this dissertation, we have made use of role theory as a general framework to describe and analyze our findings. Within the context of a role theoretical approach, we considered the three cired approaches of tole scarcity, role accumulation and role expansion as three competing hypotheses that have been tested empirically within the sample population of this study.

In line with the scarcity approach, we hypothesized that the burden of care and distress of caregivers increases rapidly when they have other commitments and roles as well. In addition, we would expect that caregivers attempt to eliminate roles, such as reducing their involvement in parent care or reducing their work hours, when care demands increase. In contrast, the role accumulation hypothesis would predict that caregivers with multiple roles fare best and will usuaily not aim to reduce their involvement in any of their roles. In line with the expansion hypothesis, we expected that women may add on the parent care role to their role set without feeling more burdened or more distressed winder the condition that they are strongly committed to that role, i.e. only when they feel strongly obliged to help their parents. If they do not feel committed, the addition of the caregiver might increase their subjective burden.

\section{FINDINGS}

\section{The magnitude of the phenomenon}

With regard to the first topic, i.e. the existence and prominence of the phenomenon labeled as the 'sandwich generation' and the prominence of the issue, we found that only relatively small proportions of women were simultaneously involved parent care, paid work and child-rearing responsibilities. Although considerable proportions -approximately $30 \%$ - were mothers, paid workers and helpers of their parents, only tiny proportions were bighly involved in these roles at the same time, despite the fact that we had selected an age group of women (40-54 years) where the likelihood of an overlap in these roles was greatest. For example, less than one percent were mothers of minor children, were helping parents at least two mornings or afternoons per week and were employed for 32 hours or more per week. Similar findings have been reported by other empirical studies in the US and Canada that made use of population-based samples (Rosenthal, Matthews and Marshall, 1989; Rosenthal, Marthews and Matthews, 1996). We concluded that the potential problem of "women-in-themiddle' or the 'sandwich generation' often is overstated. The proportion of daughters 
that are in a potentially problematic role combination is very small; hence, women have only a very small chance to get 'caught in the middle'. We concluded that the sandwich generation does not exist, since there is no such thing as a whole generation getting sandwiched between competing claims from the generations ahead and behind them.

Our data suggest that the majority of women perform the roles of paid worker, mother and helper of a parent sequentially rather than simultaneously. Consistent with demographic developments during the 20th century (Philipsen, 1995), child care and parent care years are most likely to be successive, and not overlapping, stages in life. By the time that elderly parents will call upon the help of their daughters, the daughters' children usually either have left their parents' home or may nor be dependent anymore. Another observation that we made was that women's roles seem to be complementary rather than accumulative. Women that were highly involved in one role, were less likely to have other major commitments as well. Caregivers of elderly parents that provided a larger amount of help frequently were unemployed or unmarried; and full-time working women usually had no children or no spouse.

\section{Consequences for parent care}

The overall picture was that in general multiple roles make women somewhat less available for parent care, but do not significantly reduce their inwolvement in parent care. The amount of help to parents did not depend on the number of other commitments that women had. In addition, no indication was found that daughters wirh multiple roles are more likely to withdraw from caregiving, or that women who have a family of their own are less likely to be involved in parent care.

Two other patterns were seen. First, only women with no other major commitments spent significantly more time on helping a parent and were more likely to perceive parent care as a primary responsibility. These women were 50 years of age on average, and usually were not employed, had no spouse and had adult children or no children. We argued that for these women, the help to elderly parents adds meaning and purpose to their lives.

Second, work appeared as a role that competed with parent care, although not in all respects. Employed women were less likely to start helping parents and to assume a primary responsibility in care. In particular full-time working women seemed to get involved as secondary helpers rather than as primary helpers. We hypothesized that perhaps a self-selection process takes place, with those daughters that are not too overwhelmed by other responsibilities such as work or the women that were unmarried being most likely to assume the caregiver role. The working hours of daughters, however, did not compete with the amount of help provided to parents. When factors such 
as age and education were controlled for, part-time and full-time employed caregivers provided approximately equal amounts of help.

\section{Determinants of parent care}

If mulriple roles only have a limited impact, what other factors may determine women"s help to parents? In these analyses, described in warious chapters, we examined, beside the relative weight of each of the competing roles of work, minor children, a spouse and the caregiver role, various factors. The focus was on the predictive value of (1) the demographic factor of being the only child, (2) the siruational and practical factor of geographical proximity, (3) affectionate factors, i.e. the quality of the relation with the parent and, (4) and attitudinal factors, i.e. filial obligation felt towards elderly parents. The analyses controlled for several social and demographic characteristics, such as age, education and income of the respondent, and parent characteristics such as their general health and whether they had symptoms of dementia. In addition, we examined interaction affects of specific role combinations, assuming that in particular the combination of full-time work and a family of one's own might have an exacerbating effect reducing women's involvement in parent care.

The results of these analyses revealed that factors leading to the acquisition of the caregiver role were fourfold. First, regarding the three major social roles, only work appeared as a commitment that might compete with women's involvement in parent care, but only with regard to the acquisition of the caregiver role. Employed women were less likely to get involved in parent care at all. However, once providing regular assistance, full-time and part-time employed women provided similar amounts of help as nonemployed women. Having minor children did not reduce women's involvement in parent care.

Second, geographical proximity to the parent recurred in all analyses as the strongest predictor of parent care. Women that live near a parent are most likely to assume the caregiver role, to take the primary responsibility in care and to provide a larger amount of help. Although we know that emotional support and advice can be provided across the miles over the phone or by mail, our data showed that living nearby is the main condition of being able to provide instrumental help to elderly parents.

Third, being an only child appeared as a demographic imperative, necessitating women to stare with caregiving, to continue doing so and to spend more hours on this help. However, the number of siblings affected women's involvement only in very large families. Only when daughters had more than six brothers or sisters, they were less likely to be helping their parents; having one, two or three (up to five) siblings did not affect their involvement in parent care.

Fourth, the type and level of impairment was important. As one may expect, dementia symptoms of a parent, or their general poor health made daughters more likely 
to assume the helper's role and to spend more time on this help. Remarkably, the relationship with the parent did not seem to affect women's decisions on helping the parent, at least not directly. As indicated in this dissertation, we found that a good relationship reduced in particular the subjective burden of care.

Thus, we concluded that choices of caregivers tend to be influenced by social and structural factors, such as proximity, employment, and the need of the parent rather than by personal and idiosyncratic factors such as filial obligation and the quality of the relation with the parent. Despite the significance of these structural factors, however, we do acknowledge that situational and social forces may operate outside the awareness of helpers of frail elderly. In searching to legitimize their actions, caregivers may have the honest belief that their involvement in parent care is entirely the result of their attitude of filial obligation and the quality of their relationship, unaffected by extraneous circumstances. We will discuss this further in the context of the reported motives for helping frail parents.

\section{Distress and burden}

With regard to women's multiple roles affecting distress and the subjective burden of care, we found that the caregiver role as such, that is helping parent at least three hours per week, appeared not to affect women's distress, also when various role combinations were taken into account. The lack of any general effect of caregiving on women's wellbeing is consistent with our finding that most respondents reported that helping their parents was not a burden at all to them and that they felt it as being the result of their own choice. Probably, in the general population, the majority of middle-aged women are able to integrate the caregiving tasks into their role system without major frictions and dislocations. One reason for this might be that most elderly living in the community are still relarively healthy and need only low or moderate levels of support from their daughters and daughters-in-law.

With regard to the impact of women's multiple roles on their wellbeing, our findings indicate that women's capacities are elastic rather than restricted, with the majority being able to accommodare various roles if necessary. There were no statistically significant differences in levels of distress when women had various numbers of roles or between women in various role combinations of caregiver, employee, mother and the spousal role. Among women that were not helping parents, distress even decreased significantly with the number of roles: the more social roles and social responsibilities these women had, the less distressed they fellt. Although these findings suggest that mulriple roles enhance rather than reduce women"s wellbeing, the causal direction is not clear since we based this conclusion on cross-sectional analyses. Do women fare better because they have mulriple roles? Or do the most capable women tend to accumulate more social roles and responsibilities? 
In search for a causal affect, we examined also with the help of longitudinal data whether the acquisition of the caregiver role in the past two years had affected distress levels of women in various role combinations. From these analyses (Chapter 3), again, no statistically significant differences were found between groups of women that had started caregiving for an elderly parent when they had few or multiple other responsibilities, confirming that women are able to handle multiple roles and responsibilities without major trictions.

However, one caurionary remark neds to be made. Although differences were not statistically significant, a remarkable pattern appeared. When women had many other responsibilities, the addinion of the caregiving role was associated with an increase in distress; In contrast, withdrawal from caregiving relieved women with many other roles them from this distress. When they had few other responsibilities, an opposite effect occurred: the addition of the caregiver role decreased their distress. This partern suggests that the addition of the caregiving tasks increases distress under the condition that women have many roles and decreases distress under the condition that women have few other roles. We make mention of these findings because of the consistency in the partern and because ir is plausible from a role theoretical point of view. The lack of statistically significant findings might be due to the small size of the sub-samples in these analyses. In addition, the follow-up period of 25 months might have been too short to find any substantial changes, in particular with regard to changes in major social roles. Further research with larger sub-samples and more extended follow-ups are needed to confirm whether the pattern that we found is based on coincidence or not.

Consistent with the cited pattern, we found in the longitudinal data that women with the fewest commitments appeared to be most distressed, that is women that were unmarried, unemployed, childless or with adult children. This appeared to be the case both among helpers of parents and women thar were currently not helping parents. These data suggest that the lack of roles rather than its multiplicity seem to make women more distressed. Perhaps being 'roleless" renders women devalued, depriving them of a structure in life and the legitimacy of commitments.

With regard to helpers of parents that were most distressed when they have few orher roles, an alternative explanation may be valid. Since women with few other commitments beside helping their parents, usually spend many hours per week on this task, we hypothesized that for those women, caring has become roo much their central life interest. Their life may become dominated by the care for the frail parent.

With regard to the subjective burden of care, social roles such as work, having a family of one's own, or a combination of these roles, appeared not to make women feel more burdened. A poor health of parent and the type of impairment, i.e. dementia symproms of the elderly person mainly determined the experienced burden of care. The hours of help and the quality of the relationship with the parent had an impact as 
well. A strong atritude towards filial obligation reduced feelings of being burdened by care.

Probably the quality of roles and how women experience each of these roles, rather than the number of roles, determines whether women fare well in a multiple role set. The evaluation of the caregiver role appeared as a strong predictor predicting distress.

\section{Consequences for the work place}

We examined separately whether employed women feel conflicted because of combining the dual responsibilities of work and parent care and what the consequences were for their work. The overall impression was that employed women did not find it always easy to balance work and the help to their parents, despite that they seemed to manage reasonably well. The main way of handling incompatible demands from work and parent care was to distribute vacation days over the year and taking one, or half a day, off when something unexpected occurred. Some of them also adjusted work schedules; however, using sick leaves while not being sick, or making use of special leaves, was rather the exception than the rule. None of these employed caregivers reported that the help to their parents affected their occupational careers in the sense that they had forgone career opportunities.

We need to mention that the Dutch welfare system includes an extended system of almost free community care for the infirm and elderly, in addition, employees are entithed to $30-45$ vacation days per year. It must be seen against this background that consequences of parent care for the workplace are still limited. Our data also showed that full-time working women experienced more difficulties than part-time working women. Considering the fact that in the Netherlands the proportion of full-time working women is still growing, it is realistic to expect that additional supportive measures will be needed in order to enable employed caregivers of elderly parents to combine work and parent care.

\section{Motives for prowiding care: Affection or obligation?}

The intimacy and privacy of family caregiving leads us to attribute the motives of daughters to help parents primarily to emotional attachment and affection for the parent. However, personal affinity alone does not explain why some daughters are caregivers while others are not. Sociological writing has stressed a sense of 'obligatedness' to help one another as one of the major characteristics of this type of kinship relations (Finch and Mason, 1991). Empirical studies have confirmed this: In particular the tie between parents and children is imbued with the heaviest sense of responsibility and commitment (Finch and Mason, 1991). Children are supposed to support their parents and vice versa, driven by norms of fillial obligation and reci- 
procity. Although norms of filial obligarion have generally been accepted as a 'natural' part of family life, they seldom have been subject to empirical investigation. In this section, we will discuss the main findings of our study.

Over one third of the women of our study found it hard to indicate why and how they had become the caregivers of their parents. The most frequently heard statements were that 'it happened gradually' or them 'being drifted into it'. Sometimes, and in parricular in the early stages of increasing dependency of parents, help to a parent might not be easily distinguished from mutual assistance. Care demands often are built up so slowly and fitted piecemeal into one's situation that it is hard to reconstruct at what point in time the balance shifted from dependency from, to dependency by, the parent.

A considerable proportion of women referred to the affectionate relation with the parrent motivaring them to help, illustrated by statements such as "we have a special emotional bond" or "I just love him/her". We hypothesized that love, affection and obligation are sometimes easily confused. On the one hand, in contemporary societies children are expected to be independent and free to lead their own lives. On the other hand, they feel that they are indebted to their parents and that it is appropriate to help them when they become impaired. It has been suggested that, in the process of reconciling these contradictory notions of autonomy and debt, adult children dress up their feelings of obligation by stressing that they help parents out of love and as the result of their own free choice (Allan, 1988).

Another frequently reported theme that dominated women's motives and drives to help parents were norms of intergenerational reciprocity and obligation, illustrated by statements such as "I feel obliged to do so" or "I consider it as my ducy". It has been suggested that the notion of filial obligation and being indebted to parents originates from the inherently uneven flow of support across the generations, with more support flowing downwards, i.e. from older to younger generation, than upwards. This disparity in support by older and younger generations may explain why some adult children will always feel indebted to parents and continue feeling that they 'never do enough' -no matter how hard they try and not matter how much help they provide (Brody, 1985).

Closely rellated to filial obligation is the notion of reciprocity, expressed by statements such as "I owe it to them", implicitly referring to the notion of giving something in return. This principle of reciprocity berween parents and children has been described as 'generalized reciprociry' (Gouldner, 1960). Generalized reciprocity allows a considerable time-delay between gift and return in the exchange of goods or services, as is the case with parents and children. Moreover, the exchange is not necessarily similar, including both 'tit for tit' and 'tit for tat'. Gouldner (1960) has stated that reciprocity is a universal element of all cultures and societies. As an internalized norm, or an existential folk belief that people share, it covers two interrelated demands. People should help those who have helped them, and people should not injure those who have helped them. In other words, you always have to return what you have received. In line with 
this thought, we hypothesized that adult children are morivated to help their parents by generalized reciprocity. Parent care will continue to be normal and a matter of course for daughters because these daughters have been cared for by their parents.

\section{Impact of filial obligation on parent care}

Remarkably, our data indicated that feeling strongly obliged to parents did not affect daughters' likelihood to become a caregiver at all. However, those who helped parents rended to provide more hours help when they felt strongly obliged. In other words, even if women do not feel very obliged to parents, they will help them if necessary, but they will not spend as much time on it.

Filial obligation was directly related to the quality of the relationship with the elder. As one may expect, when daughters found that the elder behaved rather negatively towards them, they felt less obliged to help and were, hence, less willing to give a large amount of assistance. As noted before, filial obligation also reduced the caregiver's feelings of burden. Feeling strongly obliged to help probably buffers for negative feelings induced by the potential burden of the caregiving role.

A comparison of the reasons for helping parents and the reasons for not helping them showed a remarkable contrast. Excuses for nor helping parents referred to structural, rather 'objective' factors such as the large geographical distance to the parent, other relatives already helping the parent and a lack of time because of their jobs. These explanations were in line with statistical analyses of women who were helping parents and those who were not. Employed women, women with siblings and those who lived rellatively far away were involved either at a secondary level only in parent care or were not helping at all. This is in line with what Pfuhl and Henry (1993) have labeled as using verbal accounts, or the vocabularies of motives, referring to the explanations that individuals use to justify or neutralize 'wrong' behavior, i.e. not helping a frail parent.

In contrast, among helpers of parents, the justifications for helping parents did not refer to practical circumstances, such as them living closest, but referred to love and obligation for the parent. Apparently, women justified their help to parents with positive, personal motives and excused their not being involved by referring to factors that were lying outside their control.

\section{THEORETICAL IMPLICATIONS}

With regard to the validity of the three hypotheses of role theory, i.e. the role scarcity, the role accumulation or the role expansion hypothesis, we found partial support for all three hypotheses. The -perhaps inevitable-conclusion is that 'it depends'. 
Among women not helping parents, strongest support was found for the role accumulation hypothesis. The significant association between social roles and distress showed that the more roles women had, the less distressed they felt. This finding supported the assumption that, most probably, the accumulation of roles provides women with sources for ego gratification, role privileges, status enhancement and personaliry enrichment. However, the causal direction between wellbeing and the number of roles might run in both directions, as we have explained earlier. Multiple roles may result in less distress and the least distressed women may be inclined to take more roles and responsibilities.

Among caregivers, most support was found for the expansion hypothesis. In general, women seem to accommodate the caregiver role into their lives without major frictions. Among helpers of parents, the subjective burden of care did not depend on the number of other social roles they had, wherher they were employed or not, or the hours they were involved in out-of-home employment, but depended on other factors such a large amount of help being given. Another indication of the validiry of the role expansion hypothesis was that role commitment appeared to affect the burden of caregivers, with those daughters who felt strongly obliged (committed) to help their parents feeling less burdened.

Least support was found for the role scarcity hypothesis. Only with regard to the question who becomes a caregiver at all and the primary caregiver within the family, did two roles compete with the caregiver role, i.e. employment and the spousal role. However, rather than employment and parent care being mutually competing roles, we got the impression that a self-selection process takes place with those daughters that were not too overwhelmed with other responsibilities such as a job, assuming the caregiver role. At the same time, however, we have to bring to the reader's attention the previously reported finding that our longitudinal data suggest that the addition of the caregiver role to a multiple role set of women may actually increase their distress.

\section{STRENGTHS AND LIMITATIONS OF THE STUDY}

One of the strengths of this study was that use was made of population-based study. The sample was a cross-section of 'ordinary women' and the high response rates of $70-80 \%$ strengthened us in our view that the findings have a representative value for the female age cohort that we focused on. Another unique feature was that this study made use of longitudinal data on parent care and women's multiple roles.

One of the limitations was that the study completely relied on self-reported data and no additional, more objective measures have been made of the situation of the daughter-caregivers and their dependent parents regarding the care they received from orher sources. Very limited information was available on the amount of professional 
care received by the elderly parents. We acknowledge that this type of-additionalsources of help may have affected the amount of help needed by parents, and the amount of the distress or role conflicts experienced by caregivers. A second limitation was that, in our longitudinal analyses, the interval of two years appeared to be too short to find major changes in the social roles that were of specific interest to this study, such as work and children having grown up. The subgroups that had changed were small which limited statistical analyses and the meaning and implications of our findings. However, we mentioned the trends in our data because of their plausibility from a theoretical point of view.

With regard to the definitions that have been used, we only want to make a remark on the terms 'help to parents' and 'the caregiver role'. We are aware of the fact that these terms refer to a very heterogeneous group of caregivers and helpers as it included a rather diverse range in assistance varying from odd errands to intensive long-term personal care. However, differentiating between women who helped with only one rask or various tasks, and between the various types of help, would have resulted in sub-samples that were too small for statistical analyses.

Another important limitation is that we had no information on the experienced quality of the roles, except for the subjective burden of care that was an indication for the experienced quality of the caregiver role. We have already stressed the importance of the quality of roles affected women's distress when they have multiple role sets.

\section{POLICY IMPLICATIONS}

Interventions should not only aim at relieving the burden of care that stems directly from the caregiving enterprise itself. Programs that are geared toward easing sources of stress that have been caused indirectly by care might be equally successful. Examples are the construction of social and leisure life through the provision of respite care for caregivers and relief from economic hardships. It is our conviction that these areas of support deserve a further exploration and should be part of intervention packlages for elder care.

We recommend further that public policies for the support of family caregiving have a high degree of flexibility and variety. Individual differences in needs and resources are large and community care should take the unique features of the situation into account. A tailored combination of services is needed rather than the proposal of a specific solution that is generally applicable for all caregivers.

A particular challenge is the support to employed caregivers, taking in to consideration the potential conflict that may arise between work and parent care when women work full-time. We recommend, first, that increased attention should be paid to the 
importance of flexibility in work schedules as one of the most important requisites to make the combination of work and care a successful enterprise.

Support from managers, bosses and co-workers and special leaves will be helpful as well. Employers need ro realize that, in the long run, it is more cost-effective to enable employees with care responsibilities to combine work and care successfully. The government can play a parr in this by providing information to employers and organizations on issues of elder care. Other possibilities are day care centers for elderly relatives of employees, similar to child care centers, perhaps even combining these two in one facility. The government and municipalities may play a role in financing and subsidizing this type of support or at least in subsidizing pilot projects of this type.

Special laws may be adopted. The legal right to work part-time for limited periods of time in order to take care for a frail parent may enable employed caregivers to sustain a high level of in-home care without endangering their jobs and, hence, their means of living.

A final recommendation concerns the reconsideration of the primary focus of social policies on individual rights, as it poses dilemmas when parent care is concerned. Caregiving for an elderly person usually involves the family, and not only the disabled parent him/herself. Our suggestion is that state support should take on the family as the unit of service when analyzing and supporting those involved in parent care, rather than focus on the care recipient or primary caregivers as individuals.

Regarding the balance of state support and the efforts that are expected from the daughters of the family, we share Finch and Mason's conclusions (1993) that, alrhough daughters generally accept their responsibility that they are the first line of assistance for elderly parents, the state cannor build their social policies for elder care on any claims or rights from relatives. Elderly people do not want to be dependent on relatives and helpers want to retain the right to provide help from their own choosing.

\section{CONCLUSION}

One of the most foremost findings of our study was that the multiplicity of women's roles had hardly any negarive impact on the distress and burden of care of women. This finding goes against the popular notion that women's multiple roles, and in particular the combination of work and care roles, is detrimental for women's mental health. Probably the experienced quality of these roles rather than mere role incumbency itself that determines women's wellbeing.

Another major finding is that the term 'sandwich generation' is not applicable. However stressed some caregivers might be because of the pressure they experience from competing demands, it does not concern a whole generation of women that are sandwiched. In addition, we like to stress that the one-sided focus on the negative as- 
pects of caregiving, as the terms 'burden' of care and the 'sandwich' generation suggest, tends to obscure any positive sides of caregiving. Without romanticizing this task, we know from our interviews that caregiving somerimes adds a completely new dimension to the relationship between adult children and their parents, connecting them in unexpecred ways. Life events, such as the onset of caregiving for an elderly parent, do have a very positive side, although its positive evaluation may occur only after some time when looking back on past experiences.

It was remarkable how common it was for middle-aged daughters to provide assistance to their parents and parents-in-law. Not only were a considerable number helping the parent regularly and had been doing so for many years, they looked upon this help as being a matter of course. Apparently, the institution of family care still exists and seems to have strong foundarions. Daughters still accept the responsibility for dependent elderly as lying first and foremost with them, and behave accordingly. In that respect our findings are in contrast to what is commonly postulated, viz. that the social value of familial obligations is waning and that parents often are being abandoned by their children. We think that, as long as parents care for their children, the universally accepted value of generalized reciprocity will motivate adult children to care for their elderly parents. We do agree with other researchers in our field that the notion of alienation and abandonment of elderly parents by their children is a deeply entrenched myth that tends to persist like a hydra-headed monster. According to Greek mythology, this monster could nor be killed because for every head that is chopped off two new heads come in place (Shanas, 1979).

We hoped that this study is another challenge to this myth.

\section{REFERENCES}

Allan, Graham. (1988). Kinship, responsibility and care for elderly people. Aging and Society, 8: 249-268.

Brody, E.M. (1985). Parent care as a normative family stress. The Gerontologist, 25: 19-29.

Brody, E. M. (1990). Women in the Middle: Their Parent-Care Years. New York: Springer.

Cörvers, C.J.M., van de Heiden, A.M., de Hoog, C., \& van Leeuwen, E.H. (1979). Huishouden, Huwelijk en Gezin. Monografie Volkstelling on 18. The Hague: SDU.

Goode, W.J. (1960). A theory of role strain. American Sociological Review 25: 483-496.

Gouldner, A.W. (1960). The norm of reciprocity: A preliminary statement. American Sociological Review, 161.

Finch, J., and Mason, J. (1993). Negotiating family responsibilities. London: Routledge.

lanssen, T. (1991). Thuiszorg: 'n hele zorg. Opvattingen en ervaringen van centrale verzorg(st)ers van hulpbehoevende oudere mensen (Home care; opinions and views of primary caregivers of frail eldery). Nijmegen: ITS. 
Centraal Bureau voor de Statistiek. (1999). Kerncijfers, website: http:/www.cbs.n//kerncijfers. Voorburg, Heerlen, Netherlands.

Lewis J., and Meredith, B. (1988). Daughters caring for mothers: The experience of caring and its implications for professional helpers. Aging and Society, 8: 1-21.

Marks, SR. (1977). Multiple rotes and rolle strain: some notes on human energy, time and commitrient. American Sociological Review 42: 921.936.

Merril, D.M. (1997). Caring for elderly parents; jugg/ing work, family, and canegiving in middle and working class families. London: Auburn House.

Philipsen, H. 1995. Rede gehouden op de $19^{\circ}$ Dies Natalis van de Rijksuniversitent Limburg 13 januari 1993 (lecture held on 3 January 1993). Maastricht: University Maastricht.

Pfuhl, E.H., and Henry, 5. (1993). The Deviance Process. New York: Aldine de Gruyter.

Rosenthal C.J., Matthews S.H., and Marshall V.W. 1989. Is parent care normative? The experiences of a sample of middle-aged women. Research on Aging, 11:244-260.

Rosenthal, C.J, Martin-Mathews, A., and Matthews, 5.H. 1996. Caught in the Middle? Occupancy in multiple roles and help to parents in a national probability sample of Canadian adults, Joumal of Cerontology, 511B: $\$ 274-\$ 283$.

Shanas, E. (1979). Social myth as hypothesis: The case of the family relations of old preople. The Cerontologist, 19:3-9.

Sieber, S.D. (1974). Toward a theory of role accumulation. American Sociological Review, 39 : $567-578$.

Uehara, E.S. (1995) Reciprocity reconsidered: Gouldner's moral norm of reciprocity and social support. Journal of Social and Personal Relationships, 12: 483-502. 
CHAPTER 2

Women of a middle generation
and parent care1,2

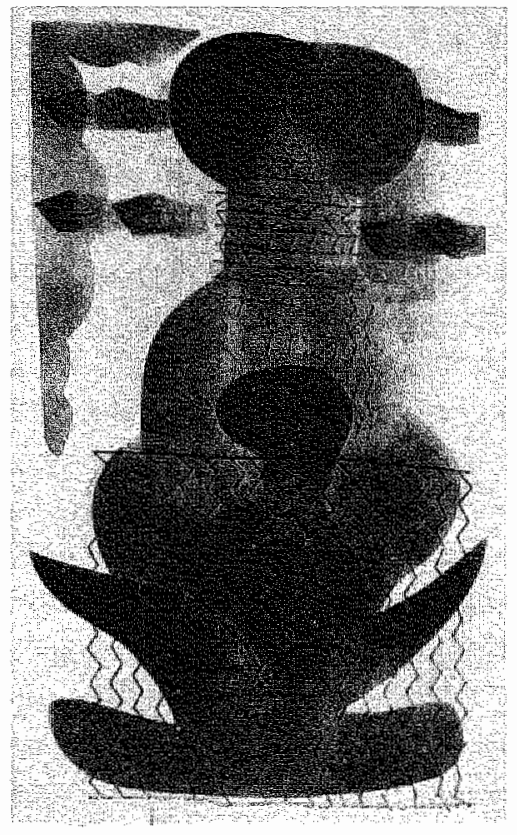


$32 /$ Chapter 2

Zoals je hoofd is afgewend, zoals je handen zijn weggelegd, zoals je zit alsof je je lichaam al hebt verlaten

Rutger Kopland 
This article addresses women who are both caring for parents and children, the so called sandwich generation or women-in-the-middle. Gerontological studies on this topic reflect controversies on the concept as well as on the size of the phenomenon.

Our study artempts to demonstrate empirically to what extent middle-aged women respond to the care demands of both the generation ahead as well as the generation behind them. Use is made of a population-based sample among women aged $40-54$ in the Netherlands ( $N=933$ ). The study indicates the prevalence of women-in-the-middle and presents analyses of their socio-demographic characteristics as well as of patterns of parent care. Further, the potential for a cross-cultural comparison between the Netherlands and other countries is discussed regarding parent care as a normative experience and the chances of middle-aged women getting "caught" between care demands from two generations.

\section{INTRODUCTION}

Empirical research on family care for the elderly documents the salience of daughters and daughters-in-law as helpers and caregivers of the elderly (Boyd \& Treas, 1989; Dwyer \& Coward, 1991; Himes, 1994; Horowitz, 1985; Mohide, 1993; Sociaal Cultureel Planbureau, 1994; Stoller, 1989). In the US it has been reported that daughters provide even more of the long-term care services than elderly peoplexs spouses do (Brody, 1990). Middle-aged daughters find themselves in a specific position. They belong to a middle generation, since they are the children of their elderly parents and may at the same time be the parents of their own children. Some authors refer to women in this position as the sandwich generation' (Duijnstee, 1992; Miller, 1981; Rosenthal, Matthews \& Marshall, 1989; Schlesinger, 1989) and others as 'women-inthe-middle' (Boyd \& Treas, 1989; Brody, 1990; Horowitz, 1985; Lang \& Brody, 1983; Spitze \& Logan, 1990; Stephens, Franks \& Townsend, 1994).

The present state of research on women-in-the-middle or the sandwich generation has wo interlinked features. First, the 'sandwich generation' and 'women-in-themiddle' have been conceptualized from different perspectives. As a consequence, opinions diverge on the number of women who actually are in such a position.

With regard to the concept, some authors appear to describe the phenomenon from a generational or demographical point of view, stressing the imbalance in exchange of services between the middle and other generations (Hagestadt, 1985; Litwak, 1965; Miller, 1981; Schlesinger, 1989). Consequently, they use the term "sandwich generation', portraying it as a middle generation providing more support and resources to younger and older generations than it receives back from either group. 
More recent literature has adopted concepts from role theory (Boyd \& Treas, 1989; Brody et al., 1983; Horowitz, 1985; Stephens, Franks \& Townsend, 1994; Stoller, 1989; Stone, 1990). These authors describe women-in-the-middle in terms of being positioned in complex role configurations. Women-in-the-middle are depicted as being "caught" between the competing roles of parent care, motherhood and employment. In addition, Brody (1990) mentions aspects of gender socialization. Parent carers are in the middle between conflicting values. Women have been raised with the traditional value that care of older people is their responsibility. At the same time they are expected to pursue interests outside their homes, in particular employment. Another point raised by Brody is that the woman-in-the-middle stands emotionally in the middle, that is between the elderly parents and her own family. Both rival for her attention and time.

With regard to the second issue, the size of this phenomenon, researchers have conflicting views. Some state that it is a widespread phenomenon, assuming that many middle-aged women are caught in the middle of multiple roles and responsibilities (Brody, 1990). Brody (1985) stated that parent care increasingly becomes a normative experience'. She points to the growing proportion of the elderly in the population and medical developments causing a prolongation of the life of chronically ill older people. Therefore, ar some stage of their lives, almost all women become involved in parent care, a responsibility which usually comes on top of their other roles.

In contrast, there are researchers who question a prominent existence of women-in-the-middle. Himes (1994) for example, call it a popular gerontological myth that many women experience the overlap between parent care, child care and employment. Both Rosenthal et al. (1989, 1996) and Spitze and Logan (1990) concluded from research in Ontario and New York that only a few women find themselves in complex role configurations. Child care may not be a major demand at the same time parent care is (see also Boyd \& Treas, 1989). In other words, these roles are performed rather sequentially than simultaneously.

In short, the sandwich generation and women-in-the-middle have been conceptualized either as a whole generation or as the specific portion of a middle generation, i.e. women in complex rolle configurations. The differences in theoretical views have led to various assumptions about the size of this phenomenon.

Empirical evidence is still scarce. Several authors have stressed the need for empirical research using population-based samples (Barling, MacEwen, Kelloway \& Higginbottom, 1994; Rosenthal, Matthews \& Marshall, 1989; Spitze \& Logan, 1990). Uhlenberg (1993) expressed the need to know how common the phenomenon actually is (Rosenthal, Matthews \& Matthews, 1996). Although several studies have been performed in the US, hardly any publications exist on the European situation. This article presents the findings of an empirical study performed in a European context. We use a conceptual framework combining both demographic-generational 
and role theoretical aspects. Use is made of a population-based survey sample among women aged 40-54 years in the Netherlands. First, we describe the prevalence of women responding to care demands from two generations. The aim is to investigate whether it concerns a large or a small proportion of middle-aged women. Second, we analyze their social, demographic and care characteristics, aiming at constructing a profile of this group of women. Third, we explore patterns of parent care by middle-aged women, examining to what extent parent care is a normative experience for middle-aged women. In line with previous research, we assumed that women with multiple roles may be less able to meet the care demands of elderly parents. Therefore, we tested the hypothesis whether women who face care demands from two generations provide less help to parents than other caregivers. Finally, we will discuss to what extent our conclusions may be relevant to some other European countries and the US.

In the remainder of this article we will use the term women-in-the-middle since it seems more neutral than the term sandwich generation.

\section{Conceptual framework}

In our conceptual framework we combined both a generational-demographical and role theoretical point of view. As a first step, we used the basic assumprions of the generational perspective, that is (1) women who belong to a middle generation in three- or four-generation families, and (2) women who provide care to a younger generarion as well as to an older generation in their family.

In the light of all possible family tree positions as well as with regard to care provided to older and younger generations, women aged 40-54 can find themselves in one of the nine care configurations. (types 1 to 9) as is shown in figure 1. In this model, G1 refers to the older generation, $G 2$ to the middle generation and $G 3$ to the younger generarion in the family tree. Care responsibilities are indicated with an arrow. In our model, four-generation families are presented as if they were three-generation families, although we are aware that some women may face care demands from three generations.

As can be seen in figure 1, a proportion of women aged 40-54 provides care to an older generation, that is types 1,2 and 3. Others do not give care, despite the fact that they have an older generation in their family (types 4,5 and 6 ). The women of types 7, 8 and 9 no longer have an older generation in their family. Among the nine types, only type 1 can be considered as women-in-the-middle, since these women provide care to younger as well as older generations.

One remark has to be made. We did not aim to reflect all possible care relations of middle-aged women. We included only the care as provided by the middle generation G2 to other generations and not the support received from other generations. Therefore, the reciprocal aspects of intergenerational relations will not be touched upon. 


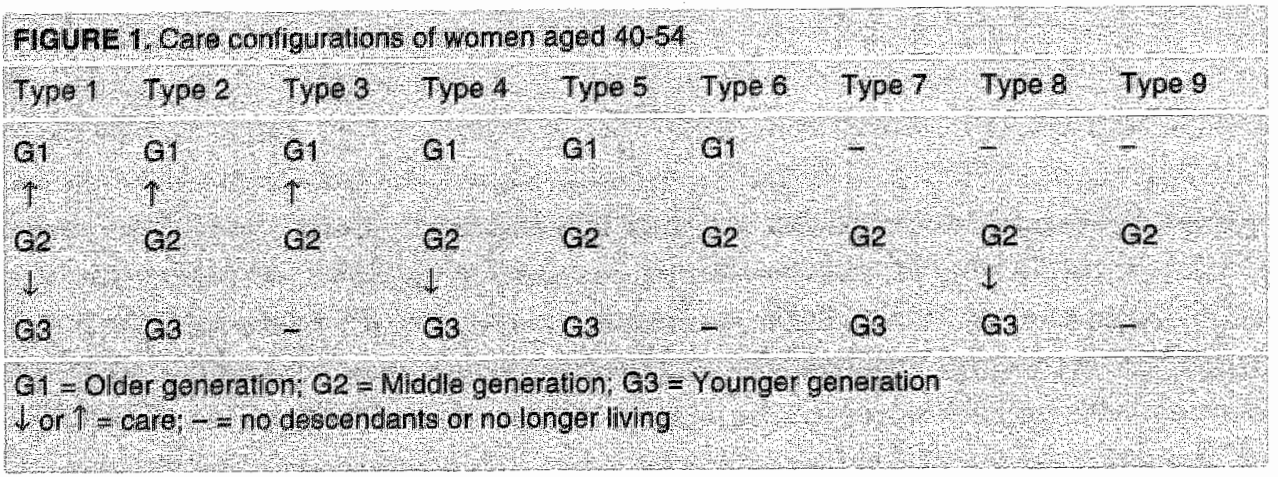

As a second step, 'care for a younger generation' and 'care for an older generation' were specified by adapting role theoretical concepts, that is 'performing the mother role' and "performing the role of parent carer'. Empirically, we defined the mother role as providing childcare, referring to sharing the household with children; the role of parent carer was specified as having provided help in the past weeks to parents or parents-in-law. No minimum level was set for child and parent care. Thus, the role of parent caregiver referred to a wide range of activiries, varying from emotional support and occasional errands, to day-to-day personal care.

Women-in-the-middle are thus empirically defined as those women who have children in their housebold and bave provided help or care in the past four weeks to one or more parents or parents-in-law. We excluded support given to adult children, to grandchildren and to other older relatives, because this help usually is much less than the support to dependent children and parents/-in-law. Other commitments, in particular employment, will be considered as a-possibly-complicaring circumstance women may find themselves in.

With this framework as a starting point, we focused the empirical investigarion on three research questions:

1. What proportion of women within a cohorr of women aged $40-54$ belong to type 1, that is providing care to both a younger and an older generation?

2. Do the women of type 1 differ from other women of the same age group (types 2-9) or from other caregivers (cypes 2 and 3 ) with regard to socio-demographic characteristics?

3. Do women-in-the-middle (type 1) differ from other caregivers (types 2 and 3) with regard to patterns of parent care?

Before addressing the first research question, a general description will be given of the care and help provided to elderly parents/-in-law by respondents of the sample. 


\section{METHOD}

Daca were obtained through a telephone survey among a cohort of women aged 40-54. The survey took place in 1994 in one medium-sized town $(80,000$ inhabitants) and three smaller towns (in total 40,000 inhabitants), in the province of Limburg, the Netherlands. The research area included an urbanized area, urbanized suburbs, dormitory suburbs and village-neighborhoods. As such, it represented a common situation for larger and smaller towns and villages in the Netherlands. The sample data on marital status, education, employment and income reflected the population census data of the Netherlands (CBS, 1991; CBS, 1994; CBS 1995).

\section{Sample}

The sample consisted only of women, because the majority of caregivers consist of women. The incorporation of men as an additional subgroup would have resulted in a more diverse sample making statistical analyses less sound.

The age cohort 40-54 was selected because women within this age group are more likely to be 'in-the-middle'. Parents of women under 40 are often not yet widowed and frail. For women of 55 and over, it is less probable that they have dependent children since the mean age of women when children leave their parental homes is about 52 years in the Netherlands (Corver et al., 1979).

Respondents were recruited on the basis of a probability sample, randomly $\mathrm{d}$ rawn from the municipality registration offices. Telephone numbers of respondents were obtained from the telephone directories. In the Netherlands less than $8 \%$ of all households have unlisted numbers. Since municipality registration offices provide samples selected by sex, marital status and age, we requested a stratified sample, with the categories 'widows' and 'unmarried' women being oversampled in order to have a sufficient number of respondents from these categories for statistical analysis. To calculate population statistics, data were weighted by marital status and three age categories (40-44, $45-49,50-54)$. The weighting procedure was based on the 1994 population census data of the towns concerned.

In total 1207 respondents were approached by telephone. Direct contact was established with 1160 respondents. A number of respondents $(N=47)$ could nor be contacted because they had moved, did not answer the telephone or had a developmental disability. In all, 933 respondents completed the questionnaire with 226 respondents refusing to cooperate. The overall response rate was $77 \%$. The reasons most frequently mentioned for not cooperating were lack of interest, lack of time and language problems. The non-response group $(\mathrm{N}=226)$ differed significantly from the response-group $(\mathbb{N}=933)$ by maritall status $\left[\chi^{2}=4.48(d f=1), p=.03\right]$. In particular wid- 
ows and unmarried women were less ready to agree to being interviewed. For widows a frequently mentioned reason was the fact that their husband had died recently.

The non-weighted sample of 933 respondents consisted of 618 respondents who were married and/or living together with a partner, 110 unmarried respondents, 115 divorced and 92 widowed respondents. As can be seen from table 1, after weighting, $79 \%$ wete married/living together with partner, $4 \%$ were not married, $13 \%$ divorced and $4 \%$ widowed. Their mean age was 46.5 years. On the average they had 2 children (ranging from 0 to 7 ). Eighty-four percent had at least one living parent or parent-in-law. The mean age of the parents was approximately 75 years. Seventeen percent had grandchildren and $10 \%$ had grandchildren as well as living parents (four-generation families).

The educational level of respondents varied from a few years of primary school to university. The majority $(74 \%)$ had completed primary and secondary education or primary school and a vocational training. Half of the respondents were employed $(51 \%)$, on average 24 hours a week. Most married respondents lived with a partner who was employed (75\%).

\section{Measurements}

In the telephone questionnaire the presence of dependent children was indicated by the question "Whom do you share the household with?". Help and care for parents/-in-law were indicated by the question: "In the past four weeks, did you give help to your parent or parent-in-law ? By help we mean things like cleaning the house, laundry, shopping, transportation and the like?". Both the frequency of help ("In the past two weeks, how often in a week did you wisit your parent or parent-in-law to provide this help?") and the time spent on the help ("In the past two weeks, how many mornings, afternoons or evenings per week did you spend on this help?") were indicative for the amount of help. Respondents were also asked which type of help they provided ("Did you help your parent/-in-law with the following: cleaning the house/laundry, food preparation, shopping, transportation, arranging appointments, bathing or dressing, finances, discussing problems?"). Further, they were asked about the duration ("Since when have you been providing this help?") and being a primary helper ("Are you the one in the family who does most or do you share caring tasks?").

Frailty of the parents was indicated by the item "Is your parent able to do his/her day-to-day activities, such as housework and transportation, by him/herself, or is s/he frail and does s/he need help in doing that?" An indication of the subjective burden of care was elicited by the question "How do you experience helping your parent: do you like doing it or is it a burden to you?" (4-point Likert scale: like/sometime like, sometimes burden/burden/heavy burden). Having a busy life was measured by the question "Do you consider yourself as having a quiet or a busy life?" ( 1 =very quiet, $4=$ very busy). 
Having a busy life was considered as an indication of the experienced daily pressure, which is not necessarily negative. In our sample $70 \%$ felt that they had a -very-busy life, of whom $58 \%$ responded that they liked that life style; only $7 \%$ explicitly stated that they felt that they were over-burdened by various demands. Help to orher relarives referred to regular help in the past weeks to older relatives other than their elderly parents, e.g. aunts and uncles (yes/no). Help to adult children was the help given to children not co-residing with them, excluding the normal visits (yes/no). Voluntary work was any unpaid work done in organized settings $(y / n)$. Respondents were also asked how many hours they spent weekly on it.

\section{Statistical analysis}

Differences between groups were indicated by bivariate tests, using $\chi^{2}$-tests and t-tests for dichotomous variables, nonparametric tests (Mann-Whitney) for variables at an ordinal level and one-way analysis of variance or t-tests where variables were measured at an interval level.

Discriminant analysis was performed as well. This multivariate (canonical) statistical procedure is useful in finding a combined set of variables serving as a basis for discriminating between two groups. As a multivariate technique, it indicates which variables are significant predictors as well as the relative importance of each variable, when all other variables are controlled for. The discriminant function as presented in a table indicates which linear combination of variables predicts group membership optimally. In our study we used it as a basis for classifying respondents as either women-inthe-middle or not. Two discriminant analysis were performed. We contrasted women-in-the-middle (type 1) to all other respondents of the sample (types 2-9) as well as to orher parent carers (types 2 and 3 ). The aim was to see whether there were systematic differences berween women-in-the-middle and other women with regard to a combined set of social and demographic variables.

For both analyses the unweighted data set was used. Where two variables correlated highly, such as frequency and amount of help to parents/-in-law, one variable was excluded from analysis. The variables were selected such that the criterion of inequality of group variance was not violated (tested by Box's M). In the procedure itself, a stepwise variable selection procedure was performed with minimizing Wilks' Lambda as a selection rule.

\section{RESULTS}

Table 1 gives an indication of the complexity of helping patterns care these middle-aged respondents were involved in. We distinguished between care demands 
TABLE 1. Sodo-denographic character istics and patterns of care provided by women of the age cohort 40.54 by different Ypes of care contigurations

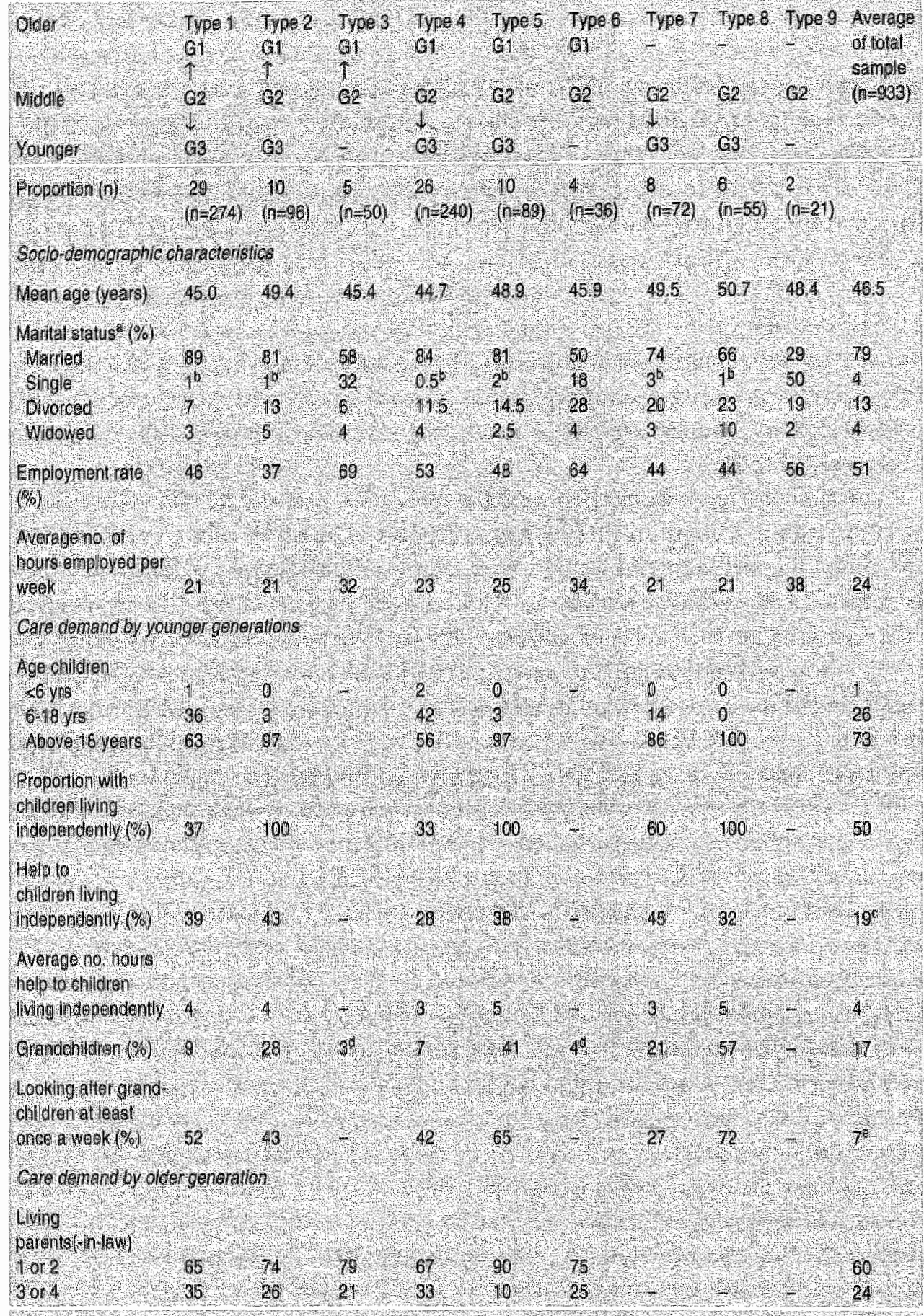




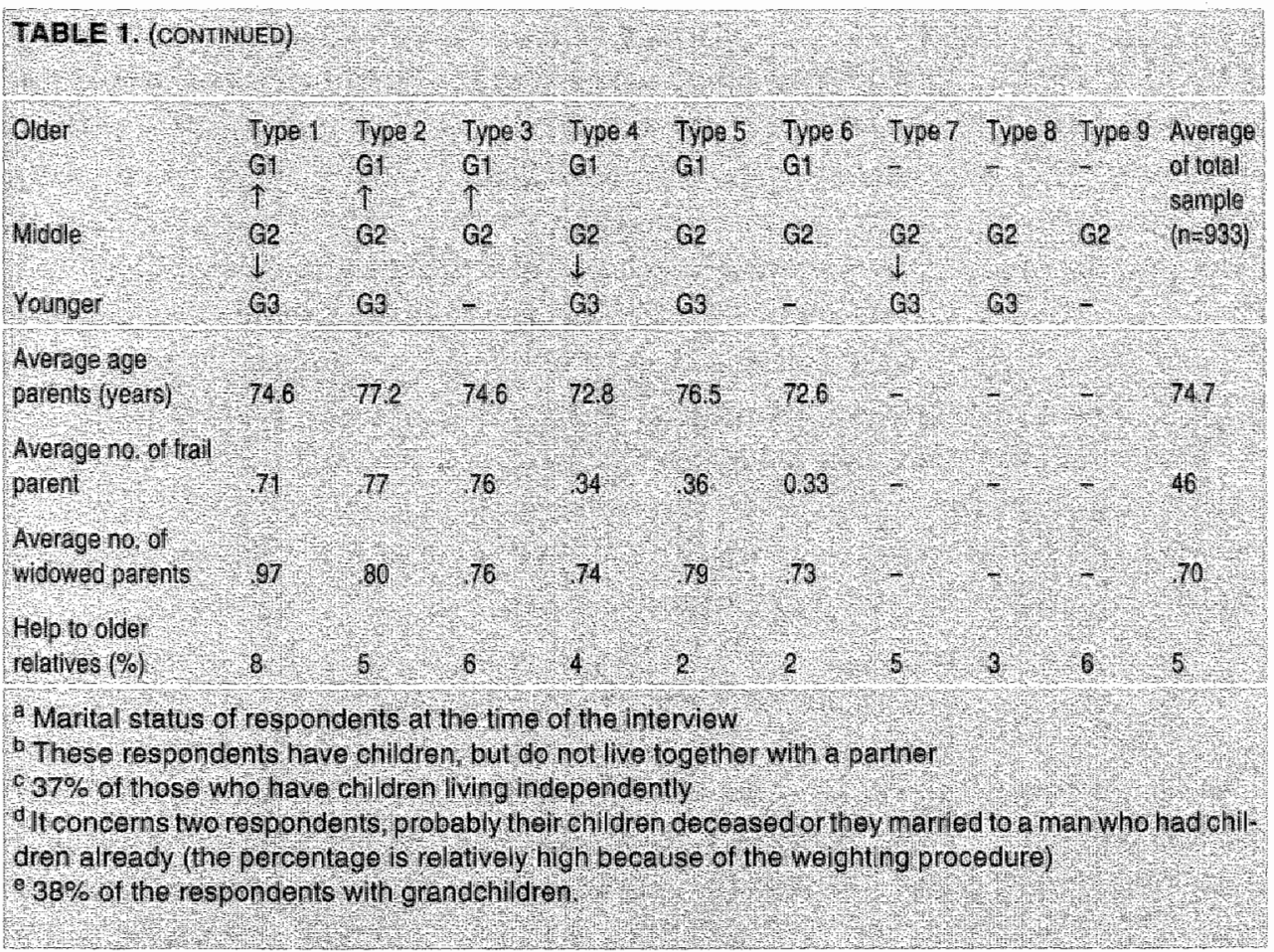

from older generations and care demands from younger generations, since the topic of our study focuses on those aspects. Since care demands from the older and younger generations may extend beyond the care for residential children and parents, table 1 also includes assistance to non-residential adult children, to grandchildren, and the regular help to older relatives, neighbors and friends. A further discussion of the helping patterns of women-in-the-middle as compared to other middle-aged women will be given under the section "prevalence of women-in-the-middle".

Before proceeding to the first research question, we will describe the care which respondents gave to their parents and parents-in-law. Table 1 indicates that many middle-aged women assist their parents/-in-law. In the past four weeks, $45 \%$ of all respondents had given help to one or more parents/-in-law; $37 \%$ had done this at least once or twice per week. When emotional support is excluded as help, $27 \%$ had helped a parent in the past month. They usually helped one parent, as can be seen in table 4, mostly the mother (not included in the table). Additional analysis showed that almost half of the respondents who did not provide help to parents-in-law at the time of the interview $(25 \%)$, had been giving help to parents/-in-law in the past. This means that two-thirds of the respondents had performed, or were performing, the role of parent carer. 
One third of the caregivers (11\% of all respondents) provided intensive parent care, i.e. more than 4 mornings/afternoons/evenings per week. Almost half of them were the primary helper ( $21 \%$ of all respondents) of a parent or parent-in-law. Other primary caregivers mainly were sisters and sisters-in-law. The common pattern was to spend one or two mornings, afternoons or evenings on the help, visiting the parent once or rwice a week for that purpose (see also table 4 ). With regard to the type of help (not included in the table), emotional support, such as discussing problems and keeping company, was mentioned most frequently by respondents (reported by $41 \%$ of the helpers), followed by shopping (18\%). Personal care, such as bathing and dressing, was provided least $(2 \%)$. Often the help stretched over years. As can be seen from table 4 , many caregivers had been giving this help for three years or longer (70\%). Most helpers reported that they liked to help their parents $(63 \%)$. Only a small minority $(6 \%)$ said that the caring task was a burden ro them.

\section{Prevalence of women-in-the-middle}

The first question concerned the prevalence of women-in-the-middle among women aged 40-54. Table 1 shows that almost one-third (29\%) of the respondents had both children in the household and provided help to their parents or parents-in-law. Apparently, care demands by two generations is the most common care configuration women can find themselves in at that age: the proportion of women belonging to type 1 is higher than that of each of the other eight types. It should be noted that $52 \%$ of the women of type I also looked after their grandchildren, meaning that $15 \%$ of these middle-aged respondents faced care demands from three generations.

Table 1 also illustrates that family care often is a sliding scale. Even when children live independently, over one third of the mothers continue to give help. On average, they spent 4 hours per week assisting with domestic chores such as the laundry. Besides that, an number of them looked after grandchildren. Help to other older relatives, such as aunts and uncles, was given as well, though by fewer women (5\%). Additional analysis showed that a broader definition of care for younger and older generations, including the help to adult children, grandchildren and older relatives (minimally 3 hours per week), would have resulted in a prevalence of women-in-the-middle of $34 \%$.

Among the nime types, the second largest group is type $4: 26 \%$ of the respondents had children in the household but did not help their parents/-in-law. Some of these women may become women-in-the-middle within a few years. Table 1 provides some evidence for this: they are about as old as the women of type 1 but the mean age of their parents is lower. Additional evidence showed that a considerable proportion reported that they did not provide care because their parents/in-law did not need it yet ( $48 \%)$. Only $5 \%$ reported that other commitments, i.e. their family $(1 \%)$ or a job ( $4 \%$ ), made it impossible for them to provide care. 
TABLL 2 Selected socio demographic character stics of women in the hiddolo (ype 1 as compared to oither women of the aige group $40-54$ (Types 2 -9)

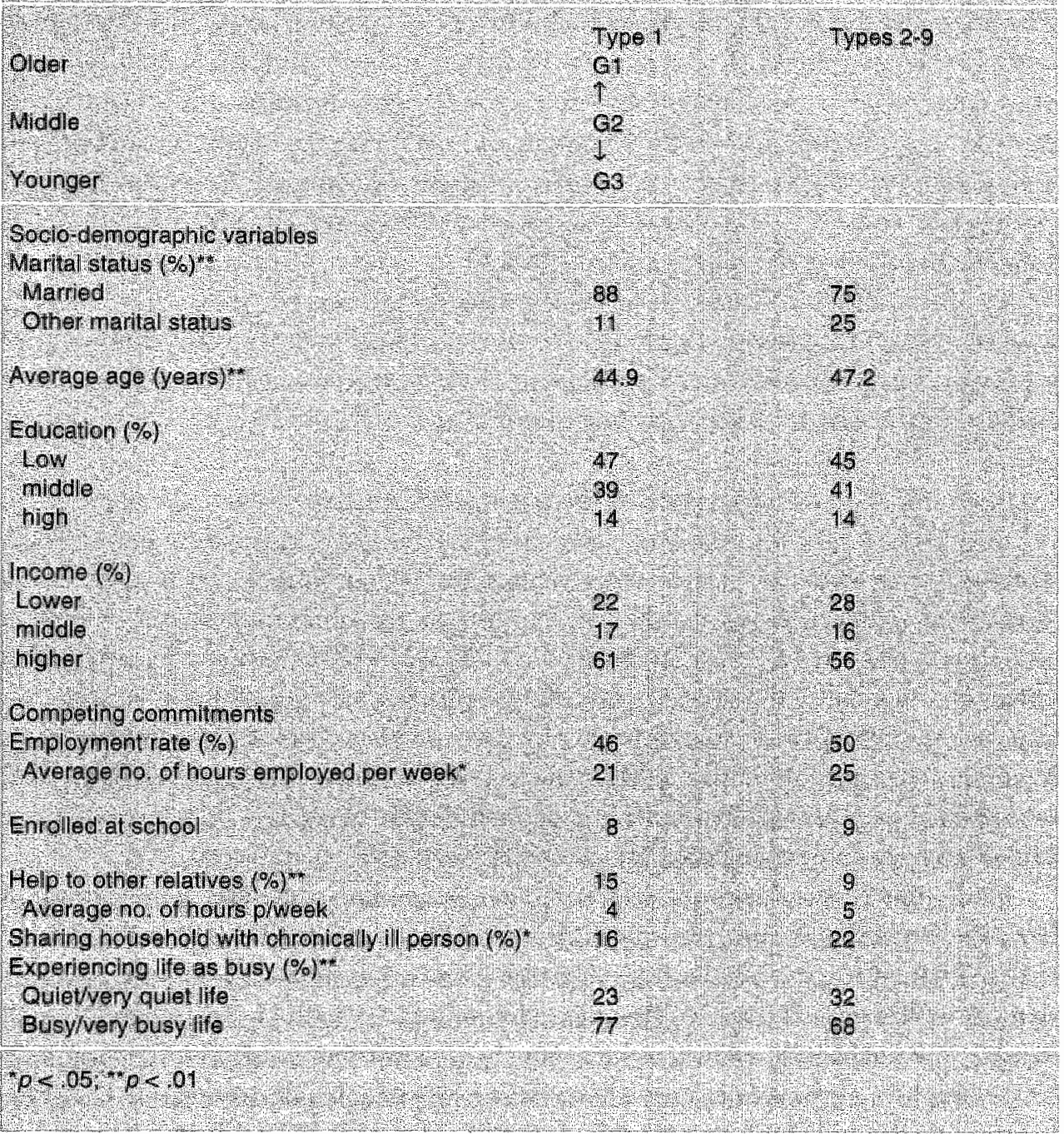

However, despite a considerable proportion of these women providing both parent and child care or combining parent care and employment, few women appeared to be in a very complex role configuration. Only $13 \%$ provided child care, parent care and had a job. Less than $1 \%$ provided intensive parent care, i.e. more than 3 mornings/afternoons per week, had children in the household and had a job of more than 32 hours per week. 


\section{Characteristics of women-in-the-middle}

The second research question addressed differences between women-in-the-middle and other women within their age group. Bivariate tests were performed on three types of variables: (1) socio-demographic factors, i.c. age, education and income, (2) compering commitments other than parent and child care, i.e. a job, involvement in voluntary work, taking courses or enrolment in an educational institurion (study), regular help to relatives, regular help to friends, and, (3) having a busy life. We also addressed characteristics of parents/-in-law.

As can be seen from table 2, women-in-rhe-middle were significantly younger, worked fewer hours per week, were more likely to give help to other relatives as well and were more likely to have a busy life. They were less likely to share the household with a chronically ill person. This person was in most cases $(82 \%)$ the respondent's child or partner.

With regard to characteristics of the parents and parents-in-law, as compared to types 2-9, women-in-the-middle appeared to have more living parents/-in-law, more widowed parents/-in-law and more frail parents $(\mathrm{p}<.01)$, despite the mean age of these parents being the same (see also table 1). Part of these difference may be due to the fact that the women of type 1 are usually married. Therefore they may have care demands from both their own parents and parents-in-law. Additional analysis showed, however, that, compared to other married women with living parents/-in-law (types 2-6), women-in-the-middle still provided help to more parents/-in-law and had more frail or widowed parents/-in-law ( $\mathrm{p}<.01$ ). Also compared to other caregivers (types 2 and 3), women-in-the-middle had more widowed parents/-in-law ( $<<.01)$.

In addition to bivariate tests, multivariate analysis were performed. The aim was to construct a profile of women-in-the-middle on the basis of a combined set of variables. It would also show the effect of the variables when others were kept constant. Three types of variables were selected: (1) socio-demographic factors, i.e. age, education and income, (2) competing commitments other than parent and child care, i.e. a job, voluntary work, raking courses or enrolment in an educational institution (study), regular help to relatives, regular help to friends and (3) having a busy life. Variables which were directly or indirectly related to the definition of women-in-the-middle, such as having children and marital status, were excluded from the analysis.

Two discriminant analysis were performed. In the first analysis women-in-themiddle (type 1) were contrasted to all orher women (types 2-9), aiming at finding a set of characteristics which might distinguish them from other women in the same age group. In the second analysis women-in-the-middle (type 1) were contrasted to other parent carers (types 2 and 3) to identify in which respect women-in-the-middle differed from other caregivers. The same set of variables as in the bivariate tests were used. The results are shown in table 3 . 


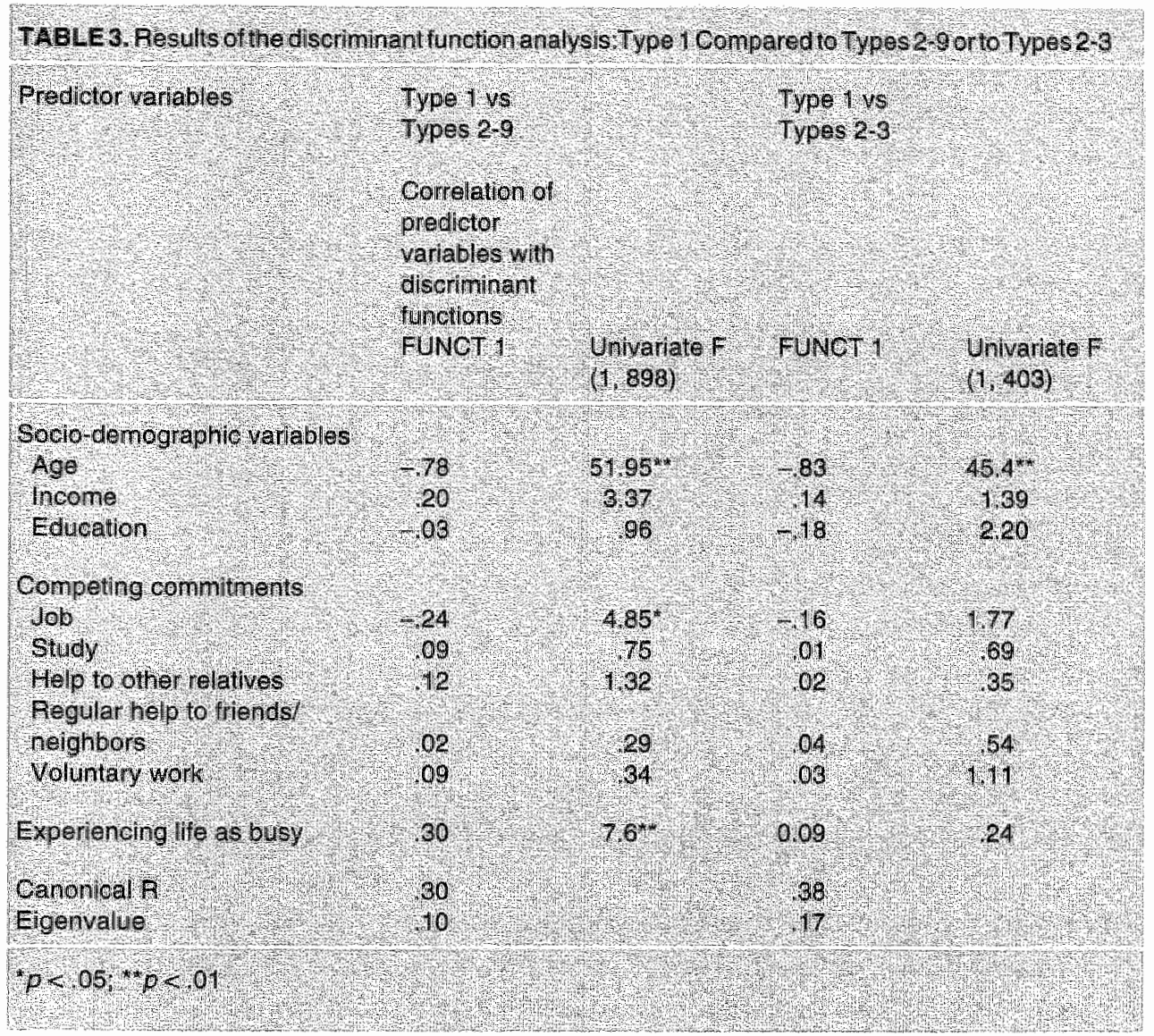

The first analysis, comparing type 1 to types 2-9, resulted in seven predicror variables. These were, in order of decreasing importance, age, busy life, employment, income, help to other relarives, study, education and voluntary help. Women-in-the-middle are in particular more likely to be younger, not to be employed, to have a busier life and to belong to the higher income groups. They also are more likely to take courses/be enrolled in an educational institution, to provide help to other relatives than their parents/-in-law and to have a lower educational level. However, as indicated in table 3 , at the univariate level, only three variables were significant below the level of $p<.05$, that is age, busy life and employment, with age as the most important predicting variable.

The set of variables reduced Wilks' lambda to 91. The predicted group membership for women-in-the-middle was relatively low, that is $12 \%$, and was high for group 2 (types 2-9), that is $96 \%$. Apparently, the selected set of variables predicted better those who did not belong to type 1 than those who did. 
46) Chapter 2

TABLE 4 Patterns of parent care differences between women in the-middle (type 1 ) gnd other parent carers (upes 2 and 3 )

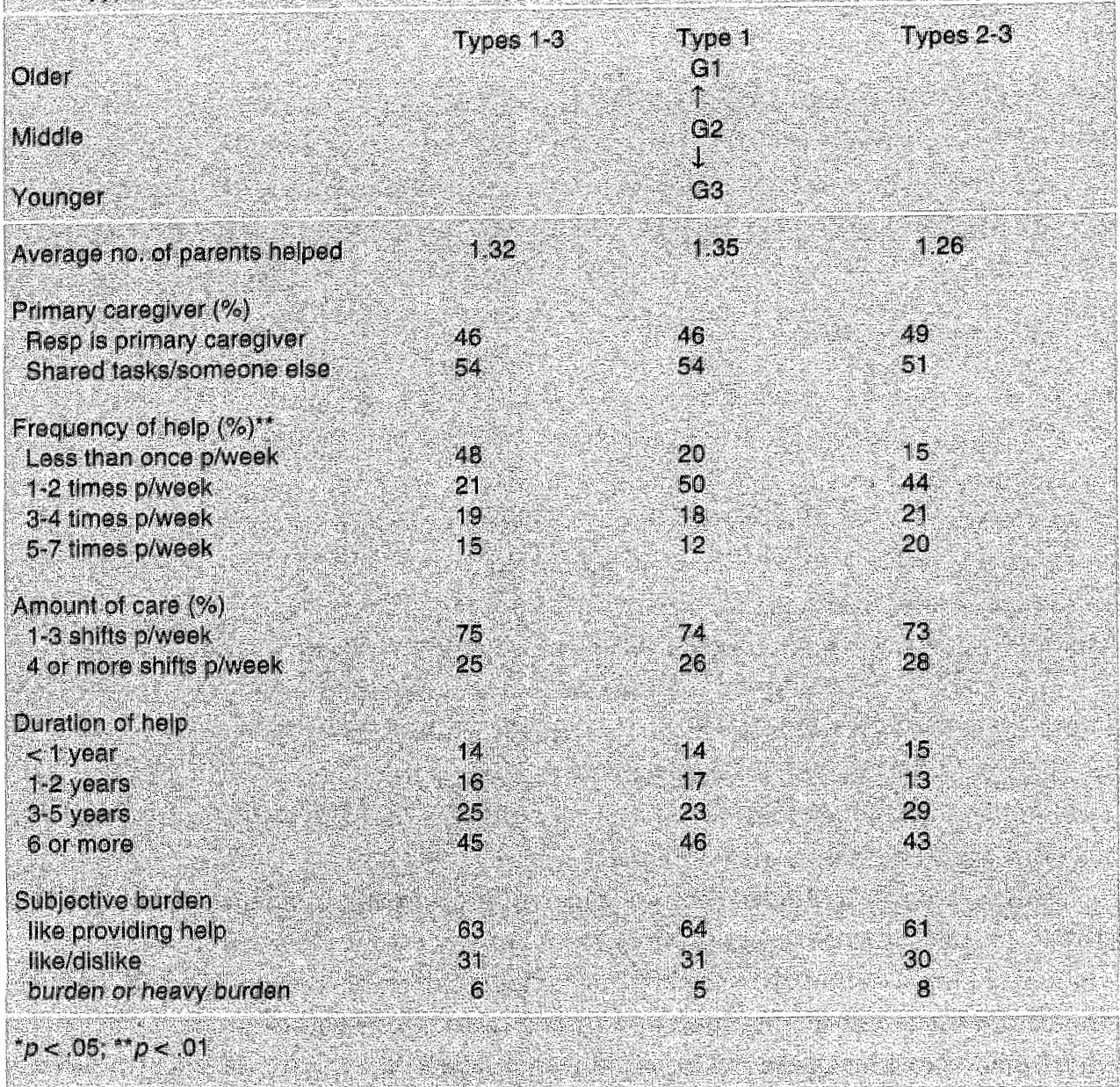

In the second discriminant analysis women-in-the-middle (type 1) were contrasted to other parent carers (type $2-3$ ). The step-wise procedure reduced Wilks' lambda to .85 . Predicted group membership for women-in-the-middle was $79 \%$ and for other caregivers $52 \%$.

As shown in rable 3 , this analysis resulted in similar, though fewer, predictor variables. As compared to other parent carers, women-in-the-middle are more likely to be younger, not to be employed, to have a lower level of education and to belong to the higher income groups, the latter probably being the case because they are married and have an income earning partner as well. Only age was significant at the univariate level. 


\section{Patterns of parent care}

The third research question addresses differences in parent care between women-in-the-middle and other caregivers. Table 4 shows that women-in-the-middlle were just as often the primary caregiver and spent similar amounts of time on parent care. They were also just as frequent providing intensive parent care, defined here as four or more mornings/afternoons per week. The only significant difference concerned the frequency of help: women-in-the-middle visited the parent less frequently.

\section{DISCUSSION}

In this article we made an artempt to indicate to what extent middle-aged women respond to care demands from older and younger generations. Gerontological studies on this topic reflect controversies, in particular on the size of this phenomenon, and little evidence so far has been given on the European situation. On the basis of a probability sample among women aged 40-54 in the Netherlands, we indicated the proportion of women who actually are in such a position and analyzed their sociodemographic characteristics. We also investigated patterns of parent care by middle-aged women and tested the hypothesis whether women with multiple roles, in particular those having children at home, provide less parent care than caregivers who did not have child care responsibilities.

With regard to parent care by middle generation women, our data showed that -despite the availability of extended community services for the elderly- it is still common and normal for women to provide support to their elderly parents and parents-in-laws. About one third helped their parents/-in-law regularly or had been giving this help. Even when emotional support was excluded, still over one quarter of the respondents had been giving help to their parents/in-law in the past month. Usually the help stretched over many years. Since a large proportion of these middle-aged respondents (approximately $75 \%$ ) had been performing the role of parent caregiver either currently or in the past, we concluded that the proportion of women who ever get involved in parent care is quite large. Thus, in our study empirical support was found for Brody's statement that parent care is a normative experience for middle-aged women. In that respect our findings contradict Rosenthal et al. (1996), who did a similar study in Canada with a large population-based sample. She concluded that the proportion of women who help a parent is very low. Differences in helping patterns between Canada and the Netherlands may partially be explained by differences in geographical distance. Netherlands is a small country; in our sample $84 \%$ of the daughters lived within 30 minures travel time of the parents/in-law. 
However, we did not find any empirical evidence that a high level of parent care was a normative experience for middle-aged women, because the majority of helpers spent only three to six hours per week on the assistance to parents. Rosenthal et al. (1989, 1996) came to similar conclusions regarding Canada. In a random sample in Ontario, they did not find any empirical support indicating that a majority of middle-aged women provided intensive care.

We expect that in other European countries such as Germany and United Kingdom, the proportion of middle-aged women helping their parents/-in-law probably is higher. The Netherlands has a strong welfare approach to the aged and infirm with an extended system of free community services for the elderly, relieving relatives from their caregiving task. The percentage of elderly making use of residential services, for example, is twice as high in Netherlands (10\%) as in West-Germany and United Kingdom (both 5\%) (Nijkamp et al., 1990). In addition, dependency ratios for the elderly, that is the ratio of people 65+ to those aged 15-64, are relatively low in the Netherlands. Dependency ratios in the US and UK are 52\% and 53\% respectively as compared to $45 \%$ in the Netherlands (United Nations, 1995).

We did not find empirical support for the Himes (1994) and Spitze and Logan (1990) statements that the roles of caregiver, mother and/or employee are performed sequentially rather than also simultaneously. A considerable proportion of respondents in our sample ( $29 \%$ ) faced care demands from two, or even three generations and half of those combined it with employment. The inclusion of help to adult children, to grandchildren and to older relarives would have resulred in even higher figures regarding the performance of multiple roles by middle-aged women. We expect that in the US or European countries like Germany and the United Kingdom, probably a larger proportion of women will be involved in various roles. Female employment rates in the US are $68 \%, 65 \%$ in UK and $61 \%$ in West Germany as compared to $51 \%$ in the Netherlands (OECD, 1993).

However, we do agree with Spitze and Logan (1990), Rosenthal et al. $(1989,1996)$ and Boyd \& Treas (1989), that complex role configurations are neither typical nor normative for middle-aged women. In our sample only a small minority found itself in a complex role configuration. The help given to parents usually was not extremely time-consuming, the majority of the caregivers did not experience it as a burden and very few respondents who helped parents had children at the pre-school age. Less than $1 \%$ of our respondents had a full-time job in combination with many hours of parent care and children at home. Thus, juggling between childcare, high-level parent care and a full-time job, was rather the exception than the rule.

Wirh regard to a profile of women-in-the-middle based on a set of selected socio-demographic characterisrics, in our data ser a woman-in-the-middle emerges as someone who is married and in her early middle-aged years and who is less likely to thave a job. She might be less highy educated, taking courses in an educarional institu- 
tion and , probably because she is married with an income earning husband, she might belong to the higher income groups.

The relatively young age of women-in-the-middle was most significant. This finding is consistent with research done by Rosenthal et al. (1989) and Spitze and Logan (1990), concluding that chances of being in the complex role figurations are higher for women below 45 years of age.

However, the predictive value of the variable set was not very high. Therefore, we assume that contingency plays an important role, supported by the finding that women-in-the-middle had, on the average, more frail and widowed parents than other married women, differences which could not be explained by a higher age of these parents. Probably, some women may get in the unfortunate situation that their parents/-in-law fall ill at a relatively young age and call on their help when they still have children at home. Another plausible explanation may refer to opportunity costs, since women-in-the-middle work fewer hours per week. They have more flexible working schedules and have no loss of income when helping parents out. The alternative hyporhesis, that caregivers may have left the labor force to take care of a frail parent, was not confirmed in our data. Only a very small percentage had quitted jobs in order to care for an elderly parent.

The third research question concerned whether women-in-the-middle might spend less time on parent care. We did not find any evidence supporting this. Women-in-the-middle provided similar amounts of help as other parent caregivers. Apparently, having a family of one's own appeared no reason to refrain from the caregiving task. This finding is consistent with research performed in the US. Boaz and Muller (1992) did not find, on the basis of a secondary analysis of two national surveys statistically significant effect of having minor children on the number of hours of caregiving.

In our sample, there was one significant difference between women-in-the-middle and other caregivers: they visit their parents/-in-law less frequently. Perhaps these women do not provide less care but, because of their partners and children, organize the care more efficiently, for instance by concentrating it in fewer visits.

This study had several limitations. Since only cross-sectional data were used, we could not take into account the dynamic nature of the role of mother, changing over a life course. Pre-schoolers, for example, require more attention and care than school going children, whereas adolescents may even assist their mothers with domestic chores and help to parents. We do not know to what extent these changes affect the role of caregiver of an elderly parent.

Second, we are aware of the fact that we have limited ourselves to the response of middle-aged women to care demands from other generations. We do not know to what extent this response is congruent with the actual demand from other generations, in 
particular the older generation, and whether women of the middle generation have the ability to meet that demand.

Third, other comparisons among the nine rypes of our conceprual model would have been possible as well, such as a selection of only three-generation-women or only women sharing the household with children. However, this would have been the result of different research questions.

Finally, we acknowledge that our definition of care, both for elderly and children, is limited and, to some extent, arbitrary. We applied a very broad definition of parent care, referring to different kinds of activities, varying both in time and burden for caregivers. Evidently, a narrower definition of care, e.g. including only intensive care, would have resulted in smaller figures.

Despite its limitations, our study is one of the very few population-based studies on women-in-the-middle, particularly in Europe. Although the exact figures and proportions will differ from region to region, due to social, demographic, economic and cultural differences, our study lends support to the conclusion that a considerable proportion of middle-aged women find thenselves in the middle of care demands from various generations. In the near future we expect this proportion will increase because of falling birth rates, postponed child bearing and decreasing caregiver-elderly ratios. It should be noted that our figures are based on cross-sectional data, measuring at one point of time. Over a life course, the proportion of middle-aged women who ever been have to deal with care demands from various generations, will be much larger.

At the same time, we question whether the phenomenon reflects a large social problem, in the sense that many middle-aged women get "caught" berween two generations or between employment and parent care. Therefore, however stressed some of them may be, speaking about "the" sandwich generation is misleading, since it concerns neither a whole middle generation of women nor a majority among them being in a potentally conflicting role configuration. The term women-in-the-middle is more appropriate, as does not contain a value judgement and leaves room for the reciprocal aspects of intergenerational relations. Furure research should focus on the specific conditions under which women-in-the-middle may experience stress and role overload.

\section{NOTES}

1. This chapter has been published: Dautzenberg, M.G.H. Diederiks, J. P.M., Philipsen, H., \& Stevens, F.C.). (1998). Women of a middle generation and parent care. International Journal for Agng and Human Development, 47, 241-262.

2. Parts of this article have been published by the cited authors in the Tijdschrift voor Geronologie en Ceriatrie (pournal for Gerontology and Geriatrics), 1996, 27, 141-149. 


\section{REFERENCES}

Barling, I., MacEwen, K.E., Kelloway, E.K., \& Higginbottom, S.F. 11994. Predictors and Outcomes of Elder-Care-Based Intertole Conflict. Psychology and Aging, 9, 391-397.

Boaz, R.F.y Muller, C.F. (1992). Paid Work and Unpaid help by Caregivers of the Disabled and Frail Elders. Medical Care, 30, 149-158.

Boyd, S.L., \& Treas, 1. (1989). Family Care of the Frail Elderly: a New Look at Women in the Middle. Women's Studies Quarterly, $1 \& 2,67-74$.

Brody, E.M., Johnson, P.T., Fulcomer M.C., \& Lang, A.M. (1983). Women's Changing Roles and Help to Elderly Parents: Autitudes of Three Generations of Women. Journal of Gerontology: Social Sciences, 38, 597-607.

Brody, E.M. (1985). Parent Care as a Normative Family Stress. The Gerontologist, 25, 19-29.

Brody, E.M. (1990). Women in the Middle: Their Parent-Care Years. New York: Springer.

Central Bureau of Statistics CBS (1991). Personele Inkomensverdeling 1987 (Distribution of individual incomes,. The Hague: SDU.

Central Bureau of Statistics CBS (1994). Statistisch Jaarboek 1994 (Statistical Yearbook). The Hague: SDU.

Central Bureau of Statistics CBS (1995). Enquête Beroepsbevolking 1994 (Survey Labor Force Participation 1994). The Hague:, SDU.

Corver, C.J.M., van de Heiden, A.M., de Hoog, C. \& van Leeuwen, E.H. (1979). Huishouden, Huwelijk en Gezin. Monografie Volkstelling nr 18. The Hague: SDU.

Duijnstee, M.S.H. (1992). De Belasting van Familie van Dementerenden. Nijkerk: Intro.

Dwyer, J.W. \& Coward, R.T. (1991). A Multivariate Comparison of the Involvement of Adult: Sons Versus Daughters in the Care of Impaired Parents . Journal of Cerontology, 46, 5259-269.

Hagestadt, C.O. (1985). Parent-child Relations in Later Lufe: Trends and Gaps in Past Research. In J.B. Lancaster, Altmann I., Rossi A.S. \& Sherrod L.R. (Edls.). Parenting Across the Life Span; Biosocial Dimensions. New York: Aldine de Gruyter.

Himes, C.L. (1994). Parental Caregiving by Adult Women, a Demographic Perspective. Research on Aging, 16, 191-211.

Horowitz, A. (1985). Family caregiving to the frail elderly. In C. Eisdorfer (ed), Annual Review of Gerontology \& Geriatrics. New York: Springer.

Horowitz, A. (1985). Sons and Daughters as Caregivers to Older Parents: Differences in Role performance and Consequences. The Gerontologist, 25, 612-617.

Lang, A.M \& Brody, E.M. (1983). Characteristics of Middlle-aged Daughters and Help to their Elderly Mothers. Joumal of Marriage and the Family, 193-201.

Litwak, E. (1965). Extended Kin Relations in an Industrial Democratic Society. In E. Shanas \& Streib G.F.(Eds.), Englewood Cliffs, N.J.: Prentice Hall.

Miller, D.A. (1981). The 'Sandwich Generation': Adult Children of the Aging. Sacial Work, 419-423. 
Mohide, E. (1993). Informal Care of Communify-dwelling Patients with Alzheimer's Disease: Focus on the Family Caregiver. Neurology, 43, 516-519.

Nigkamp, P., Pacolet, 1. Spinnewyn, H., Vollering, A., Wilderom, C., \& Winters, S. (1990). Services for the Elderly in Europe; a Cross-National Comparative Study, Brussels: Commission of the European Community.

Organisation for Economic Co-operation and Development. 1993). OECD Systems: The Socio-Economic Enviromment; Statistical References, Health Policy Studies 3, Paris: OECD.

Rosenthal, C.J, Mathews, S.H, Marshall, V.W. (1989). Is Parent Care Normative? The Experiences of a Sample of Middle-aged Women. Research on Aging, 11, 244-260.

Rosenthal, C.), Martin-Matthews, A, Matthews, S.H. (1996). Caught in the Middle? Occupancy in Mulliple Roles and Help to Parents in a National Probability Sample of Canadian Adults. Joumal of Gerontology, $518(6), 5274-5283$.

Schlesinger, B. (1989). The 'Sandwich Generation': Middle-aged Families under Stress. Canada's Mental Health, $11-14$.

Spitze, G. \& Logan, I. (1990). More Evidence on Women (and Meny in the Middle. Research on Aging, 12, 182-198.

Spitze, G., Logan, I.R., Joseph, G., \&ee, E. (1994). Middle Generation Roles and the Wellibeing of Men and Women. Journal of Gerontology: Social Sciences, 49, S107-S116.

Stephens, M.A.P. Franks, M.M., \& Townsend, A.L. (1994). Stress and Reward in Women's Multiple Roles: the Case of Women in the Middle. Psychology \& Aging, 9, 45-52.

Stoller, E.P., \& Pugliesi, K.L. (1989). Other Roles of Caregivers: Competing Responsibilities or Supportive Resources. Journal of Gerontology: Social Sciences, 44, 5231-238.

Stoller, E.P., Forster, L.E., \& Dunho, T.S. (1992). Systems of Parent Care within Sibling Networks. Research on Aging, 14, 28-49.

Stone, R.I, \& Short, P.F. (1990). The Competing Demands of Employment and Informal Caregiving to Disabled Elders. Medica/ Care, 28, 513-526.

United Nations. (1995). Demographic Yearbook 1993. New York: United Nations.

Uhlenberg, P. (1993). Demographic Change and Kin Relationships in Later Life. In G.L. Maddox and M. Powell-Lawton (Eds.) Focus on Kinship, Aging and Social Change. New York: Springer. 


\section{CHAPTER 3}

Multigenerational caregiving and wellbeing; Distress and burden of middle-aged daughters providing assistance to elderly parents ${ }^{1}$

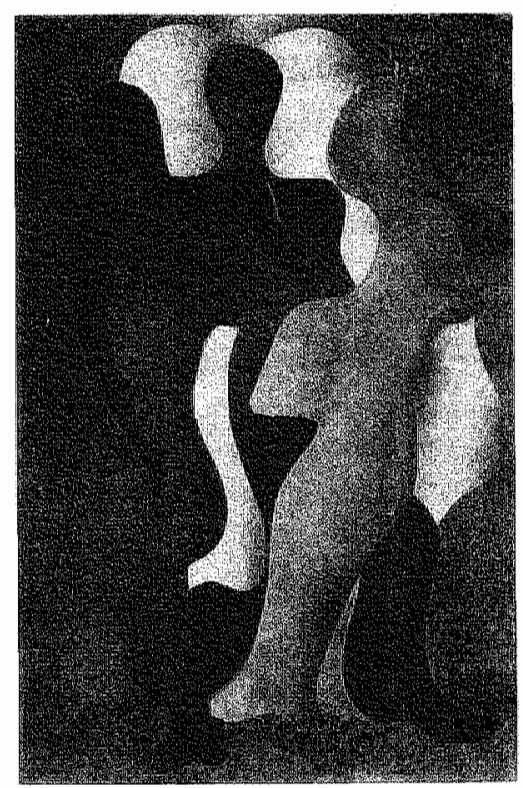




\section{Sterfbed}

Mijn vader sterfi; als ik zijn band wasthoud, voel ik de botten door zijn huid heen steken. Ik zoek natr woorden, madar bij kon niet spreken en is bij elke ademtocht benautwd.

Dus schud ik kussens en verschik de deken, waar bij met krachteloze band in klauwt; ik blifft zijn kind, al ward ik eewwen oud, en blijf als kind woor eewrig in gebreke.

Wij volgen één voor één hetzelfde pad, en worden met dezelfde maat gemeten: ik zie mijzelf nu bij zijn bed gezeten.

Zoals bij bij zijn eigen vader zat: straks is bij weg, en beeft bij nooit geweten hoe machteloos ik bem beb liefgelsad. 


\section{ABSTRACT}

This article investigares whether being a caregiver of an elderly parent and the caregiver's involvement in multiple roles increases distress in middle-aged women. Previous studies assumed that providing care to frail parents causes distress in women, in particular when they have other social roles as well. Longitudinal data were collected within a cohort of middle-aged women $(n=934 ; n=743)$. The acquisition or loss of the caregiver role did not appear to affect levels of distress of middle-aged women, nor did addirional roles of caregivers increase distress levels or caregiver role strain. Most distressed were women not performing any major social role, suggesting that the lack of social roles rather than the multiplicity of roles are associated with distress. The caregiver role might even reduce distress when women have very few other roles. Findings are explained in terms of the role scarcity, the role expansion and role accumulation hypotheses of role theory.

\section{INTRODUCTION}

Demographic and medical developments have resulted in increased longevity and larger numbers of chronically ill elderly living in the community, usually calling on the assistance of their daughters or daughters-in-law (Horowitz, 1985). In addition, the unprecedented influx of married women on the labour market has raised concerns among policy makers that women might become overburdened, because they assume the role of paid worker without concomitant decreases in family care responsibilities. These women, often in their middle age, have been depicted as juggling their time and energy between the competing demands of teenage children, jobs and elderly parents. They are labelled as 'women-in-the-middle' (Brody 1981, 1990) or the 'sandwich generation" (Miller, 1981; Schlesinger, 1989), the latter teferring to a middle generation being 'caught' between the needs of their ageing parents and the care for their own off-spring. Because of their multiplicity of roles, women are assumed to be at risk of becoming stressed and burned out.

Empirical evidence on multiple roles of caregivers is scarce. Studies on women's involvement in multiple roles traditionally have focused on the roles of wife, mother and employee, generally overlooking the role of caregiver of an elderly parent (e.g. Thoits, 1983; Verbrugge, 1983). Research on caregiving has studied the distress of caregivers mainly in isolation from other social roles of caregivers (e.g. Braithwaite, 1996; Montgomery, Gonyea and Hooyman, 1985; Zarit, Reever, Bach-Peterson, 1980). Moreover, the focus on stressful aspects of parent care implicitly assumes that performing the caregiver role mainly has a negative impact on the women involved in this task, in particular when women already perform other social roles. The goal of this study is to 
investigate whether this negative presumprion is justified. Does the caregiver role negatively affect women's wellbeing? Do caregivers with multiple roles feel more distressed and have a higher burden of care?

Relatively few studies have studied the impact of the caregiver role on the wellbeing of middle-aged women in the context of their other social roles. Spitze, Logan, Joseph and Lee (1994) made use of a probability sample including a comparison group of women not providing parent care. No significant association was found between the caregiver role on the one hand, and women's distress and feelings of being over-burdened by family responsibilities on the orher. Sundies on caregivers multiple roles have yielded inconsistent findings. Spizze et al. (1994) found that other roles of caregivers such as being employed or having co-residing minor children or a spouse had no significant effects on distress and subjective family burden. Stoller and Pugliesi (1989) found that employment increased the subjective burden of care, but only when combined with many hours of help. Ar the same time, however, employed caregivers who provided a large amount of help also had higher levels of wellbeing. Brody (1992) reported on the spousal role as having a positive effect on caregivers' wellbeing, wirh married caregivers having an emotional advantage over their unmarried counterparts.

\section{Theoretical notions}

A negative association between multiple roles and wellbeing originates from what has been labelled as the 'role scarcity' or the 'competing demands' hyporhesis of role theory. This approach is based on Goode's hypothesis on role strain, assuming that individuals tend to accumulate roles until their total role obligations are overdemanding (Goode, 1960). The involvement in multiple roles inevitably leads to role strain and distress. In the process of acquiring roles, after an initial decrease an exacerbating effect takes place, as role strain increases more rapidly with the number of roles than the corresponding role rewards do. The individual's main problem is how to make the role set manageable and keep role strain within acceprable limits. Role strain can be handled by bargaining on role relations, such as the delegation of role rasks or the comparmentalisation of roles, referring to the restriction of roles to specific places or siruarions. Even the expansion of roles can help to reduce role strain, as it may function as an excuse not to be bound by other role obligations.

The role strain hypothesis has been opposed by the role accumulation bypothesis of Sam Sieber (1974), assuming a positive association between wellbeing and multiple roles. In line with Durkheim"s theory on the function of social ties (Doress-Wolters, 1994), Sieber stresses the integrative aspects of multiple social roles being beneficial for mental heal th. Multiple roles give access to the privileges deriving from those roles, resulting in ego gratification, status enhancement and status security. Although multiple 
roles might increase role strain, eventually the ner gains of multiple roles will outweigh the strains involved.

Stephen Marks (1977) too stated in his role expansion bypotbesis that indiwiduals may expand their role sets without concomitant increases in role strain and distress. However, instead of proposing a merely additive model of role accumulation, Marks highlighted the concept of role commitment. The impact of multiple roles on role strain is mitigated by role commitment. Individuals are more likely to become stressed and tired when they have to perform an additional role to which they feel undercommitted, whereas their energy and time is abundant when they are strongly committed to that role. Societal values determine to which role individuals feel committed.

The three cited hypotheses of role theory provide only a very general analycical framework. In this study additional formal hypotheses were formulated regarding (a) the relation berween the caregiver rolle and distress of middle-aged women and (b) multiple roles of caregivers and distress. On the basis of the three hypotheses, we predict three possible outcomes. The hypotheses were tested empirically in a probability sample of middle-aged women that included a comparison group of women not providing care. The research design was longitudinal. Measurements were done in two waves with an interval of two years.

First, we examined how the caregiver role affects distress levels of middle-aged women. In line with a role strain approach, we hypothesised that distress levels increase when the role-set is expanded with the caregiver role, in particular when women are in complex role configurations. The role accumulation hypothesis, however, predicts that distress levels decrease when women add the caregiver role. The role expansion hypothesis predicts that women can expand their role set without a concomitant increase or decrease in distress, under the condition that the commitment to the caregiver role is high.

Second, we investigated the relationship between multiple roles of caregivers and their levels of distress and role strain. In line with a role strain approach, distress of caregivers would decrease when caregivers have only a few other social roles, and increase rapidly when women have multiple roles. The role accumulation hypothes is predicts that distress levels will decrease when the number of roles increase, whereas the role expansion hypothesis predicts that multiple roles have no impact on caregivers' distress or role strain when caregiver role commitment is high.

Four roles were included in this study: the role of caregiver of an elderly parent or parent-in-law, the role of mother of minor children, the wife (spousal) role and the role of employee. Other social roles, such as being a voluntary worker or a srudent, were considered as involving less responsibility and commitment and were therefore only used as control variables. 


\section{METHOD}

Data were obrained through a telephone survey in four municipalities: one medium-sized town ( 80,000 inhabitants) and three smaller towns (in total 40,000 inhabitants) in the southern part of the Netherlands. The research area included an urbanised city centre, as well as suburbs and village neighbourhoods.

\section{Sample}

Respondents were recruited through a probability sample drawn from local municipality registration offices. Only women were included because they were expected to be most involved in parent care. The birth cohort 1940 - 1954 was selected because the women of this age group of $40-56$ was most likely to perform simultaneously the roles of mother, employee, spouse and caregiver. Respondents were interviewed by relephone in two waves, with an interval of 25 months. The first wave (T1) took place in $1994(\mathrm{n}=934$; tesponse rate $79 \%)$ and the second wave (T2) in $1996(\mathrm{n}=743$; response rate $80 \%$ ). The overall response rate was $62 \%$. At both waves, the most frequently mentioned reasons for not co-operating were lack of interest, lack of time, privacy considerations or being tired of telephone surveys. A non-response analysis comparing responders at $T 1$ with responders at $T 2$, was done with the help of logistic regressions. Only a higher education and having children remained as variables significantly increasing the odds for response.

Analyses were performed only on respondents with at least one parent or parent-in-law still alive. In 1994 (T1), 84\% ( $n=786)$ had at least one living parent or parent-in-law. Of those 786 respondents, the mean age was 45.6 years, $82 \%$ were living with a partner. Forty-nine percent were employed, on average 24 hours per week, and $49 \%$ had children below the age of 18 . Most respondents ( $84 \%$ ) had completed primary and secondary education, or primary education combined with a vocational training. In $1996(\mathrm{~T} 2), 78 \%(\mathrm{n}=581)$ had at least one parent/parent-in-law. Of these 581 respondents, the mean age was 48.9 years (range $42-56$ ). Three-quarters were living with a parner and $34 \%$ had at least one minor child. Half of them were employed (49\%); they worked on average 25.6 hours a week (range: $2-70$ hours). Only $2 \%$ were staying with a parent/parent-in-law. At $T 2$, the mean age of the parents/parents-in-law varied berween 75 and 77 years (range $53-95$ years).

In the remainder of this article, 'parents' will refer to both parents and parents-in-law. 


\section{Measurements}

Parent care referred to any help provided to parents or parents-in-law in the past four weeks, such as doing household chores (cleaning, laundry, preparing food), providing personal care (bathing and dressing), transport, taking care of administrative and financial matters, gardening, house repairs and giving emotional support. Interviewers were instructed not to consider the ordinary social visits to a parent as emotional support. For every morning, afternoon or evening of help an equivalent of three hours was calculated. Women not providing assistance or helping parents less than three hours of assistance per week were considered as "non-caregivers". The mother role was indicated by having minor children (younger than 18 years) and employment by having a job or working in a family enterprise. The spousal role referred to living with a partner, including heterosexual relations and homosexual relations, common-law defined relationships (husbands and wives) and not legally defined relationships.

Income level was self-assessed, with respondents being asked to indicate whether their total household income was lower (1), equivalent (2) or higher (3) than the net modal income in the Netherlands. Health status of the respondent was self-assessed by one item (five-point Likert type). Health status of the parent (five-point Likert-type) as well as dementia symptoms of the parent (dichotomous) wrere assessed by respondents.

Caregiver role commitment was measured by a filial obligation scale, consisting of six irems (five-point Likert type) on the responsibility respondents believe that adult children should have for elderly parents in (1) providing companionship, (2) helping and supporting them with household chores and transportation, (3) providing advice and guidance, (4) providing personal and health care, (5) providing financial support and (6) providing housing. Possible scores could vary berween 6 and 30 . The filial obligation scale had been tested and proved to have a good reliabiliry and stability over time (Mangen et al., 1988). The Cronbach's alpha in the sample was .82. The relationship with the parent was measured by a single item on how the respondent assessed the relationship (five point: very good - very bad).

Caregiver role strain was indicated by interference by parent care in the social and personall life of the caregiver" and was covered by two items $(r=81 ; p<.01)$. One item indicated the extent to which parent care interfered with the privacy of the caregiver and another item indicated the difficulty experienced in combining parent care with other responsibilities, such as a farmily or a job. 'Interference by parent care' was one of the three sub-scales of a scale that has been labelled as the "Caregiver"s Sense of Competence Scale. The latter scale consists of seven irems (five-point, Likert type) and had been tested among various caregiver groups where it appeared to have good psychometric properties (Vernooij-Dassen et al., in press). The second sub-scale of the 'Caregiver's Sense of Competence Scale', labelled as 'satisfaction with the relationship with caregiver' (two items; $r=.78 ; p<.01$ ), focused on the relationship and contact with 
the parent. The third sub-scale was labelled 'satisfaction with the attitude of the care recipient' (three items; $\alpha=87$ ) and indicated manipulative and negative behaviour of the elder towards the caregiver.

Distress was measured by the modified Langner scale (Cockerham, Kunz, and Lüschen, 1988), indicating symptoms of depression and anxiety. The shortened version consisted of six items with a four-point Likert-type scalle $(\alpha=76)$. Items indicated to what extent the respondent felt nervous or tense, suffered from bad sleep, had memory problems, felt restless, asked herself whether life still had any meaning, and felt that things in life had not worked out well. The correlation of the distress scale with the 'Caregiver's Sense of Competence Scale' was $\mathrm{r}=-.45$ ( $\mathrm{p}<.00)$.

\section{Statistical analyses}

T-tests were used to assess statistically significant differences of means between subgroups, nonparametric tests (Mann-Whitney) when ordinal variables were used, and chi-square tests to assess differences in proportions when dichotomous variables were used. One-way ANOVA t-tests of means were applied for multiple comparisons, with Tukey's b indicaring between which pairs (subgroups) the significant differences lie. In the longitudinal analyses, difference scores were calculared, subcracting the score at the first wave (T1) from the score at the second wave (T2). Again, t-tests were used to indicate statistically significant differences between subgroups, including ANOVA for multiple comparisons. At the multivariate level, hierarchical regression analyses were performed. For most analyses, the data of the second wave (T2) were used, in particular because data on caregiver role strain were available only for respondents interviewed at T2. The regression model assumptions of linearity, homogeneity of variance and the normal distribution of residuals were nor violated.

\section{RESULTS}

Descriptive statistics of all variables used in the analyses are presented in table 1 . On average, caregivers are slightly older than non-caregivers and less likely to be employed. Caregivers are also more likely ro have a parent with bad health, a parent with dementia symptoms, and a widowed parent. Apparently, the parents of caregivers are more in need of help and may lack an important atrernative source of help, i.e., their spouse.

\section{The caregiver role and distress}

First, the impact of the caregiver role on distress levels of middle-aged women was examined with the help of cross-sectional and longitudinal analyses. 
TABLE 1 . Descriptive statistics for variables used in the analysis of women with 2 I living perent(s) $(n-576)$, a companison ol caregivers $(n-244)$ and non caregivers $(n-332)$

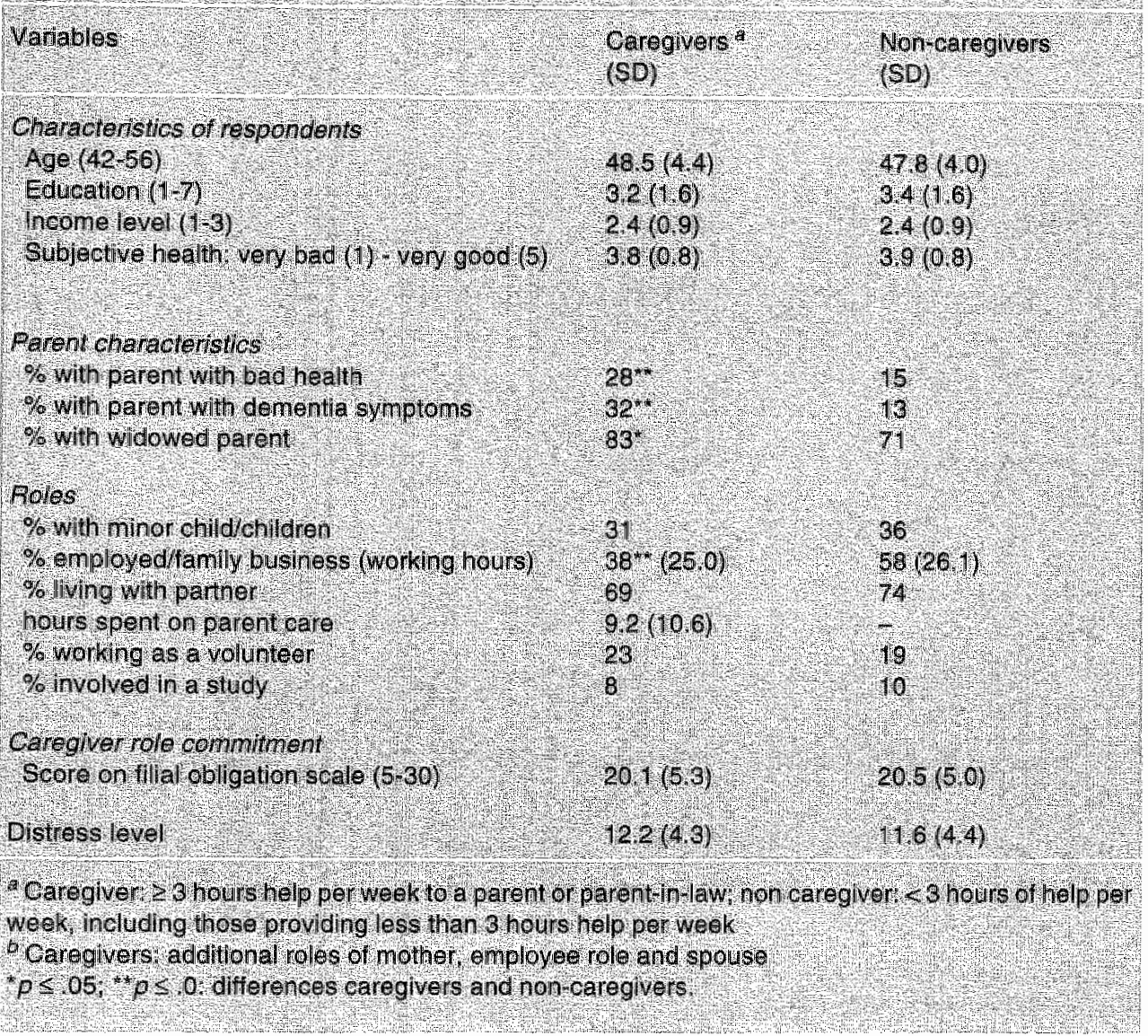

In the cross-sectional analyses, a multivariate hierarchical regression was performed with distress levels as the dependent variable and the caregiver role and caregiver role commitment (filial obligation) as independent variables. We controlled for age and educational level of respondents, social roles such as employment, a spouse, and caring for minor children, and physical and cognitive health of the parent. Regression analyses were hierarchical in order to see the contribution of each group of variables to the explained variance. The potentially mediating effect of 'caregiver role commitment' on distress was tested by a comparison of the regression coefficients before and after this predictor had been entered in the analysis.

Table 2 presents the findings with the standardised regression coefficients after the last step. 
TABLE 2. Herarchical multip te regression with the caregiver role predicting distress of middle aged Women with iving parents bivariate correlations and nulvariate standlardised regression coeflicients $10-542$

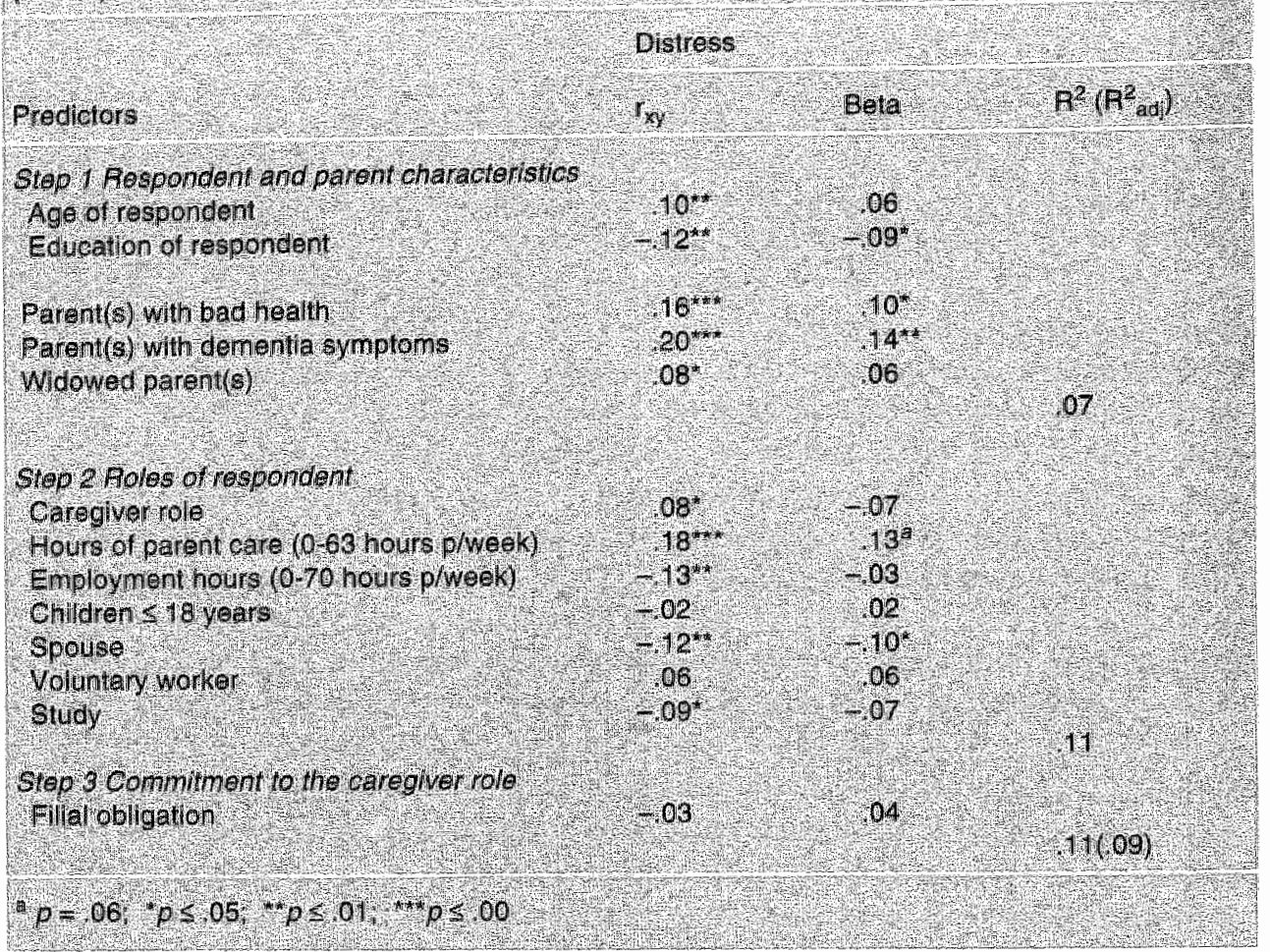

Table 2 shows that the caregiver role was not associated with higher levels of distress, nor when orher social roles such as paid work, being a mother and having a spouse were controlled for. A comparison of the regression coefficients before and after entering "caregiver role commitment" showed that caregiver role commitment did not moderate the impacr of the caregiver role on distress.

Among the four social roles, only the spousal role had an independent impact, apparently enhancing the wellbeing of these middle-aged women. Social roles of women explained only $4 \%$ of the variance in distress of middle-aged women. In separate multivariate analyses (not presented here) we examined with the help of dummy variables the impact of the number of social roles and all possible role combinations of caregiver, employee, morher and spouse on distress levels of middle-aged women. Only when women performed none of the four major social roles, did they appear to be significantly more distressed. 
TABLE 3 . Changes inlevels of distress between 11 (1994) and 12 (1996) when tha caregiver wole has ehanged

Fole contiguration (h)

\section{Never been caregiver?}

2. Remained careglver

smaller amouni of help at $12(n=7)$

same amount of help T2 and $1994 \mathrm{n}=66)$

greater amount of help at $72(n-49)$

\section{Acquired caregliver role $\mathrm{T}_{2}$ ?}

0or 1 role at 11 , care role ar $12(1-26)$

2 or 3 roles at 11, + care role al T2 $(n-10)$

\section{Lost caregiver role T2}

caregiver $+2 / 3$ roles at $1 / 2 / 3$ ioles at 12 (n- 7 )

caregiver 40 t. role at T1, 0/1 rolle at 22 (n $=34$ )

\begin{tabular}{|c|c|}
\hline $\begin{array}{l}\text { for or } \\
\text { respondents }(n)\end{array}$ & $\begin{array}{l}\text { RDistress } \\
\text { so) }\end{array}$ \\
\hline$(216)$ & $-0,02(3.6)$ \\
\hline $1(190)$ & $\begin{array}{r}0.56(3 \mathrm{~g}) \\
0.32(3.9) \\
0.27(3.8) \\
1.22(3.4)\end{array}$ \\
\hline (63) & $\begin{array}{r}0.59(4.2) \\
-0,15(4,1) \\
1,44(3.6)\end{array}$ \\
\hline$(110)$ & $\begin{array}{r}00(3.7) \\
0.72(9) \\
0.48(2.6)\end{array}$ \\
\hline
\end{tabular}

$100(569)$
$0.22(37)$

All tespondents with parent(s)

A Respondents proveling no help or less than three hours of help per veek at Tt and T?

brespondents providing at least 3 hours of help per Week at $T$ t and $T 2$, the totals of he sub- sample of the first columin do not add op to 89 because of hissing data on the amount of help $(n-3)$

CThe totals of the sub-samples in the first eolumi do not add up to the total $n$ the second column bo: cause the first column lineludiss ony respondens who remained th exactly the same role configuration besides the acquisit on or withdrawal from the careguer rolo.

Longitudinal analyses examined whether the acquisition of the caregiver role was associated with a change in levels of distress when distress levels at T2 (1996) were compared with distress levels at T1 (1994). The findings are presented in table 3.

Women who had acquired the caregiver role had become slightly more distressed, whereas women who had withdrawn from the caregiver role had become slightly less distressed. Similarly, women who were caregivers at both points of time had become more distressed, in particular caregivers who were giving a larger amount of care at $\mathrm{T} 2$, whereas women who were not helping parents at all had become slightly less distressed. However, differences between the sub-sers of respondents were smail and stariscically not significant.

Despite the lack of statistically significant differences, the findings presented in rable 3 suggest that the number of roles of caregivers have an impact on their distress. Women who had acquired the caregiver role at $T 2$ became less distressed when they had very few roles ( $\Delta$ distress $=-0.15$ ), whereas they became more distressed when they already two or three other roles ( $\Delta$ distress $=+1.44$ ). Withdrawal from the caregiver role reveals a similar pattern, suggesting that withdrawal of the caregiver role among women with multiple roles was associated with a decrease in distress ( $\Delta$ distress $=-$ 
0.72 ), whereas withdrawal of the caregiver role by women with few roles seemed to result in more distress ( $\Delta$ distress $=+0.48$ ). Again, however, differences between the sub-sets were very small and statistically not significant.

An additiona! multivariate analysis was performed (not presented in table 3) with changes in distress as the dependent variable and the acquisition of the caregiver role as the independent variable. In this analysis, we controlled for changes in employment, minor children, and the spousal role, in subjective health of the respondent, in income level as well as the respondent's age and educational level. Only a deterioration of the respondents' health $(\mathrm{p}<.00)$ and the loss of a spouse $(\mathrm{p}=.06)$ were associated with an increase in distress of respondents.

\section{Multiple roles of caregivers and distress}

Second, we examined whether multiple roles of caregivers and specific role combinations of caregivers were associated with distress and role strain. Table 4 presents the findings of a cross-sectional, hierarchical regression analysis with distress of caregivers and caregiver role strain as the dependent variables and other social roles as independent variables. The analysis controlled for social and demographic characteristics of the respondent, the assessed health status of the parent, caregiver role commirment and the relationship with the carc recipient. Again, groups of variables were entered hierarchically in order to see the separate contributions to the explained variance and the impact of caregiver role commitment. A comparison of the regression coefficients before and after entering 'caregiver role commitment' indicated the potentially mediating effect of this predictor on distress and caregiver role. Table 4 presents the standardised regression coefficients after all predictors had been entered.

None of the three major additional roles of caregivers appeared to affect their levels of distress. Also caregiver role strain was not affected by additional roles of caregivers. Separate multivariate analyses (not presented in tables here) examining the impact of the number of other roles on caregiver distress and caregiver role strain, revealed no significant outcomes as well; neirher did interaction terms of the amount of care with each of the other four social roles.

Distress of caregivers was mainly affected by the strain relared to the caregiver role, in particular the extent to which parent care interfered with the social and personal life of caregivers and the quality of the relationship with the elder. Neither caregiver role commitment nor the amount of care affected levels of distress of caregivers.

Caregivers felt more strain when they gave a larger amount of help, when their own health deteriorated and when the elder had bad health. Higher educated caregivers were also more likely to report more role strain, whereas a good relationship with the elder reduced feelings of caregiver strain. Table 4 suggests that only when the amount of care has caused interference in the social and personal life of caregivers, will distress levels of caregivers increase because of the amount of help. 
TABLE4. Hierarchical multiple regression prediching distress and caregiver ole strain bivariate corre. Tations and standardised regression coefficients ( $n=205$ )

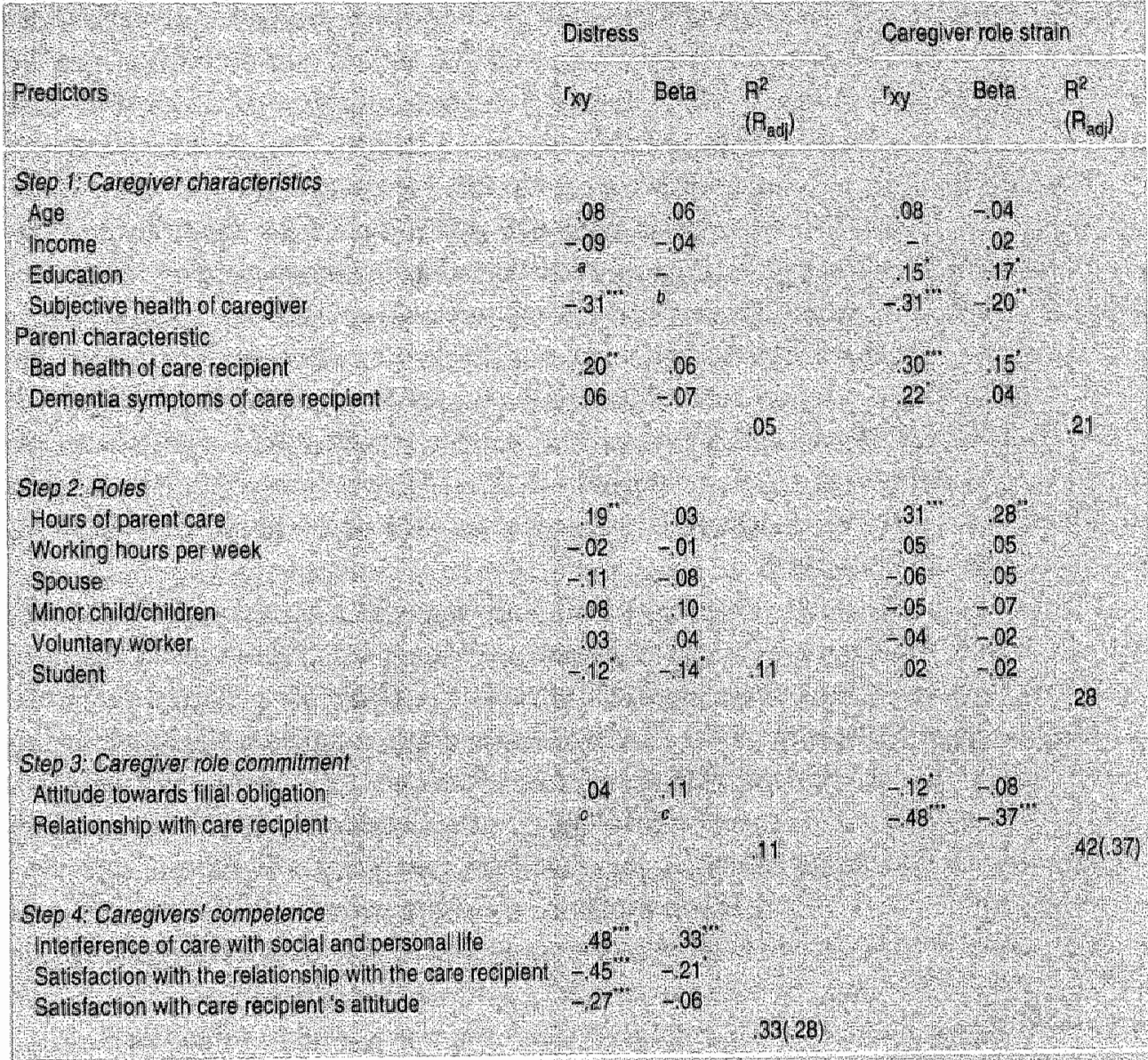

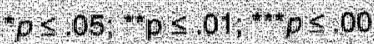

6i Education was excluded from the analysis becaus of its significant correlation with working hours

6 Because or the conceptual overlap and consequent high correlation between subjectlve heath and distress this predictor was excluded from he anclysis predicting caregivers distress

- Relationship with the care rediplent was one or the ite ms of the sub scale satistactian wilh oneself as a careg wer therefore this tem was excluded trom the analysis: 
This article examined, first, whether the role of caregiver of an elderly parent affects levels of distress of middle-aged women and, second, whether multiple roles or specific role combinations of caregivers affecr distress and caregiver role strain. Use was made of a probability sample of middle-aged women and a longitudinal research design.

The caregiver role appeared to have no profound impact on distress levels of middle-aged women with living parents. Cross-sectional comparisons showed that caregivers are slightly but not significantly more distressed than women not providing care. Also longitudinal analyses indicated that the acquisition or withdrawal from the caregiver role was associated with only small and statistically not significant changes in levels of distress. This finding is consistent with the cross-sectional study by Spitze et al. (1994) in New York that also made use of a probability sample. Our longitudinal data on changes in distress suggest that women in their middle years are more affecred by a deterioration of their own health and the loss of their spouse than by the care responsibility for their elderly parents.

One of the reasons that the caregiver role might not have a profound impact on women in their middle years is that, in the general population, elderly parents are not very ill and only receive relatively small amounts of help. Our cross-sectional data indicared that caregivers become more distressed only when caregiving demands are so heavy that it causes interference with the social and personal life of caregivers. Spitze et al. (1994) and Stoller and Pugliesi (1989) have reached similar conclusions regarding the importance that the amount of care can have in generating a burden of care. Another reason for the relatively small impact of the caregiver role on distress levels of middle-aged women is that providing assistance to parents can be rewarding as well. It is plausible to assume that in most care relations costs and rewards are balanced. These reciprocal aspecrs in parent care have generally been overlooked in other studies and deserve further explorarion.

Our cross-sectional and longitudinal analyses showed that multiple roles do not have negarive consequences for caregivers. This finding is consistent with other empirical studies on caregivers (Spitze et al., 1994; Stoller and Pugliesi, 1989). Thus, in contrast to what the literarure on women-in-the-middle and the sandwich generation suggests (Brody, 1981, 1990), our data do nor indicate that additional roles cause significant increases in distress or strain experienced in the caregiver role. The subjective evaluation of the caregiver role and not the number of hours of help affected distress of caregivers. The significance of the experienced quality of roles rather than the mere occupancy of roles has been srressed in other studies as well (Barnett and Baruch, 1985; Parris Stephens and Townsend, 1997).

Instead of women being negatively affected by a mulriplicity of roles, we found an opposite trend, with women performing neither the caregiver role nor any of the other 
three social roles being most distressed. Being 'roleless' may render women devalued, depriving them of a structure and legitimacy of commitments, thereby threatening their wellbeing. Similar results have been reported by research focusing on the roles of mother, employee and spouse. Women performing multiple roles appeared to have berter or similar physical health, mental health and mortality risks when compared to women performing few roles (Adelmann, 1994; Froberg, Gierdingen and Preston, 1986; van Poppel, 1996; Spreitzer, Snyder and Larson, 1979; Thoirs, 1983; Verbrugge, 1983; Waldron and Jacobs, 1989). Although these findings suggest that multiple roles are beneficial rather than detrimental for women, we must stress that the causal relation may also run the opposite way, with more distressed women withdrawing from social roles. Thus, those who are less capable tend to do less.

Regarding the three cited hypotheses of role theory, our data lend support mainly to the role expansion and the role accumulation hypothesis, a finding that is in line with the majority of other studies. Women might expand their tole set with the caregiver role without showing significant changes in their levels of distress, and caregivers with other roles are not more distressed. Despite this evidence supporting the role expansion hypothesis, filial obligation, our indicator of commitment to the caregiver role, appeared to reveal hardly any moderating impact of the caregiver role on distress.

One cautionary remark has to be made. Although no statistically significant associations between multiple roles and distress were found, our longitudinal analyses showed that women with very few roles become less distressed when they acquire the caregiver role, whereas women with multiple roles become more distressed. The caregiver role may add a sense of meaning and belonging to the life of women who perform wery few other roles, but increases the pressure on women when their life is already filled with many other responsibilities. The consistency in this pattern found in our data requires further study to determine whether the lack of statistically significant differences is due to small sub-samples and large individual variations.

Previous studies have created an artificial contrast between the role conflict and the rolle expansion hypotheses. Rather than looking for empirical support of either of those, it might be more realistic to consider them as complementary views and explore the specific conditions under which they have empirical validity. In particular, the concept of role bargaining deserves further elaboration and empirical validation. Perhaps women who can strike the best role bargains and who derive satisfaction from doing so successfully are able to keep role strain within acceptable limits. Since a one-sided focus on the harmful impact of multiple roles on women might contribute to a negative picture of women with multiple responsibilities, we suggest that future research should explore determinants and strategies contributing to successful coping with the caregiver role and with multiple roles. 


\section{NOTES}

1. This chapter has been published: Dautzenberg, M.G.H., Diederiks, I. P.M., Philipsen, H. \& Tan, F.E.S. (1999). Multigenerational caregiving and wellbeing; Distress and burden of middle-aged daughters providing assistance to elderly parents. Women \& Health, 29 , 5774.

\section{REFERENCES}

Adelmann, P.K. (1994). Multiple roles and psychological wellbeing in a national sample of older adults. Journat of Gerontology: Social Sciences, 49, $5277-5285$.

Baruch, C.K. (1984) The psychological wellbeing of women in the middle years. In G.K Baruch \&). Brooks-Gunn (Eds). Women in Midlife, pp. 161-225. New York: Plenum Press.

Barnet, R.C. \& Baruch, G.K. (1985). Women's involvement in multiple roles and psychological distress. Journal of Personality and Social Psychology, 49, 135-145.

Baruch, G.K. \& Barnett, R.C. (1986). Role quality, multiple role irvolvement and psychological wellbeing in midlife women. Journal of Personality and Social Psychology, 51, 578-585.

Braithwaite, V. (1996). Understanding stress in informal caregiving. Is burden a problem of the individuall or of society? Research on Aging, 18, 139-174.

Brody, E.M. (1981). "Women in the middle" and family help to older people. The Cerontologist, $21,471.480$.

Brody, E.M. (1990). Women in the Middle: Their Parent-Care Years. New York: Springer.

Brody, E.M. (1992). Differential effect of daughters' marital status on their parent care experiences. The Gerontologist, 32, 58-67.

Cockerham, W.C., Kunz, G. and Lüschen, G. (1988). Psychological distress, perceived health status, and physician utilization in America and West-Germany. Socia/ Science and Medicine, $26,829-839$.

Doress-Worters, P.B. (1994). Adding elder care to women's multiple roles: a critical review of the caregiver stress and multiple roles literature. Sex Roles, 31, 597-616.

Goode. W.I. (1960). A theory of role strain. American Sociological Review, 25,483-496.

Froberg, D. Gjerdingen, D. \& Preston, M. (1986). Multiple roles and women's mental and physical: What have we learned? Women \& Heath, 11, 79-96.

Horowitz, A. (1985). Family caregiving to the frail elderly. In C. Eisdorfer (ed), Annual Review of Gerontology \& Geriatrics. New York: Springer.

Mangen, D.J , Bengtson, V.L. \& Landry, P.H. (eds) (1988). Measuring intergenerational relations. Newbury Park, CA: Sage.

Marks, S.R. (1977). Multiple roles and role strain: Some notes on human energy, time and commitment, American Sociological Review, 42, 921-936. 
Miller, D.A. (1981). The 'sandwich' generation: Adult children of the aging. Social Work, 419-423.

Montgomery, R.V.J, Gonyea, J.G. \& Hooyman, N.R. (1985). Caregiving and the experience of subjective amd objective burden. Family Relations, 34, 19-26.

Parris Stephens M.A. \& Townsend A. (1997). Stress of parent care: Positive and negative effects of women's other roles. Psychology \& Aging, 12, 376-386.

Poppel van, F. (1996). Dubbele belasting van de vrouw en de effecten op haar sterftekans Women's doubled burden and its effects on Mortality Risks). Demos, Netherlands Interdisciplinary Demogrpahic Institute, 12, 21-24.

Schlesinger, B. (1989). The 'sandwich generation': Middle-aged families under stress, Canada's Mental Health, 11-14.

Spreitzer, E., Snyder, E.E. \& Larson, D.L. (1979). Multiple roles and psychological wellbeing. Sociological Focus, 12, $141-148$.

Sieber, S.D. (1974). Toward a theory of role accumulation. American Sociological Review, 39, $567-578$.

Spitze G., Logan I.R., Joseph G. \& Lee E. Middle generation roles and the wellbeing of men and women. Jourmal of Gerontology: Social Sciences, 49, S107-S116.

Stoller E.P. \& Pugliesi K.L. (1989). Other roles of caregivers: Competing responsibilities or supportive resources. Journal of Cerontology: Socia/ Sciences, 44, S231-238.

Thoits P.A. (1983). Multiple identities and psychological wellbeing: A reformulation and test of the social isolation hypothesis. American Sociological Review, 48, 174-187.

Verbrugge L.M. (1983). Multiple roles and physical health of women and men. Joumal of Health \& Social Behavior, $24,16-30$.

Vernooij-Dassen M.J.F.J., Felling A.J.A. Brummelkamp, E., Dautzenberg M.G.H., van den Bos, G.A.M. \& Grol, R. in press. Assessment of caregiver's competence in dealing with the burden of caregiving for a dementia patient: a Short Sense of Competence Questionnaire (SSCQ) suitable for clinical practice. Jownal of the American Geriatric Society, 47, 220-225.

Waldron 1. \& Jacobs 1.A. (1989). Effects of women's multiple roles on women's health ewidence from a national longitudinal study. Women \& Health, 15, 3-19.

Zarit S.H., Reever K.E. \& Bach-Peterson. (1980). J. Relatives of the impaired elderly: Correlates of feelings of burden. The Gerontologist, $20,649-655$. 


\section{CHAPTER 4}

The competing demands of work and parent care; Middle-aged daughters providing assistance to elderly parents ${ }^{1,2}$

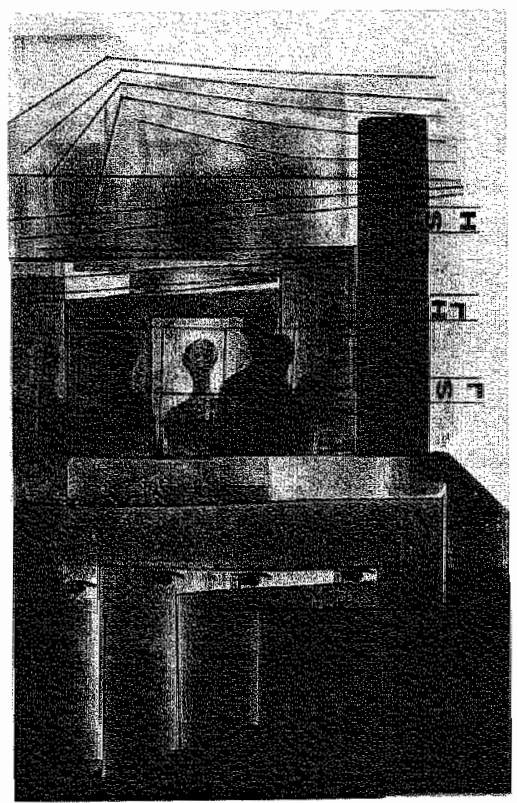


72 Chapter 4

Is bet vandaug of gisteren, wraagt wijn moeder. altijd vandaag, zeg ik. Ze glimlacht vaag en zegt: zijn we in Roden of Den Hadg? wat later: kindje ik word veel te oud. Ik troost haar, dierbare sneewwwitte astronawt zo ver al van de adrde weggedreven, zo moedig wigestapt en in de ruinte zwevend zonder bestek en ber en der.

Zjizoekt - het is een so.s. haar herkomst ew har zijn als kind en niemand wiemand, die hatr vindt zoals zij was.

M. Vasalis 
This article investigates the potentially competitive relationship between paid work and parent care provided by daughters and daughters-in-law. In line with the scarcity hypothesis of role theory, four sub-hypotheses were formulated and tested empirically. In a population-based probability sample of middle-aged women $(n=581)$, only partial empirical support was found for the scarcity or role conflict hyporhesis. It appeared that employment significantly reduces the chances of becoming a caregiver. However, parent care and employment are not conflicting in time as the amount of care provided to parents was not affected by out-of-home employment. Parent care has only a small impact on work decisions and employed caregivers do not experience more caregiver role strain. We hypothesized that employed women not yet providing care anticipate a role conflict when a parent becomes frail and needs help. Consequently, a self-selection process takes place, whereby the nearest living daughter with the least competing demands is most likely to accept the caregiver role. Once the caregiver role is accepted, both role strain and the time spent on parent care are determined by factors other than employment status or work hours.

\section{INTRODUCTION}

In most industrial societies increasing numbers of women are working on a steady basis and are entering occupations once considered the exclusive domains of men. In particular middle-aged women have entered the labor force. In the US, it has been reported $60 \%$ of the women between 45 and 54 are involved in paid work (Brody 1983). In the Netherlands, female labor force participation of women aged $40-49$ has risen from $17 \%$ to $52 \%$ in the past 30 years (Central Bureau of Statistics 1994).

Since daughters are the major source of help for frail elderly parents, the involvement of women in out-of-home employment has raised concern among policymakers about female employment as a competing demand for elder care. Paid work may pull women away from parent care and increase the costs of community services and institurionalization of the elderly. Employers worry that long-term parent care may result in stress and burn-out of employees, lowered production, increased absenteeism and higher job turnover.

This article investigates the - potentially - comperitive nature of female employment and parent care. Does out-of-home employment have negative consequences for parent care? Does parent care affect employee absenteeism and work decisions? Do employed helpers experience a higher subjective burden of care?

Empirical studies on employed women providing parent care suggest that paid work makes women somewhat less available, but does not reduce significantly the time 
spent on helping parents. Most studies report only small differences among nonemployed, part-time and full-rime employed daughters with regard to the hours spent assisting elderly parents (Lang and Brody 1983; Pert, Caserta, Hurron, and Lund 1988; Scharlach 1987; Stoller 1983; Tennsted and Harrow 1996). Only a few studies found that employment has a negative effect on hours of care. Brody and Schoonover (1986) as well as Lang and Brody (1983) reported that employed daughters provided less instrumental help to their mothers than unemployed daughters. The mothers, however, received equal amounts of help because employed daughters arranged for ad. ditional sources of support, such as purchased help. In two other studies, an impact was found of number of hours worked, with full-time work reducing the rime spent on assisting parents, whereas part-rime work did not (Boaz and Muller; 1992; Stueve and $\mathrm{O}^{2}$ Donell cited in Gibeau and Anastas 1989).

With regard to the adverse impact of caregiving on poberformance, findings are contradictory (Gerstel and Galagher 1993). On the one hand, studies have highlighted the negative consequences of combining elder care with paid work (Allen 1996; Barling et al. 1994; Gordieb, Kelloway, and Fabroni 1994; Scharlach and Boyd 1989; Soldo and Myllyluoma 1983). Caregiving causes employees to arrive late to work, leave early, miss work or to experience frequent work interruptions. Employed caregivers have been reported to quir jobs or to be planning to do so, with percentages varying berween 14\% and 20\% of employed caregivers (Brody 1987; Gibeau and Anastas 1989; Muttschler 1994; Petry and Friss 1987; Scharlach and Boyd 1989; Stone and Short 1990). Neal, Chapman, Ingersoll-Dayton and Emlen (1993) reported that in particular, multiple caregiving roles and working more hours contributed to absenteeism. On the other hand, Marthews, Werkner and Delaney (1989) articullated that almost all caregivers remain in their job and manage fairly well in combining both work and caregiving responsibilities. In a survey among 50 employed women, only 1 had quit her job because of caregiving. Similarly, Pohl, Boyd, Liang and Given (1995) did not find any association between negative employment decisions of caregiving daughters, such as leaving jobs, and a decline in health of their elderly mothers.

With regard to the impact of employment on the subjecrive burden of care, no consistent evidence is found. In general, authors assume a negative impact of combining employment and parent care on the well-being of caregivers (Barling 1994; Gottieb, et al. 1994; Horowitz 1985; Mui 1992 1995; Azarnoff and Scharlach 1988). In contrast, Pett et al. (1988) could not find any significant differences in the burden of care experienced by non-employed and employed primary caregivers of a demented elderly relarive, regardless of whether they worked part-time or full-time. Neal et al. (1993) reported that working mone hours, providing a larger amount of care and having fewer, instead of more, other caregiving roles contributed to a higher burden of care of employed caregivers. Scharlach (1994) reported that caregivers also experience a positive impact of combining work and elder care. 
The assumed negative impact of combining work and family roles is based on what has been labeled as the scarcity approach of multiple roles, also described as the role conflict hypothesis, or the competing demand hypothesis (Marks 1977; Barling 1994; Mui 1992; Parris Stephens 1994). It rests on the assumption that the total role system of individuals tends to be overdemanding and, hence, induces role strain. The individual's main problem is how to manage the total role set and keep role strain within acceptable limits. Role strain can be reduced by the delegation of role tasks and the reduction of time spent on a specific role, or by reducing the number of roles (Goode 1960).

The role scarcity hypothesis has been challenged by the role accumulation bypothesis of Sam Sieber (1974) and by the role expansion hypothesis of Stephen Marks (1977). The role accumulation hypothesis assumes that the beneficial impact of occupying multiple roles usually outweighs the stressful aspects, since multiple roles provide access to multiple sources of status enhancement, status security, role privileges and sources for ego gratification. In other words, multiple roles increase the individual's well-being. The role expansion hypothesis also assumes that individuals can expand role sets without concomitant increases in role strain and distress, but states that it depends on the extent to which the individual feels committed to each of these roles. Individuals are more likely to become stressed and tired when they have to perform an additional role to which they feel uncommitted, whereas their energy and time can be abundant when they are strongly committed to that role.

The role scarcity, role accumulation and role expansion hypotheses, however, only provide a very general framework. Therefore, in this article four sub-hypotheses were derived on paid work by women and elder care. We used the scarcity approach as a starting point, because ir is still the dominant perspective in the research agenda and policy debates on work and family roles of women.

First, we expected that employed women might be less likely to be a caregiver of an elderly parent as compared to unemployed women, assuming that women might foresee a role conflict between their jobs and elder care when parents fall ill and, therefore, be less willing to accept that role. Second, the scarcity hypothesis considers work and elder care as competing in time and energy. Consequentlly, we expected that the time spent on employment might be inversely related to the time spent on assistance to parents, assuming that the more hours women work, the less time remains for providing assistance to parents. Third, we expected a similar impact in the opposite direction: the more hours women work, the more interference they experience of caregiving with work. Fourth, we aimed at testing whether the combination of elder care and work increased caregivers' role strain.

Although we used the scarcity approach as a starting point in our analyses, a measurement of caregiver role commitment was included, i.e. filial obligation. Therefore, 
we could examine a potentially buffering effect of caregiver role commitment on caregiver role strain.

Previous research focused mainly on employment reducing the hours available to assist parents. This study extends the scope of previous studies by investigating whether employment status of women affects choices about whether the caregiver role is accepted at all. In addition, we examined the impact of employment and work hours on role strain, an issue that has not frequently been subjected to empirical investigation. Finally, previous studies have been criticized for analyzing nonrepresentative samples, low response rates and for not including a 'control group' of employees that are not inwolved in parent care (Loomis and Booth 1995; Scharlach and Boyd 1989; Scharlach, Sobel, and Roberts 1991; Starrels, Ingersoll-Dayton, Neal, and Yamada 1995). Our study made use of a population-based probability sample of middle-aged women, including employed and unemployed caregivers, as well as women not providing parent care.

\section{METHOD}

Data were obtained through a telephone survey in four municipalities, one medium-sized town $(80,000$ inhabitants) and three smaller communities (in total 40,000 inhabitants) in the southern part of the Netherlands. The research area included an urbanized city center, as well as suburbs and village neighborhoods. As such, it represented a common situation for medium-sized cities and small towns in the Netherlands.

\section{Sampling procedure}

Respondents were middle-aged women (42-56 years), recruited through a population-based probability sample drawn from local municipality registration offices $(n=934)$. They had been interviewed on similar issues in 1994 (response rate $79 \%)$ and were approached again by telephone in 1996 . Out of 934 respondents interviewed in 1994, 65 respondents could nor be traced in 1996 because they had moved, currently had an unlisted telephone number, or did not answer the phone. Of the remaining 868 respondents, 743 completed the questionnaire, with 125 refusing to co-operate. The rotal response rate for 1994 and 1996 was $80 \%$. The most frequently mentioned reasons for not cooperating were lack of interest, lack of time, privacy considerations and being tired of telephone surveys. A non-response analysis was performed by a logistic regression, entering the variables that showed significant differences on the bivariate level in combination with the parent characteristics age, traveling time to 
parents and help to parents. Only the respondent's education and having children were significant predictors increasing the odds of response $(p<.05)$.

Analyses were performed on respondents who had at least one living parent or parent-in-law $(n=581)$. In the remainder of this article, the word parent will refer to either a parent or parent-in-law.

\section{Measurements}

Help to parents was solicited by a question on the type and amount of assistance given to a parent in the past four weeks, indicated by the weekly number of mornings, afternoons or evenings spent on this help. Help referred to assistance such as preparing meals, cleaning the house, personal care, providing transport, financial administration, gardening or making repairs, or emotional support such as providing comfort and consolation when the parent felt lonely or depressed. Ordinary social visits to parents were not considered as help. Respondents were requested to estimate how many mornings, afternoons or evenings they spent on helping the parent. When the amount was less than one full morning, afternoon or evening, respondents were asked to indicate what fraction of a morning, afternoon or evening they spent on assisting the parent, considering that one morning, afternoon or evening was approximately 3 hours. An equivalent in hours was calculated using three hours for every morning, afternoon or evening of help. Being a caregiver implied that at least three hours of help per week was given. Primary caregivers were those who indicated that they did most when compared to other caregivers involved, including paid helpers.

Educational level was assessed by indicating the highest level of education completed by the respondent, varying from primary school (1) to university (7). Health of the parent and the respondent was self-assessed by a one-dimensional, Likert-type, five-item scale (very good to very bad). The respondent assessed dementia symptoms of the parents by a single dichotomous item (yes or no). Distance to parents was measured in traveling time (minutes). Income level was self-assessed with three coding categories, with respondents being asked whether their rotal household income was lower (1), equal (2) or higher (3) than the net modal (individual) income in the Netherlands.

Filial obligation was measured by a six-item 5 -point scale on the responsibility respondents believe that adult children should have in (1) providing companionship, (2) helping and supporting their parents with household chores and transportation, (3) providing advice and guidance, (4) providing personal and health care, (5) providing financial support, and (6) providing housing. Possible scores were berween 6 and 30. The filial obligation scale had been tested in the US on reliability and stability over time (Mangen, Landry and Bengtson 1987). Cronbach's alpha in our sample was 82.

Caregiver role strain was measured by one of the three sub-scales of the Sense of Competence Questionnaire, a measure for subjective caregiver burden that was devel- 
oped on the basis of Zarit's Burden Scale and the family crisis model of Bengtson and Kuijper (Vernooij-Dassen, Persoon and Felling 1996). The Sense of Comperence Questionnaire has been used in its original, 27 -item version and a 7 -item version. Both versions had been tested among warious caregiver groups, where they appeared to have good psychometric properties (Vernooj-Dassen, Felling, Brummelkamp, Dautzenberg, wan den Bos, and Grol 1998). In our study, caregiver role strain referred to one of the three sub-scales, labeled as 'Parent care interfering with the social and personal life of the caregiver". In the shortened Sense of Competence Questionnaire this scale consisted of two, Likert-type items $(r=.67, p<.001)$. The first item indicated whether various responsibilities were difficult to combine for the caregiver; the second item indicated to what extent parent care interfered with the caregiver's privacy. The remaining two sub-scales of the Sense of Competence Questionnaire were not included in our study since they measure the subjective burden of caregivers of dementia parients.

\section{Statistical analyses}

At the bivariate level, differences between groups were determined by ch-square tests when variables were dichoromous, nonparametric tests (Mann-Whitney) when variables were measured at the ordinal level and test of means when variables were measured ar the interval level.

At the multivariate level, a logistic regression was performed when the dependent variable was dichotomous. Multiple linear regression was used when dependent variables were continuous. Predictors were entered simultaneously in the analysis. Model assumptions of linearity, homogeneity of variance and the normal distribution of residuals were examined and appeared not to be violated. In the analysis with hours of help as the dependent variable, the dependent variable was transformed into the square root in order not to violate the model assumption of homogeneity of variance. Collinearity was tested by the Variance of Inflation Factor (VIF), which appeared in both regression analyses to have an acceprable maxinum of 4.1 .

\section{RESULTS}

The sample consisted of 743 respondents, with 581 having at least one living parent. As table 1 shows, of these 581 respondents, the mean age was 48.9 years (range 42-56). The majoricy was living with a partner $(72 \%)$ and had children $(85 \%)$, although only $25 \%$ had children under the age of 18 . Half of che respondents were employed $(49 \%)$; on average they worked 25.6 hours a week (range: $2-70$ hours). Most respondents came from large families: only four percent were an only child (not in table 1), the others having 3.5 siblings on average (range 1-12). Respondents usually rated their 


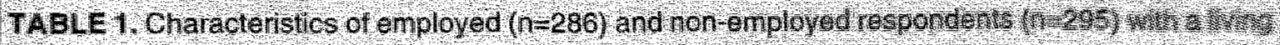
parent $(n=581)$

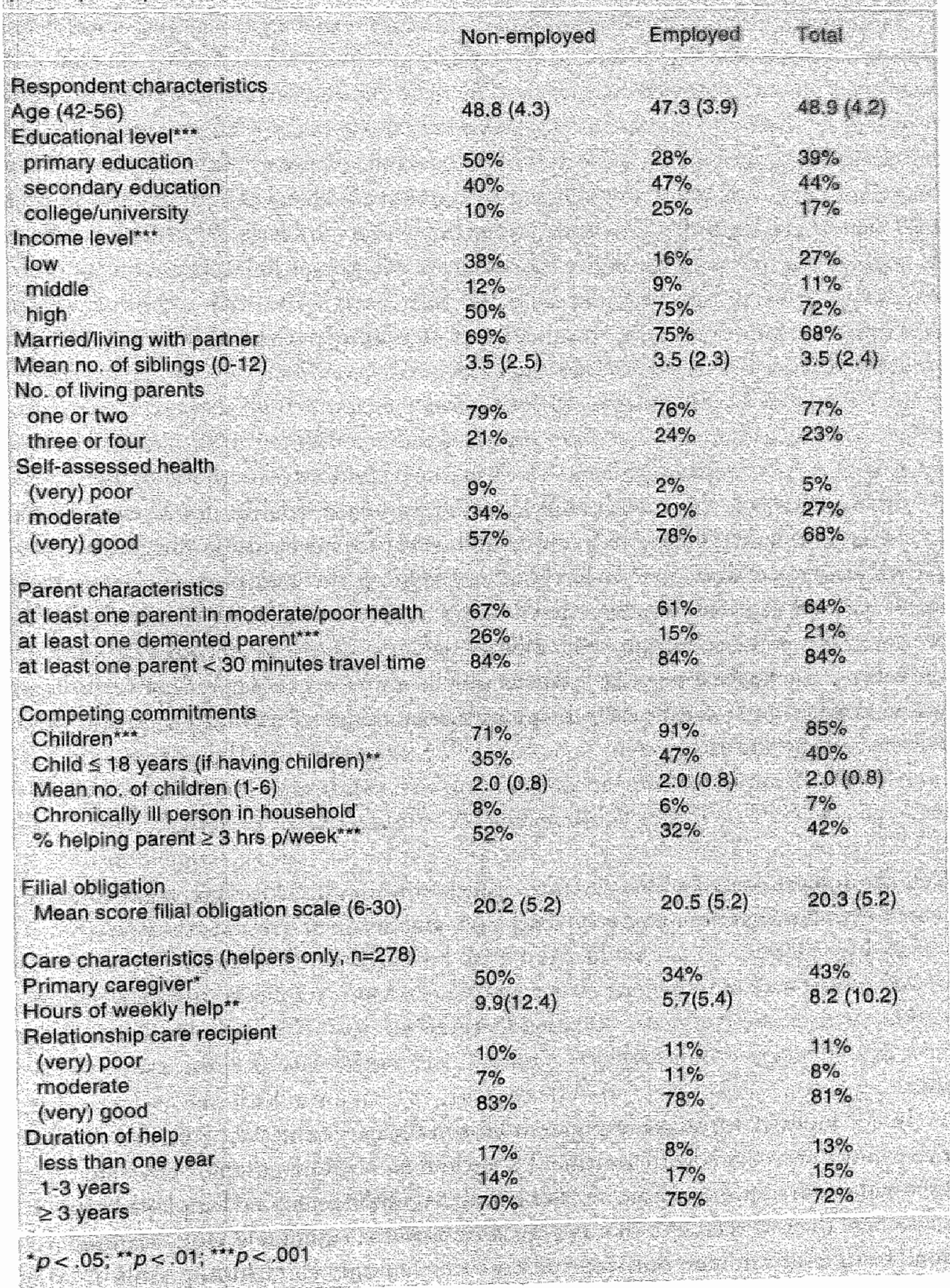


own healch as good or very good $(68 \%)$, a minority described it as moderate $(27 \%)$ or bad $(5 \%)$.

Commonly, one or two parents were srill alive and about two-thirds $(64 \%)$ reported having at least one parent with a moderate or bad health. Twenty-one percent had a parent with dementia symptoms. The majority ( $84 \%$ ) lived within 30 minutes traveling time of one of the parents. Usually the help was stretched over years: $72 \%$ had been helping the parent for more than three years (53\% more than three years), 34\% between one and six years and $13 \%$ less than one year. About half of the respondents $(42 \%)$ had been helping a parent for at least three hours per week. The mean numbers of hours of help per week was eight, including providing emotional support (e.g., keeping company when they thought the parent felt lonely). The majority of caregivers rated the relationship with the care recipient as good or very good ( $81 \%)$. Only $2 \%$ shared residence with a parent (not shown).

As compared to unemployed women, employed women were more highly educated, had higher incomes and were less likely to have children. If they had children, employed women were more likely to have younger children (i.e., under the age of 18). A striking difference concerned parent care. Employed women were less likely to be the helper of an elderly parent, and less likely to be the primary caregiver of a parent. Employed caregivers also gave fewer hours of help to their parents compared with nonemployed caregivers ( 6 hours per week compared to 10 hours by nonemployed women). It was also surprising that employed women were less likely to have a parent with dementia symptoms ( $p<.00$ ). We do not know whether the latter figure reflects an actual difference or a difference in perceprion, because dementia symptoms were self-assessed by the caregiver.

\section{Employment and the caregiver role}

The first hypothesis examined whether employed women are less likely to be the caregiver of an elderly parent, assuming that employment affects women's decision to start caregiving. This question was addressed, first, by a logistic regression analysis with the dichotomous variable caregiver role as the dependent variable, examining wherher employment reduced chances of being the caregiver of an elderly parent. Second, we investigated whether noncaregivers reported paid work as a reason for not providing care.

In the logistic regression, caregiver role was defined as helping a parent three or more hours per week. Predictor variables were social and demographic characteristics of respondents (age, education, income, number of siblings, subjective health), characteristics of parents (distance in traveling time, assessed health, dementia symptoms), competing commitments (employment, spouse, child under eighteen, chronically ill person in household) and filial obligarion. To facilitate the interpretation of data, pre- 
dictor variables were categorized (see Table 2). We included an interaction term ("enployment and having children under the age of eighteen") in order to test whether the combined responsibility of having both a job and a family of one's own might have an exacerbating effect decreasing chances of becoming the caregiver of a parent. All vary ables were entered simultaneously in the analysis. Table 2 presents the significant predictors in order of relative strength of the odds ratios.

Table 2 shows that employment was a significant predictor reducing the likelihood of daughters to be the helper of a parent, also when other relevant factors such as the parents' health and traveling time to parents were controlled for. Women who were not employed were five times as likely ro be a helper as full-time working women. As Table 2 shows, full-timers did not differ" significantly from part-timers.

Besides employment, geographical distance to a parent increased the chance to become a caregiver, i.e. when respondents had a parent living within 30 minutes traveling rime. Other relevant factors were cognitive and physical impairment of a parent., being unmarried, having many siblings, and belonging to the higher income groups. Apparently, the spousal role as well as the work role competed with the caregiver role. Only when women originated from a very large family (i.e., when they had more than six siblings) were they able to leave the caregiving task to another sister or brother. In orher words, being an only child or having few siblings did not increase the likelihood to become a helper. Although women from higher income groups were more likely to report helping a parent, cross tabulations showed that they reported in particular more frequently on helping parents with socializing activities, such as taking them out for shopping and trips. Women living in lower income households were more likely to spend time on cleaning the house $(\mathrm{p}<.00)$.

The classification table shows that the above set of variables resulted in $72 \%$ of the respondents being correctly classified: $61 \%$ of the helpers and $79 \%$ of those nor providing help.

The importance of employment reducing chances of being a helper was confirmed by an additional analysis that determined whether women reported that their job was the reason for not providing help. Among the 278 women not providing any help, 63 respondents were employed and did not provide assistance despite their parents' needing help. Alnuost half of those $(n=29)$ respondents, reported that they did not provide assistance because of their jobs.

\section{Employment and bours of assistance}

The second hypothesis examined the (potentially) competing relation between hours of employment and hours of assistance to parents. This hypothesis was tested in a multivariare analysis with hours of weekly help as the dependent wariable. Predictor variables were, again, employment, social and demographic characteristics of the care- 
a2 Chapter 4

TABLE 2. LGgisticregrossion coefficients and odds ratios for tactors predicting regular help to parents (n-540), only significant wariables and ranked in order of strength of odds ratios

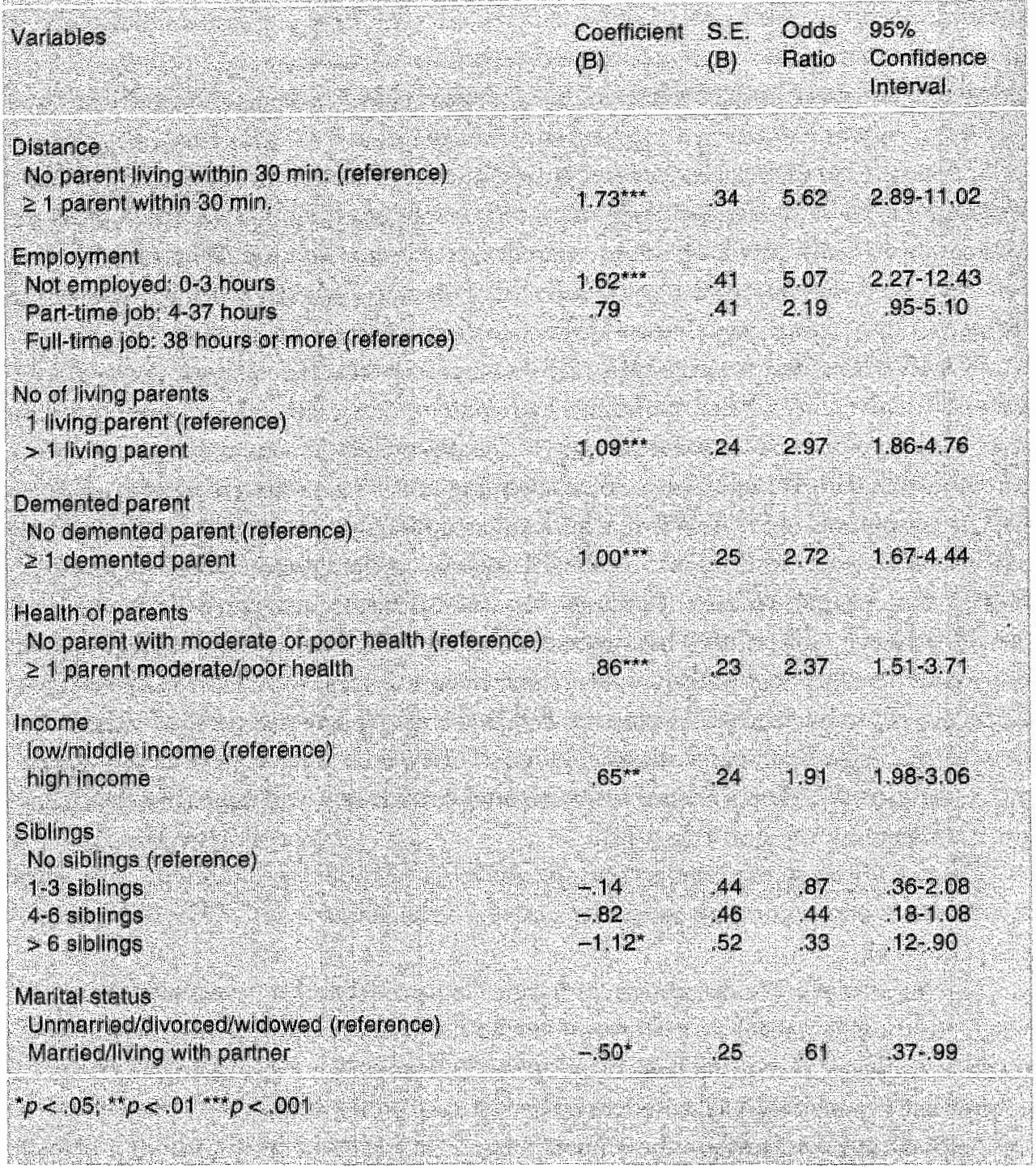

giver, characteristics of the parent, additional competing commitments and filial obligation. We added the perceived quality of the relationship with the care recipient because we expected that a good relationship encourages caregivers to spend more time on parent care.

Table 3 shows that, at the multivariate level, neither employment status nor the number of work hours reduced the amount of care. Subsequent regression analysis 


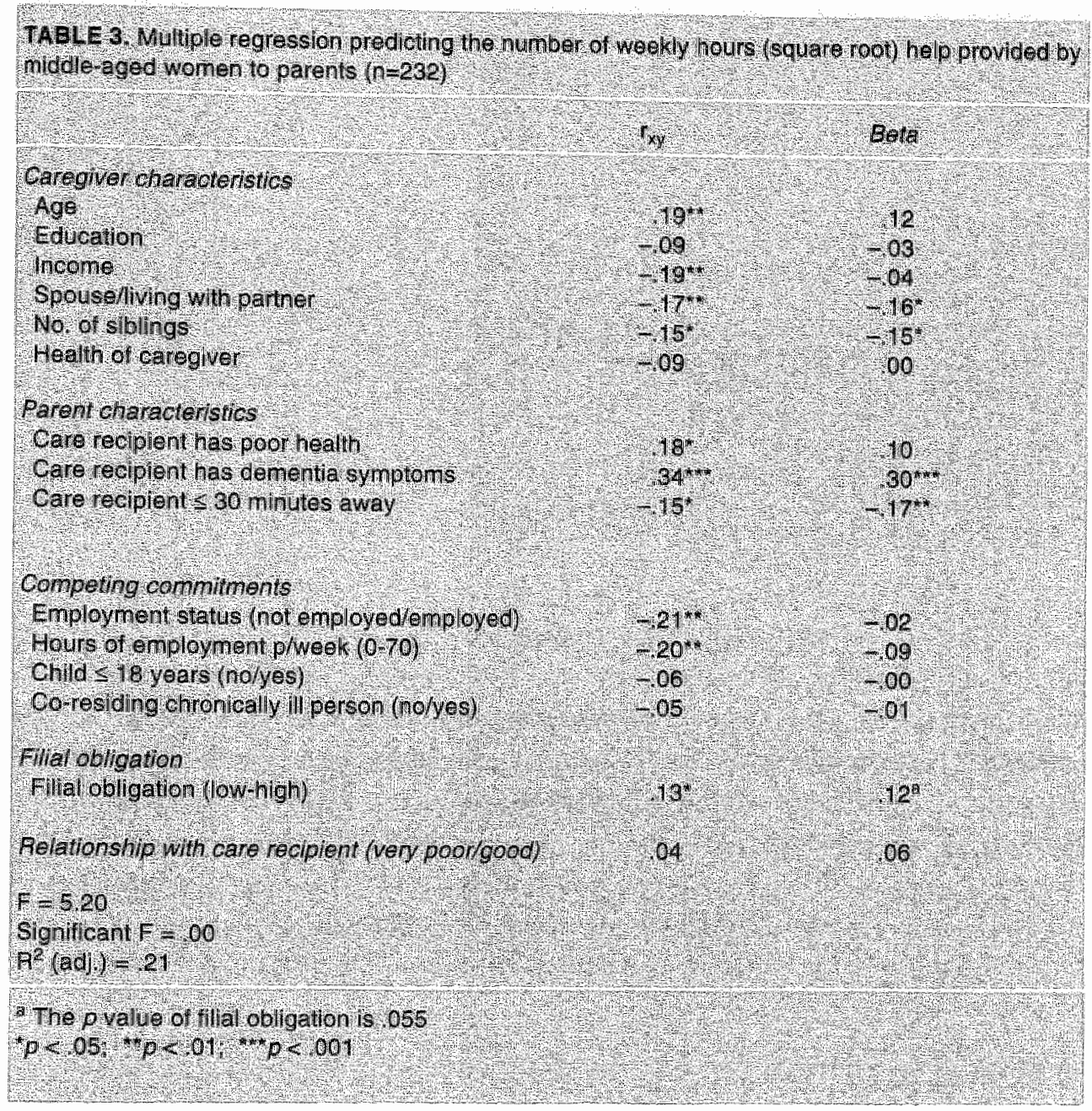

among employed caregivers (not shown) revealed similar results: the time spent on helping parents did not decrease when they worked more hours.

Respondents spent more time on parent care when the care recipient suffered from dementia and lived within 30 minutes traveling time from the caregiver. Hours of help also increased when respondents were unmarried, older and when they had a stronger positive attitude towards filial obligation, although age and filial obligation did not reach the .05 -significance level when examined at the multivariate level. The presence, and probably help, of siblings reduced the care task.

Bivariate analyses indicated that in particular women who had never married provided more hours of help $(\mathbb{p}<05)$. As Table 3 shows, the total set of variables explained $22 \%$ of the variance in hours of help. 
TABLE 4 Interierence of parent care with work as indicaled by employed caregivers $(n=118)$

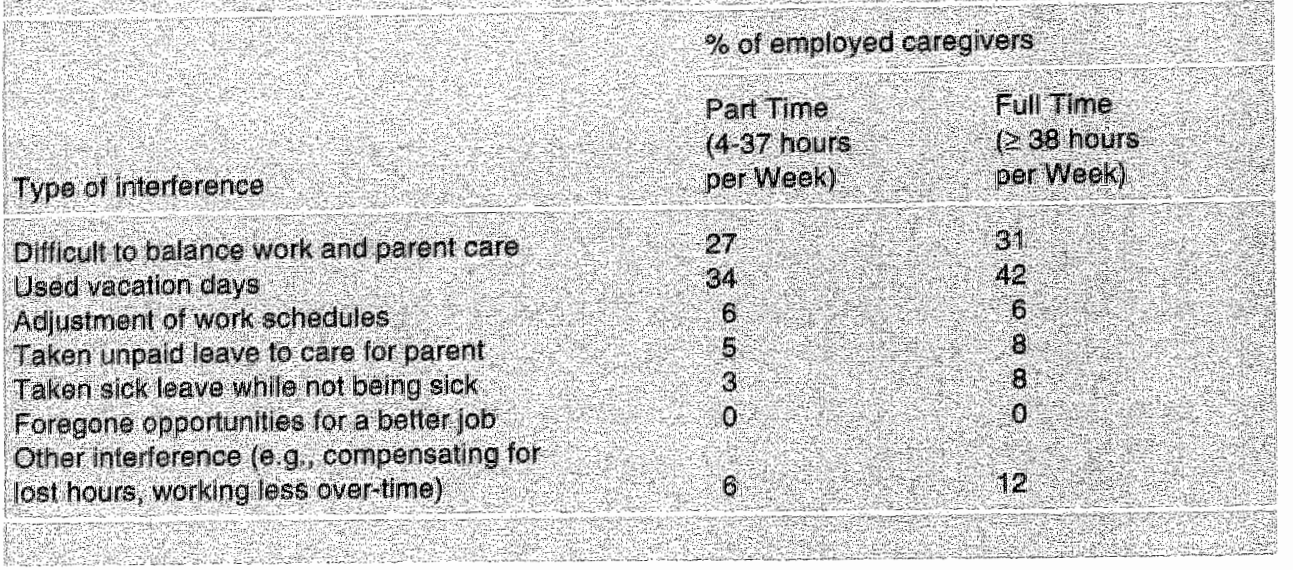

\section{The impact of caregiving on work}

The third hypothesis addressed the potentially adverse effects of caregiving on the workplace (i.e. caregiving responsibilities making employed caregivers feel conflicted and increasing their absenteeism at work). We tested this hypothesis by determining first whether full-time and part-time employed caregivers had been using vacation days, taking sick leave while not being sick, making use of umpaid leaves, adjusted work schedules or had been foregoing opportunities for better jobs. In addition, we examined longitudinal data to determine whether changes in time spent on parent care were related to changes in work hours.

Table 4 presents interference of work caused by parent care among employed caregivers. Twenty-seven percent of employed caregivers found it difficult to balance work and elder care and $30 \%$ to $40 \%$ had been using vacation days to fulfil parent care responsibilities. Only very few caregivers had taken sick leave while nor being sick or made use of unpaid leave. None had foregone better job opportunities, despite the fact that three-quarters had been giving assistance to the parent for more than three years. Although full-time employed caregivers more frequently reported interference with than part-time employed caregivers, differences between full-timers and part-timers were statistically not significant.

Longitudinal data provided information on whether changes in the amount of help were associated with changes in work hours over a period of two years. This appeared not to be the case: an increase in hours of help was not associated with a decrease in work hours $(r=.05 ; p=.59)$. In addition, caregivers were probed at $T 1$ on the reasons for reducing their involvement in various activiries such as work. Among those who had reduced the time spent on paid wotk, only $7 \%$ reported that this was because of the 
TABLE 5 Multiple regression predicting car eglvers role strain (perceived interterence by marent cara) or middte aged women providing assistance to parents $(n-232)$

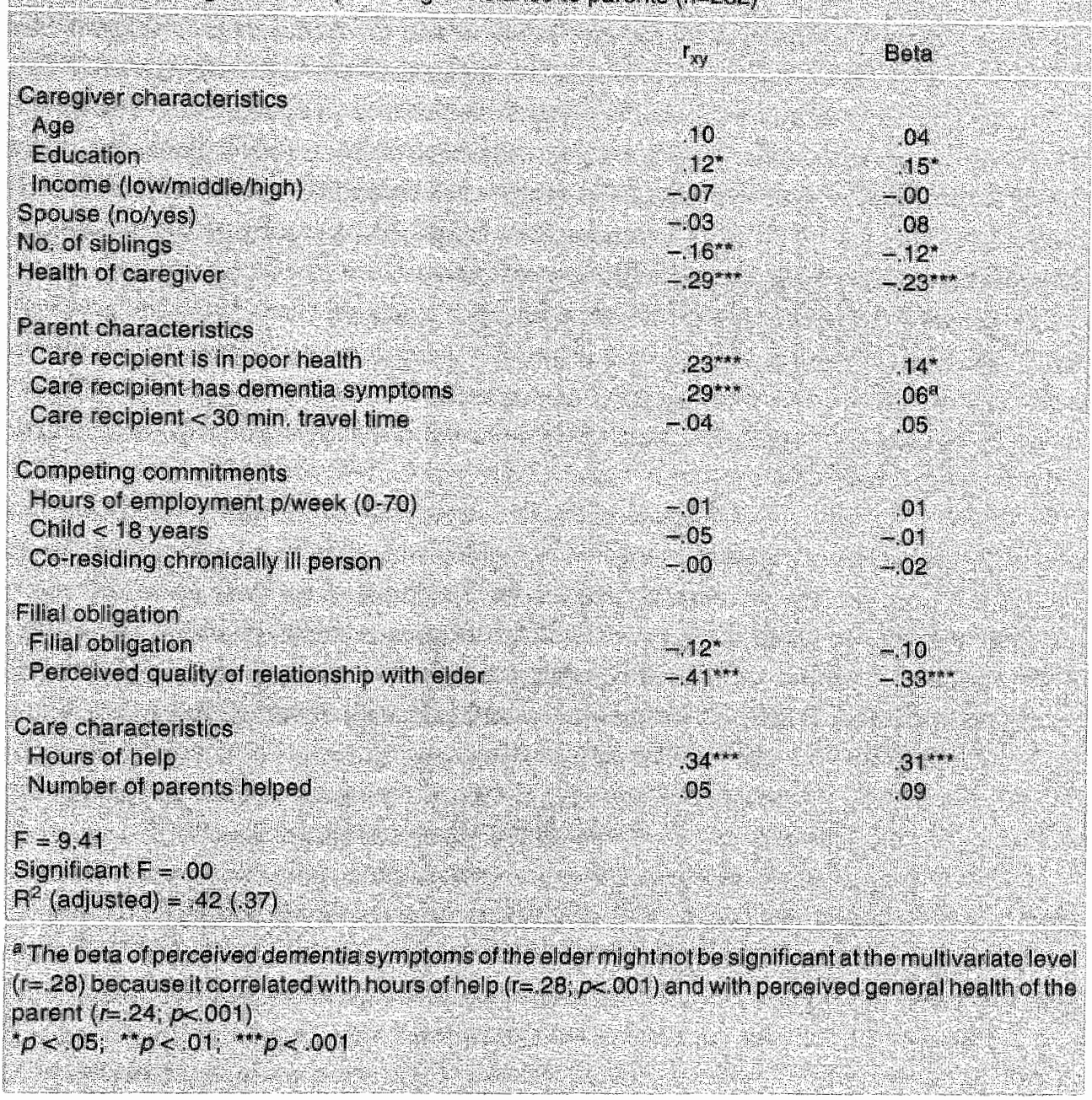

help they had been providing to their parents. Among those who reduced their help to parents $(n=55), 18 \%$ reported that this was because of their jobs. In other words, parent care did not force a majority of these employed caregivers to make negative job decisions, such as quitting jobs or reducing work hours. Our findings suggest that employed caregivers tend to reduce caregiving hours rather than work hours. 


\section{Employment and caregiver role strain}

The fourth hypothesis tested whether employment and the number of work hours had a negative impact on caregiver role strain (i.e., the extent to which caregivers felt that the help to their parents interfered with their social and personal life). A multiple regression was performed with role strain as the dependent variable. Predictors were the same sets of predictor variables used in previous regression analyses. In addition, several care characteristics were included (i.e., hours of care and number of parents helped), since these variables were expected to increase caregivers' role strain.

Table 5 shows that work hours do not affect the role strain of caregivers. Because we expected an exacerbating effect when respondents work many hours and provide a large amount of help, we examined in a separate analysis with the same predictors interacrion effecrs between employment, employment hours and hours of assistance. These proved to be nonsignificant.

Caregivers felt more interference when the caregivers' own health was not all too well, when the relationship with the parent was poor and when they had fewer siblings. Feelings of interference also increased when the health of parent was poor and more hours were spent on care. A strong posirive artitude towards filial obligation was associated with less role strain at the bivariate level but lost its impact at the multivariate level. In other words, filial obligation did not have a buffering effect for caregiver role strain.

\section{DISCUSSION}

This paper examined the potential conflict of female employment and elder care as would be expected from the perspective of the scarcity hypothesis of role theory. In line with this view, work and elder care are potentially incompatible roles. We formulated four sub-hypotheses on the compering relationship between female employment and elder care and tested these hypotheses empirically. First, we invesrigated wherher paid work pulls women away from the caregiver role and, second, whether it reduces the time spent on parent care. Third, we explored an effect in the opposite direction (i.e. whether caregiving negatively affects the workplace such as quitting or reducing hours). Fourth, we examined whether out-of-home employment increases role strain of caregivers. In a population-based sample among middle-aged women, we found only partial empirical support for the role scarcity hypothesis.

Our first hypothesis was confirmed: paid work pulled women away from parent in the sense that it reduced the likelihood that women became the caregiver of an elderly parent. Employment as such and not the number of hours worked were relevant: full-time working women were as likely to be a caregiver as part-time working women. The relevance of employment as a competing demand for parent care was confirmed 
by employed women who were currently not providing assistance to a frail parent, of whom a considerable proportion reported that they were not able to give help because of their jobs.

Not only employment had a major impact derermining whether women become caregivers. Living near a parent was the most important determinant of the caregiver role, a finding that is consistent with a number of other studies (Stern 1995; Stern 1996). Never being married also increased the likelihood of being the caregiver of a parent, probably referring to the phenomenon of the traditional 'maiden aunc'. Apparently, these practical and situational factors rather than a feeling of moral obligation to help (as indicared by the artitude regarding filial obligation) affected whether women became caregivers.

With regard to the second hypothesis on work hours affecting help to parents, we found that hours of care for an elderly parent appeared to be determined by factors orher than employment of the caregiver. More help was provided when the parent had symptoms of a cognitive impairment and when he or she lived nearby, and when caregivers had no spouse and fewer siblings. In addition, a strong attitude regarding what should be done for parents (filial obligation) encouraged women to provide more help. However, the causal effect may run in borh ways: spending much time on helping parents may increase feelings of moral obligation.

The impact of caregiving on work, tested in the third hypothesis, appeared to be limited. Only a small minoricy adjusted work schedules or used sick leave and none had foregone career opportunities; the overall prevalence of absenteeism due to family care was low. Employed caregivers used vacation days for helping the parent, suggesting that when employees have sufficient vacation days, these are used to combine work and elder care. It should be noted, however, that in the Netherlands employees are encitled to 25-40 holidays (work days) per year when they work full-time.

The fourth hypothesis examined whether paid work of caregivers increased caregiver role strain. This appeared not to be the case. Role strain was affecred by personal characteristics of the caregiver, such as having poor health, by parent characteristics such as the deteriorating health of the elder and by interactive characteristics such as having a poor relationship with the parent.

To summarize, limited empirical support was found for the role scarcity hyporhesis of role theory. Our findings suggest that this hypothesis is only valid with regard to the onset of caregiving, with employment being a legitimate reason for women not to become involved in parent care. Our data suggest that a selection process takes place, with the daughter who lives nearby and who has the least competing demands being most likely to become the caregiver. However, once women have accepted the caregiver role, they seem to provide care according to the needs of the parent and regardless of their other responsibilities such as a job or a family. The relatively small impact of work hours on hours of assistance by daughters is consistent with a number of studies 
done in the US (Lang and Brody 1983; Pett et al. 1988; Scharlach 1987; Stoller 1983; Tennstedt and Harrow 1996).

With regard to the potentially adverse impact of caregiving on work, our data confirmed the findings of studies reporting that employed caregivers, however stressed some of them might be, usually manage reasonably well in combining the responsibilities of work and elder care. The use of vacation days have also been reported by Matthews and Rosenthal (1993), for example, who found that 34\% of Canadian employees had been using vacation days to deal with family responsibilities. Scharlach and Boyd also (1989) reported that only a minority of employed caregivers $(2-14 \%)$ had been taking days off, used vacation time, refused a promotion or changed work schedules because of care demands. Perhaps in the general population, where elderly parents are still relatively healthy and only need small amounts of help, women add on the caregiver role without concurrent decreases in the time spent on work. In various respects, our findings confirm the role expansion rather than the role scarcity hypothesis.

Only partial support was found for the buffering effect of caregiver role commirment indicated by our measurement of fillial obligation. A strong attitude of filial obligation did neither encourage caregivers to become a caregiver nor reduced role strain. It only seemed to encourage daughters to provide a larger amount of care, although we do not know, as stated before, in which direction the causal effect between hours of help and of filial obligation runs.

One of the limitations of this sudy might be that the causal relation between employment and distance affecting the acceptance of the caregiver role might run in borh ways as well. Perhaps families adjust decisions where to live and work, long before the care is needed. The implication is that the coefficients of employment and distance might be overestimated in the statistical analyses. Our longitudinal data on reduced work hours or quitting jobs related to increased amounts of parent care, indicate that this problem might not be very severe.

We also acknowledge that the sample of this study consisted of respondents with many siblings, which was typical for the Catholic region where the study took place. Therefore, as compared to other regions, employed women in our sample might have had more unemployed and part-time working sisters who could take up the role of caregiver when they themselves were not able to. In addition, the Netherlands has a strong welfare approach towards the infirm and offers a wide range of -almost-free home care services for frail elderly, relieving caregivers from the care task. However, when comparing our data with empirical studies in the US, strikingly similar results were found with regard to determinants of hours of care and factors determining the caregiver role.

Finally, we acknowledge that in our study "parent care" refers to a rather broad range of activities, varying from occasional errands to long-term intensive care. Nar- 
rowing this definition down to specific tasks, such as personal care, might have resulted in different results.

Despite its limitations, our study showed that the combination of paid work and parent care does not necessarily make caregivers feel conflicted. Probably a preselection process has taken place excluding those who are too busy or who prefer not to get involved in parent care. In addition, we expect that the qualitarive aspects of roles, such as job satisfaction, the intensity of workplace demands, or the behavior of the parent towards the caregiver, are more important causing distress than the amount of hours that women work or provide help to parents.

Because several studies have reported on caregivers expressing a strong desire to fulfil both work and elder care responsibilities (e.g. Scharlach 1994), we suggest that policy measures should be directed at supporting employed caregivers so that painful choices such as reducing work hours or reducing the hours spent on elder care can be avoided. The combination of employment and elder care certainly is less problematic when a variety of community services are available and employees have sufficient vacation days and family illness leave, as is the case in the Netherlands. One of the most important measures are flexible work schedules, community services for the elderly and family supportive personnel policies. Although these might be costly for companies, in the long run they will result in greater productivity among employees who are also involved in parent care (Neal et al. 1993).

\section{NOTES}

1. This chapter has been published: Dautzenberg, M.G.H. Diederiks, J. P.M., Philipsen, H. Tan, F.E.S., \& Vernooij-Dassen, M.J.F.J. (2000). The competing demands of work and parent care; Middle-aged daughters providing assistance to elderly parents, Research on Aging, 22, 165-187.

2. The burden-scale used in this chapter has been assessed in: Vernooij-Dassen, M.J.F.J., Felling, A.J.A., Brummelkamp, E., Dautzenberg, M.G.H., van den Bos, G.A.M., and Grol, R. (1999). Assessment of Caregiver's Competence in Dealing with the Burden of Caregiving for a Demented Patient, a Short Sense of Competence Questionnaire (SSCQ), a Short Suitable for Clinical Practice. Journal of the American Geriatrics Society, 47, 220-225.

\section{REFERENCES}

Allen, Janice. 1996. "Race Comparison of Factors Affecting Family Caregiver's" Health". Paper presented at the 91 st Anmual Scientific Meeting of the American Sociological Association.

Azamoff, Roy S., and Scharlach, Andrew E. 1988. "Can Employees Carry the Elder Care Burden?" Personnel lournal, September: 60-76. 
Barling, Jullian, MacEwen, Karyl E., Kelloway, Kevin, and Higginbottom, Susan F. 1994. "Predictors and Outcomes of Elder-Care-Based Internole Conflict." P5ychology and Aging 9 . $391-397$.

Boaz, Rachel F, and Muller, Charlotte F. 1992. "Paid Work and Unpaid Help by Caregivers of the Disabled and Frail Elders" Medical Care 30:149-158.

Brody, Elaine M., and Schoonover, Clair B. 1986. "Patterns of Parent Care when Adult Daughters Work and When They Do Not." The Cerontologist 26:372-381.

Central Bureau of Statistics. 1994. 1899-1994; Vifennegentig laren Statistiek in Tijdreeksen. Den Hagg: SDU.

Gerstel, Naomi, and Gallagher, Sally K. 1993. "Kinkeeping and Distress: Gender, Recipients of Care and Work-Family Conflict." Journal of Marriage and the Family 55: 598-607.

Coode, Williaml. 1960. "A Theory of Role Strain". American Sociological Review 25: 483-496.

Cottlieb, Benjamin H., Kelloway, Kevin, and Fraboni, Maryann 1994. "Aspects of Elder Care that Place Employees at Risk." The Gerontologist 34: 815-821.

Horowitz, Amy, 1985. "Family Caregiving to the Fraill Elderly." Pp. 194-246. Annual Review of Gerontology and Geriatrics. Edited by C. Eissendorfer.

Lang, A.M., and Brody, Elaine M. 1983. "Characteristics of Middle-aged Daughters and Help to their Elderly Mothers." Journal of Marriage and the Family. February: 193-201.

Loomis, Laura S., and Booth, Alan. 1995. "Multigenerational Caregiving and Welll-being: the Myth of the Beleaguered Sandwich Generation." Jounal of Family Issues 16:131-148.

Mangen, D.I., Landry, P.H., and Bengtson, Vern L. 1987. The Measurement of Intergenerational Relations. Newbury Park CA US: Sage Publications.

Marks, Steven R. 1977. "Multiple Roles and Role Strain: Some Notes on Human Energy, Time and Commitment." American Sociological Review 42: $921-936$.

Matthews, Sara H., Werkner, J.E., and Delaney, P. 1989. "Relative Contribution of Help by Employed and Nonemployed Sisters to Their Elderly Parents." fournal of Gerontology 44: $\$ 36-\$ 44$.

Matthews, Anee Martin, and Rosenthal, Carolyn J. 1993. "Balancing Work and the Family in an Aging Sociely." Amnual Rewiew of Gerontology and Geriatrics 13: 96-117.

Mui, Ada C. 1992. "Caregiwer Strain among Black and White Daughter Caregivers: A Rolle Theory Perspective." The Gerontologist 32: 203-212.

Neal, Margaret B., Chapman. Nancy I., Ingersoll-Dayton, Birit and Emlen, Arthur C. 1993. Balancing Work and Caregiving for Children, Aduls and Elders. London: Sage Publications.

Parris Stephens, Mary A. 1994. "Stress and Rewards in Women's Multiple Roles: the Case of Women in the Middle." Psychology and Aging 9: 45-52.

Pett, Marjorie A, Caserta, Michael S., Hutton, Ann P., and Lund, Dale A. 1988. "Intergenerational Conflict: Middle-Aged Women Caring for Demented Older Relatives." American loumal of Orthopsychiatry 58: $405-417$.

Petty, Diana and Friss, Lynn. 1987. A Balancing Act of Working and Caregiving." Business and Health October: $22-26$. 
Pohl, IM., Boyd, C., Liang, J., and Given, Charles W. 1995. "Analysis of the Impact of Mother-Daughter Relationship on the Commitment to Caregiving." Nursing Research, March/April, 68-75.

Scharlach, Andrew E. 1987. "Role Strain in Mother-Daughter Relationships in Later Life:" The Gerontologist, $27: 627-631$.

Scharlach, Andrew E, and Boyd, Susan L. 1989. "Caregiving and Employment: Results of an Employee Survey." The Cerontologist 29: 382-387.

Scharlach, Andrew E, Sobel, Eugene L., and Roberts, Robert E.L. 1997. "Employment and Carem giver Strain: an Integrative Model." The Gerontologist 31: 778-787.

Scharlach, Andrew E. 1994. "Caregiving and Employment: Competing or Complementary Roles?" The Gerontologist 34: 378-385.a

Soldo, B.J., and Myllyluoma, J. 1983. "Caregivers Who Live with Independent Elderly." The Cerontologist $23: 605-611$.

Starrels, Marjorie E., Ingersoll-Dayton, Birit, Neal, Margaret B., and Yamada Hiroko. 1995. "Intergenerational Solidarity and the Workplace: Employees Caregiving for their Parents." Journal of Marriage and the Family 57: 751-762.

Stern, Steven 1995. "Estimating Family Long-Term Care Decisions in the Presence of Endogenous. Child Characteristics." The Journal of Human Resources XXX: 551 -583.

Stern, Steven 1996. "Measuring Child Work and Residence Adjustment to Parents" Long-Term Care Needs." The Cerontologist 36:76-87.

Stoller, Eleanor P. 1983. "Parental Caregiving by Adult Children." lournal of Marriage and the Family November: 851-858.

Stone, Robin I., and Short, P.F. 1990. "The Competing Demands of Employment and Informal Caregiving to Disabled Elders." Medical Care 28: 513-526.

Tennstedt Sharon L., and Harrow, B.S. 1996. "The Simultaneous Influences of Paid Employment, Secondary Caregivers and the Use of Formal Services on Caregiving for African American, Puerto Rican and White Elders." Paper presented at the $49^{\text {th }}$ Annual Scientific Meeting of the Cerontological Society of America.

Vernooij-Dassen, Myrra J.F.J., Persoon Jean M.C., and Felling, Abert J.A. 1996. "Predictors of Sense of Competence in Caregivers of Demented Persons." Social Science and Medicine 43: $41-49$.

Vernooij-Dassen, Myrra J.F.J., Felling, Albert \.A., Brummelkamp, Erik, Dautzenberg, Maaike G.H., van den Bos, Geertrudis A.M., and Grol, Richard. 1999. "Assessment of Caregiver"s Competence in Dealing with the Burden of Caregiving for a Demented Patient, a Short Sense of Competence Questionnaire (SSCQ), a Short Suitable for Clinical Practice." Journal of the Amer" ican Geriatrics Society, 47:220-225. 


\section{CHAPTER 5}

Multiple roles of women as determinants of caregiver responsibility; Why some daughters become primary helpers of elderly parents and others secondary helpers

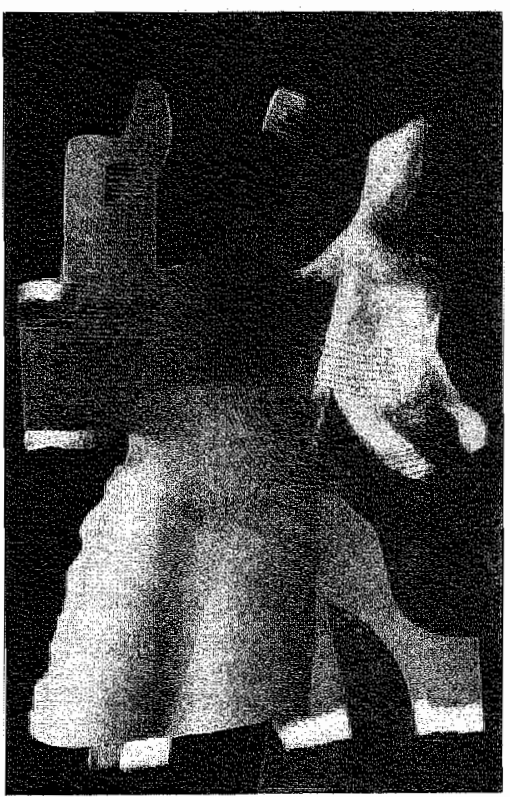


94) Chapter 5

Toen jij was beengegaan dacht ik dat de wereld stil was blijuen statan.

Maar de mensen bleven lachen en taarijes eten. en dat beb ik ben in stilte verweten.

Jou tegenkomen in de dagelijkse dingen

versoent me met je dood.

Ik woelde in de jaren die vergingen:

zolang ik leef

ben jij niet dood.

L. Grandiean-Grashwis 
This article examines the social determinants of the amount of responsibility that daughters assume when they are the helpers of elderly parents. We investigated in particular whether multiple roles of women, such as paid work and orher care roles, compete with women's ability to take responsibility in parent care. A random, population-based sample was drawn among middle-aged women in the Netherlands and a telephone survey was carried our $(n=581)$. The results from aggregate analyses indicate a significant impact of practical and structural factors such as work, proximity and siblings on levels of responsibility. In contrast, caregivers themselves perceived affection for the parent and norms of filial obligation as the most important factors determining them to be the primary helper of their parent. We concluded that both the top-down and the bottom-up perspectives are two layers of the day-to-day realiry in parent care.

\section{INTRODUCTION}

The responsibility for providing assistance to a frail parent does not fall equally to all children. Some are primary caregivers whereas others are involved in parent care only at a secondary level. Selection processes of who becomes the primary or secondary caregiver in families have been poorly understood. Only gender has been consistently reported as a powerful determinant of caregiver commitment, with daughters outnumbering sons in ratios of four to one in the US (Stone, Cafferta \& Sangl, 1987; Brody, 1990) and nine to one in the Netherlands (Janssen and Woldringh, 1991). When sons are involved, their wives, that is the daughters-in-law, usually provide most of the day-to-day help to parents (Brody, 1990). In most industrialized countries, pollicymakers have raised concern that competing demands of women, and in particular the combination of paid work and child-rearing responsibilities, endanger the principal role of women in parent care, raising institurionalization rates and the costs of community care for the elderly. Delayed childbirth and the massive influx of women into the labor force (Central Bureau of Statistics, 1994; OECD, 1993) increase the odds that women get "caught" berween the care for children, their jobs and the needs of their aging parents. This article examines to what extent social roles of women, and in particular the parental role and role of employee, affect the responsibility women assume in parent care. To what extent do women themselves feel that other social roles restrict their taking responsibility in providing assistance to parents, and what motivates them to continue providing this help?

Research on parent care has focused mainly on primary caregivers, despite the fact that multiple caregivers have been reported as the most common pattern for frail el- 
derly (Penrod, Kane, Kane, \& Finch, 1995; Stommel, Given, Given \& Collins, 1995). Relatively few studies have distinguished between primary and secondary caregivers, permitring a detailed analysis of the determinants of each group. Only paid work has been reported as competing with caregiver involvement, with primary caregivers being less likely to be involved in out-of-home employment or to work fewer hours per week as compared to secondary caregivers (Stone et al., 1987; Tennstedt, McKinlay, \& Sullivan, 1989; Penrod, Kane, Kane, \& Finch, 1995).

Other factors that might affect the amount of responsibility assumed by daughters are geographical proximity and the presence of siblings. Although sharing residence or living closeby has been reported to increase the amount of help to frail parents, siblings do not always decrease the likelihood of becoming a caregiver because they are not always available, able or willing to help (Brody, Lirvin, Hoffman and Kleban, 1995; Merrill, 1997; Robison, Moen and Dempster-MacClain, 1995).

Motives for helping parents have received relatively little attention in research on carregiving. Several studies have stressed the importance of the relationship with the parent and internalized norms of duty and reciprocity (Pohl et al., 1995; Cicirelli, 1993). A study by Silverstein, Parrot and Bengtson (1995) suggests that for daughters intergenerational affection is more important than norms of fillial obligation, which motivated in particular sons to provide more help to frail parents. However, findings are not consistenr. Brody et al. (1995) found that filial obligation and the emotional bond with the parent were far less important reasons for becoming the primary caregiver than the lack of other resources of help, in particular siblings.

Data on multiple caregivers or motives of caregivers are still scarce. Previous studies have been rarher descriptive than explanatory (Stone et al., 1987; Tennstedt et al., 1989; Penrod et al., 1995). The majority has used relarively small and nonrepresentative samples (Brody, 1990; Brody et al., 1995; Merrill, 1997) or very heterogeneous samples of caregivers, including spouses, adult daughters, sons and in-laws (Penrod et al., 1995; Stommel et al., 1995). This study extends the scope of previous research by making use of a population-based probability sample of one type of caregivers, i.e. adult daughters. In addition, an attempt will be made to explain the differentiation in levels of caregiver responsibility with the help of a multivariate explanatory model. Two research questions will be addressed. First, we will investigate the determinants of the differentiation in levels of caregiver responsibility. Second, we will examine the reasons and motives of caregivers to help parents. The 'objective' figures on determinants of caregiver responsibility will be contrasted to the subjective perceptions of caregivers on why they are helpers of a parent.

Our explanatory model included four sets of predictor variables. The first set was labeled as presumptive factors, i.e. situational and structural factors that make it more likely that daughters assume caregiver responsibility. Presumptive factors are geographical proximity, being the only child or having few siblings, and being in a good 
health and hence able to help. The second set of factors are competing roles, such as employment, having a spouse, having minor children or having other care roles, which are expecred to reduce the likelihood to assume a high level of responsibility. "The third factor is affection, referring to a personal drive, i.e. quality of relationship with the parent, which we assumed to encourage caregivers to provide more help. The fourth factor is attitudinal, i.e. filialobligation and refers to internalized norms prevalent in society on what adult children should do for their parents, which was also expected to increase caregiver commitment. We focus primarily on the relative importance artached to compering roles as compared to other factors such as proximity to the parent, having no siblings to share caregiving tasks, emotional attachment to the parent and filial obligation.

\section{METHOD}

Data were obtained through a telephone survey in four municipalities, one medium-sized town $(80,000$ inhabitants) and three smaller towns (in total 40,000 inhabitants) in the south of the Netherlands. The research area included an urbanized city center, as well as suburbs and village neighborhoods.

\section{Sample}

Respondents were recruited through a probability sample drawn from local municipality registration offices. The birth cohort 1940-1954 was selected because the women of the age group of 40-56 were most likely to perform simultaneously rhe roles of mother, employee, spouse and caregiver. Participants were interviewed by telephone in two waves, with an interval of 25 months. The first wave (T1) took place in 1994: 1206 respondents were approached and 934 agreed to participate, resulting in a response rate of $79 \%$. The second wave (T2) took place in 1996: 865 respondents were traced again, of whom 743 agreed to participare, resulting in a response rate of $80 \%$ (743/934). The overall response rate was 62\% (743/1206). At both waves, the most frequently mentioned reasons for not co-operating were lack of interest, lack of time, privacy considerations or being tired of telephone surveys. A non-response analysis compared responders at $T 1(n=934)$ with non-responders at $T 2(n=743)$ on several social demographic characteristics such as age, education and variables relevant for the study such as help to parents, number of living parents, age and health of parents, employment and children. Variables that appeared significant at the bivariate level were examined with the help of a logistic regression analysis. Only a higher education and having children significantly increased the odds for response. 
Analyses were performed on the subsample of respondents who had at $T 2$ at least one parent or parent-in-law still alive. For the cross-sectional analyses, data of the second wave (T2) were used because this data-set included information on the relationship with the parent and the filial obligation scale. At $T 2,78 \%(n=581)$ had at least one parend/parent-in-law and $51 \%$ were currently helping a parent. Of these 581 participants, the mean age was 48.9 years (range $42-56$ ). Three-quarters were living with a partner and $34 \%$ had at least one minor child. Half of them were employed ( $49 \%$ ), working on average 25.6 hours a week (range: $2-70$ hours). Only $2 \%$ were living with the parent/parent-in-law. The mean age of the parents and/or parents-in-law (maximally four) was approximately 76 years (range $53-95$ years).

In the remainder of this article, 'parents' will refer to both parents and parents-in-law.

\section{Measurements}

Assistance to parents referred to any instrumental or emotional support given to parents in the past four weeks. Ten types of assistance were listed one by one and participants indicated whether they helped the parent with it. Assistance included: cleaning the house and/or doing the laundry, preparing meals, shopping, providing personal care (bathing, dressing and giving medication), transportation, taking care of administrative and financial matters, making appointments with doctors or other professionalls, gardening or house repairs, offering comfort and advice (emotional support) and other types of help. Interviewers were instructed to state explicitly that the ordinary social visits to the parent were not considered as help.

Caregiver responsibility was self-assessed by the item "Are you the one who is doing most, do you share tasks equally with others, or is someone else doing most?". It resulted in the three comparison groups: caregivers with the primary, an equally shared and a secondary responsibility in care.

Presumptive factors. Income level was self-assessed, with participants being asked to indicate wherher their total household income was lower (1), equivalent (2) or higher (3) than the net modal income in the Netherlands. Geographical distance was measured by the minutes of traveling time needed to reach each of the living parents. Health status of the respondent was self-assessed by one item (five-point Likert scale, very good-very poor).

Need factors. Health status of the parent (five-point Likert scale: very good-very poor) and dementia symptoms (dichotomous: yes/no) were assessed by participants.

Competing roles. The mother role, the spousal role and employment were indicated by dichotomous irems on, respectively, having minor children (under 18 years), living with a partner, and having a job or working in a family enterprise. Help to children that were not co-residing, or looking after grandchildren, was indicated by a dichotomous 
question asking whether this help had been provided on a regular basis in the past weeks.

Affection and flial obligation. The relationship with the parent was indicated by a response (completely agree-completely disagree) no the statement "I do not haveagood relationship with my parent". Filial obligation and normarive obligarions rowards parents were indicated by a flial obligation scale, developed in the US and translated into Dutch. This scale had proved to have a good reliability and stability over time in the US (Mangen, Landry, \& Bengtson, 1987). It consists of six items (five-point Likert scale) on the responsibility participants believe that adult children should have for elderly parents in (1) providing companionship, (2) helping and supporting them with household chores and transportation, (3) providing advice and guidance, (4) providing personal and health care, (5) providing financial support, and (6) providing housing. Posm sible scores could vary between 6 and 30 . In our sample the Cronbach's alpha of the scale was 81 . Reasons for helping parents were solicited by an open question "What are the reasons for you to help your parent(s)?" Most responses fitted into one of the coding categories that were formulated on the basis of findings from previous studies.

Motiver for helping parents. Motives for helping parents were indicated by the question "What are the reasons you are helping your parents?". It included several precoded categories, for example 'proximity to the parent", 'I feel obliged to/owe it to him/her', 'it is my duty as a woman', 'only child' and 'affectionate relationship". Answers that did not fit into one of the precoded categories were coded afterwards.

\section{Statistical analyses}

Bivariate differences in means were tested by one-way ANOVA t tests of means for multiple comparisons when continuous variables were used, with a Scheffe test indicaring between which groups the significant differences lay. Nonparametric tests (Mann-Whitney) were used to test differences in ordinal variables and chi-square tests to assess differences between dichotomous variables. At the multivatiate level, logistic regression analyses were performed entering all variables simultaneously.

\section{RESULTS}

Before addressing the research questions, the three aregiver groups were compared on caregiver characteristics in order to see whether the self-assessed responsibility in care reflected real differences in the objective burden of care and the complexity of care tasks.

Table 1 shows that this appeared to be the case: the more responsibility, the larger the actual amount of care given. Primary caregivers, as compared to caregivers with less responsibility, provided significanty more hours of help, were involved in more rypes 
TABLE 1. Characteristes of caregivers with pimary, shared and secondary responisibility in plarent care $(\mathrm{n}=294)$

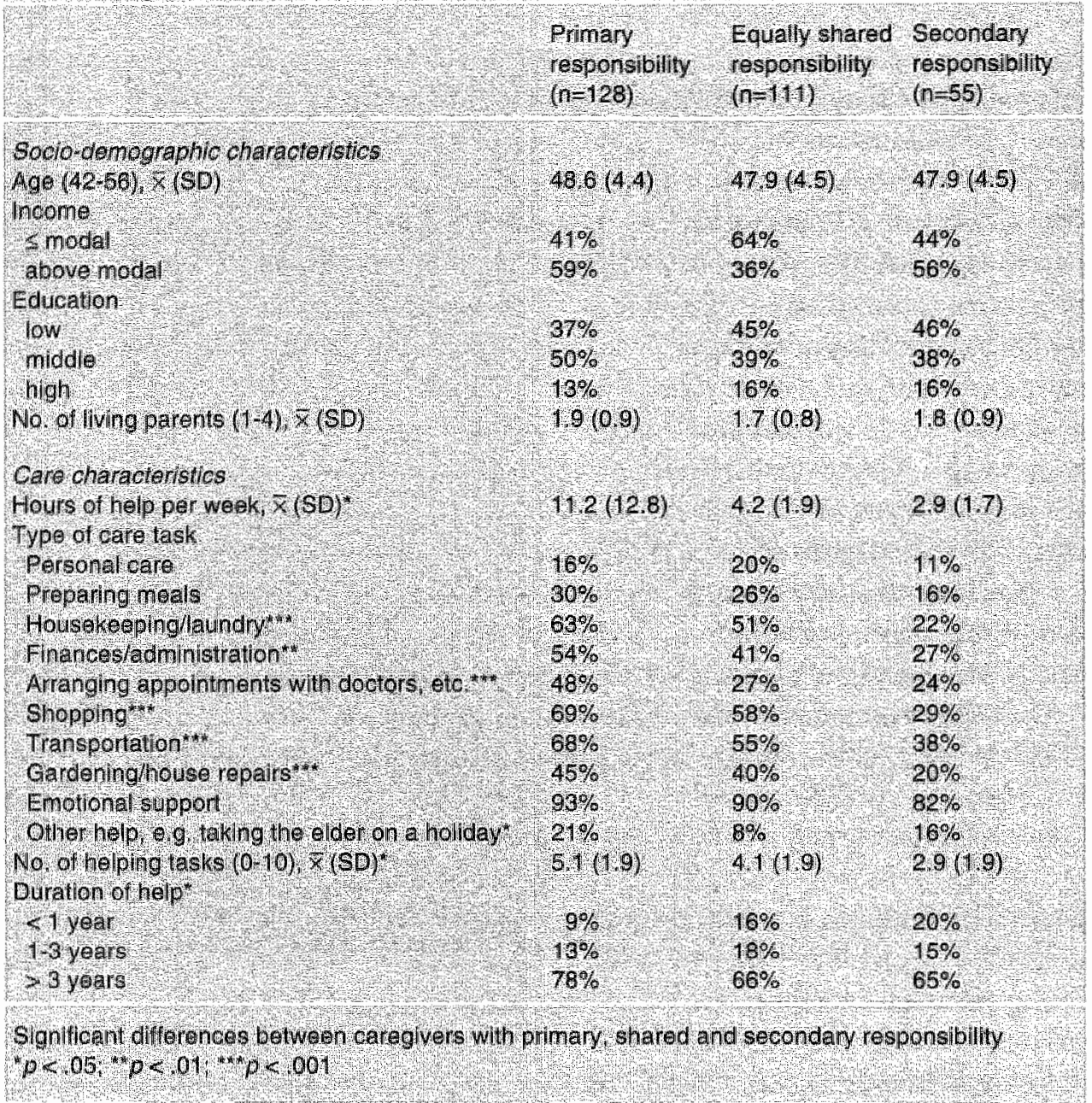

of assistance and had been providing this help for a longer period of time. In fact, as compared to secondary caregivers, primary caregivers were more likely to be involved in any rype of help, with an exception of emotional support, personal care and the preparation of meals where no significant differences were found. Caregivers with different levels of responsibilities did not differ with regard to any of the general social and demographic characteristics, such as age, income, educational level and the number of living parents. 


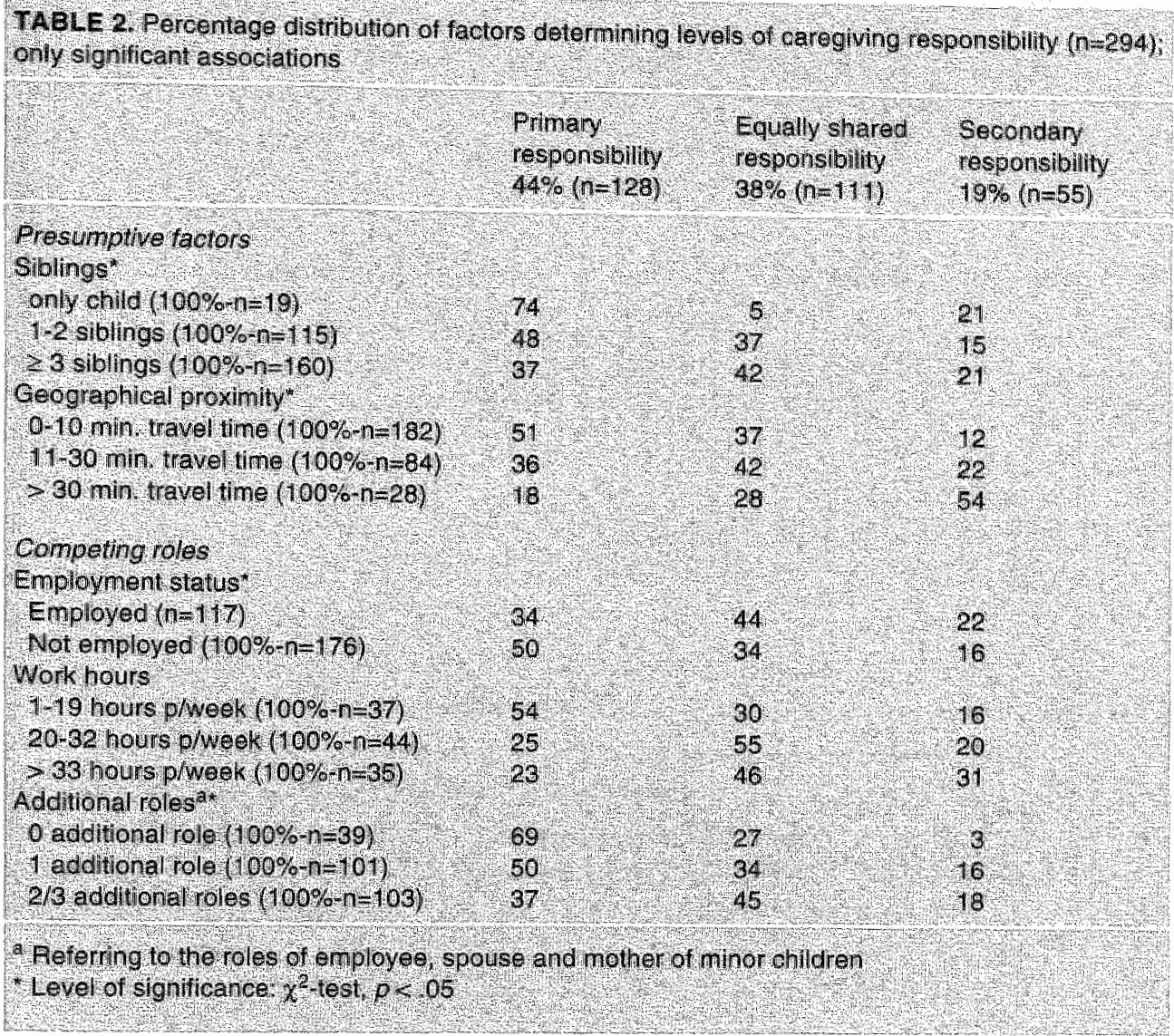

\section{Determinants of caregiver responsibility}

All potential relevant factors were tested at the bivariate level, i.e. the presumptive factors of proximity, siblings, self-assessed health of the caregiver; the competizg roles of paid work, minor children, having a spouse, having a chronically ill person in the household, helping out non-co-residing children, looking after grandchildren, doing volunteer work and the number of roles; affection for the parent, i.e. the qualiry of the relationship with the parent; and filial obligation. Table 2 shows only the factors that were significantly associated with levels of caregiving responsibility.

Among the presumptive factors, proximity and siblings appeared to be significant. Primary caregivers lived closer to the elderly parent and were more likely to have fewer siblings. They were in particular more likely to have fewer sisters (not shown in table). A closer analysis of distance to each of the parents and parents-in-law (not shown) indicated that primary caregivers lived in particular significantly closer to their own moth- 
TABLE 3. Logistic regress Ion contrasting primary caregivers to caregivers that share tasks equally: $(n=111)$ and caregivers with secondary responsibily $(n-55)$, all factors inctuded in the nultivariate nodel and controlling 1 or $\mathrm{age}$ and Ircome of caregivers

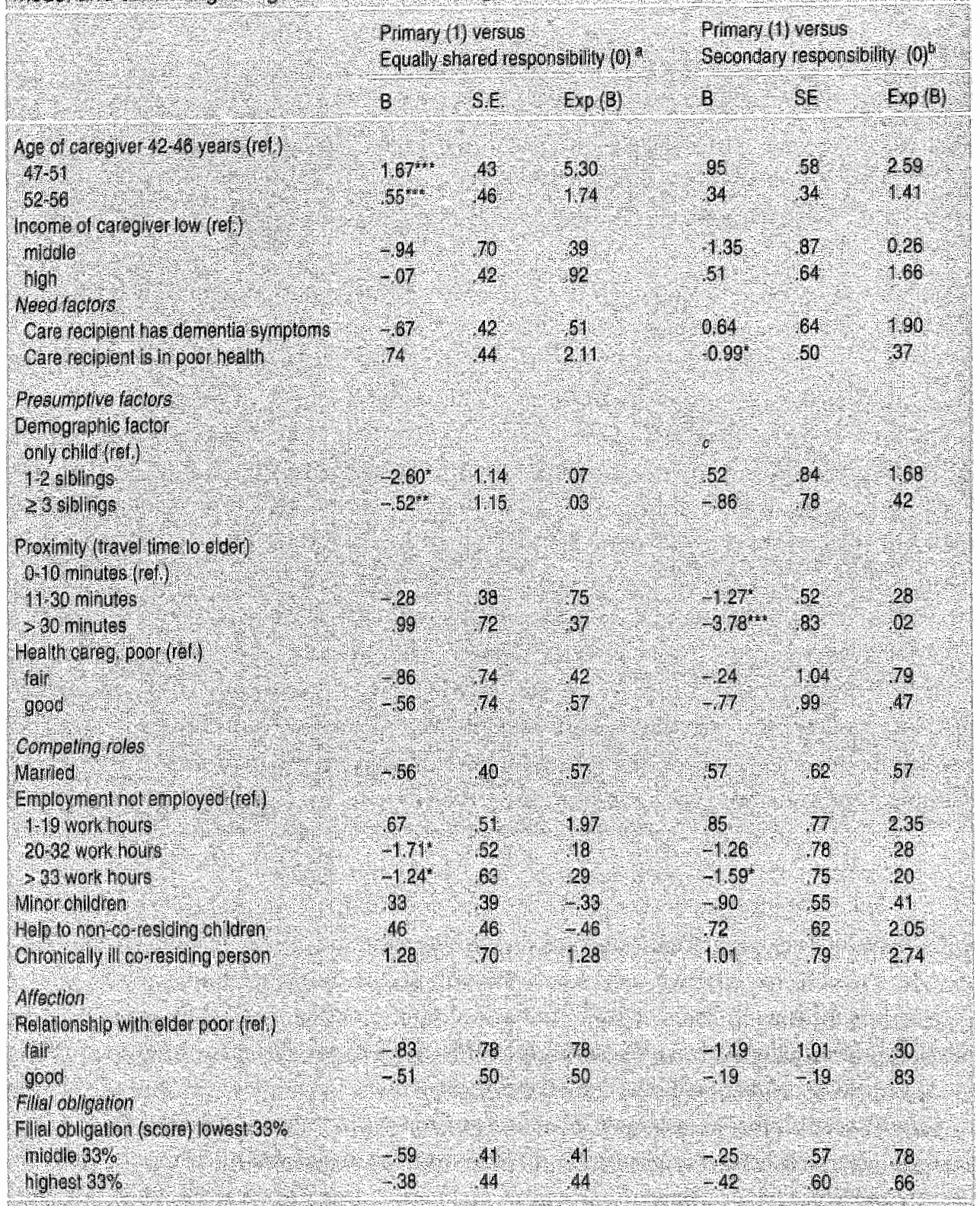

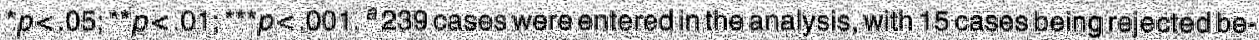
eause of missing data on ene of the variables. The lotal set of variables resulted in $70 \%$ of the partici. bants being corre olly olassified 4.183 cases were entered ha the ahalysis of which 9 were rejected be. cause of missing data on ene of the variables. Ihis analysis resulted in $84 \%$ of the participants bising correctly elassiffed 0 overall effect of the predictor is significant $(0<05)$ 
ers and fathers and not to their mothers-in-law and fathers-in-law. Caregivers with a poor health were not less likely to assume a high level of responsibility.

Among the competing roles, only employment appeared to affect caregiver responsibility. Employed caregivers were significantly less likely to be assume a primary responsibility in parent care. When they were employed, they worked fewer hours per week. Primary caregivers also appeared to have significantly fewer competing roles, including the roles of employee, mother and the spousal role. However, the causal relation may run in both directions, with women having given up social roles because of caregiving. Regarding other potentially compering roles, such as having minor children or a disabled co-residing person, differences were very small and not significant. Neither a good relationship with the care recipient or filial obligation was associated with a higher level of responsibility.

In addition to the bivariate analyses, two multivariate analyses were performed. The aim was to determine which factors would remain significant when other factors were controlled for. Logistic regressions contrasted primary caregivers to each of the other two groups in order to see where significant differences lie. Since we aimed at testing the relevance of all variables of our explanatory model, all predictors were entered in the analysis. In addition, we controlled for the general health and dementia symptoms of the parent as perceived by the helper.

In the first logistic regression, primary caregivers were contrasted to caregivers that shared tasks equally. This analysis showed that employment and the number of siblings predicted levels of caregiver responsibility. However, it was not a job as such that had an impact, but work hours, with the cut-off point lying around twenty hours per week. In a separate analysis examining interaction effects of work hours with orher social roles, no indication was found of exacerbating effects of combining employment with orher care roles, such as having minor children, a spouse or sharing residence with a disabled person.

Surprisingly, the age of caregivers had an effect. Older caregivers were more likely to be a primary caregiver with the odds being five times higher for the age group 47-51 as compared to women who are five years younger. Addirional analyses (not shown here) showed that primary caregivers were slightly-though not significantly-more likely to have a parent above 75 years of age (i.e., $85 \%$ of the primary caregivers as compared to $76 \%$ of the secondary caregivers).

In the second logistic regression analysis primary caregivers were contrasted to secondary caregivers. Again, siblings and work hours reduced the likelihood to become the primary caregiver. As in the previous analysis, it was not a job as such, but work hours that were relevant. Caregivers were only more likely to have a secondary responsibility when they worked more than 33 hours per week. In addition, distance to the parent distinguished primary from secondary caregivers, with caregivers that lived closeby being more likely to be a primary tather than a secondary caregiver. Again, no 
TABLE 4 . Percentage distrilution of reasons for providing help to parents as reported by caregivers: With prinary shered and secondary responsibility?

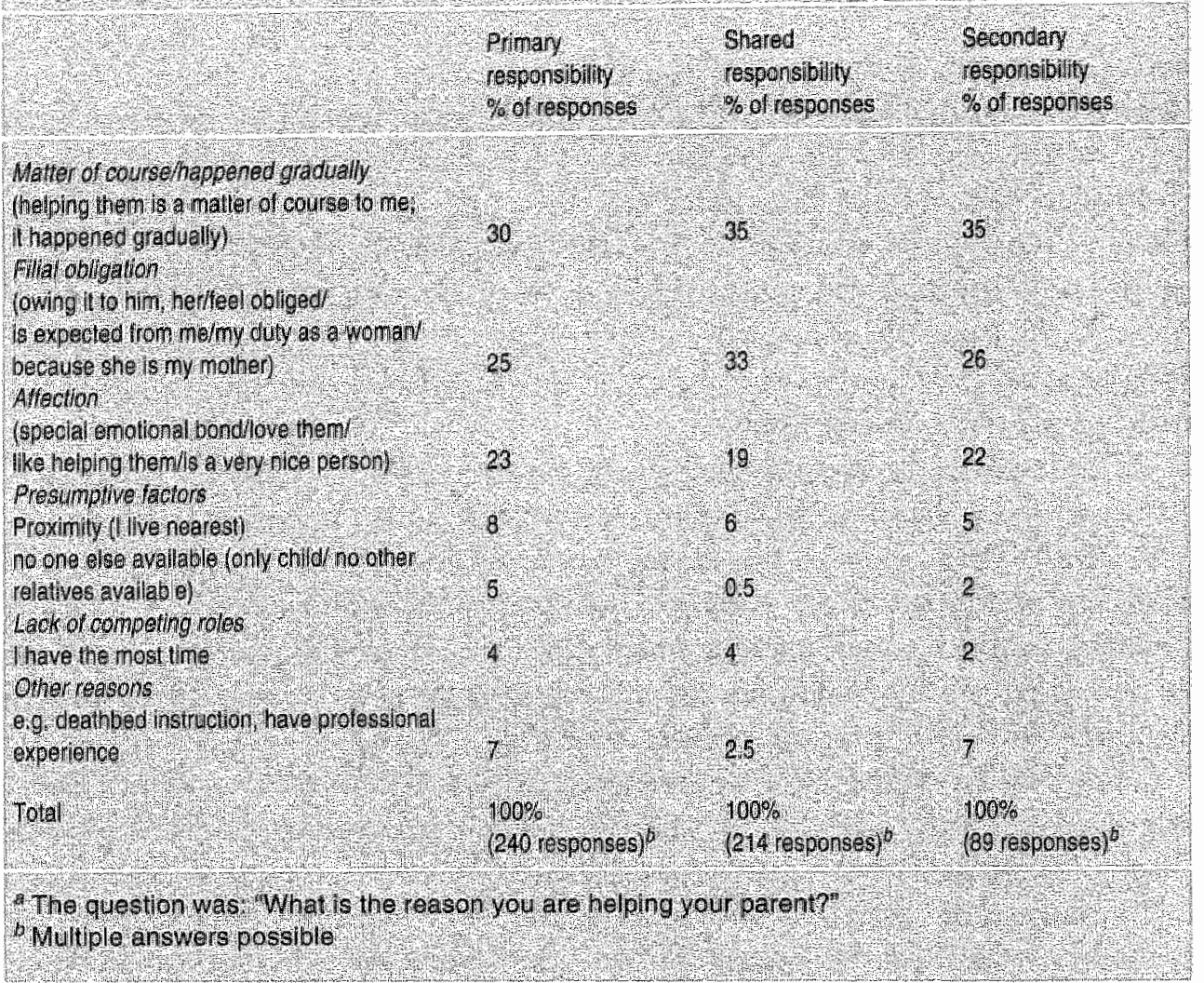

interaction effects were found of work hours and other social roles, or between work, distance, affection and filial obligation. Surprisingly, secondary caregivers were more likely to have a parent in poor health, suggesting that perhaps secondary caregivers will be called in for help when the parent's health is really gerring worse.

In sum, pairwise comparisons of primary caregivers with the other two caregiver groups indicated that when caregivers work more hours per week and have more siblings, they are more likely to share caregiving tasks rather than to assume the primary responsibility in parent care. When they live farther away from the parent, they are more likely to be involved in parent care only at a secondary level.

\section{Motives for belping parents}

Table 4 presents the reasons that participants reported for helping the parent. From the perspective of the caregivers, the relative weight of presumptive factors, competing 
roles, affection or filial obligation was very different from what our previous results had indicated. Distance and siblings were not considered as very relevant. Even among the caregivers who were the only child, only a minority reported that they helped the parents because they were the only child or because no-one else was available ( 7 out of 29). Relarively few caregivers referred to the lack of competing roles as the main reason for them being the helper of the parent $(2 \%-4 \%)$. Caregivers said that they helped the parent in particular out of affection (20-23\%) and because they felt obliged to do so (25-32\%). A considerable proportion could not say why they helped the parent: they reported implicit reasons, such as the help to the elder being a matter of course for them and it just having happened that way (29-33\%). As table 4 indicates, there were hardly any differences in reasons for helping the parent among caregivers with primary, shared or secondary responsibility.

\section{DISCUSSION}

This article examined two research questions. First, we investigated the factors that determine whether daughters become the primary or the secondary caregiver of an elderly parent or parent-in-law. Second, we explored the reasons respondents gave for being the helpers of parents. We were particularly interested in whether other social roles of women affected the responsibility they assume in parent care and whether caregivers feel that additional roles affected that decision.

Our main finding was, first, that, at the aggregate level, caregiver commitment appeared to be determined by situational factors, such as siblings and geographical and proximity, rather than by emotional and normative factors, such as the relationship with the elder or having strong views on filial obligation. Regarding competing roles, only out-of-home employment was associated with reduced caregiver responsibility, a finding that is consistent with the study of Stommel et al. (1995) who reported that employment reduced the number of hours of help provided by primary caregivers. In particular full-time work might reduce the level of responsibility women are able to assume in parent care.

We hypothesized that women's central role in parent care might be jeopardized especially by three developments: an increase in women's working hours, falling birth rates resulting in fewer siblings to share caregiving tasks with, and an increase in geographical mobility of the population causing families to living farther away from parents. The impacr of other care roles, such as child-rearing responsibilities, most probably will be very limited.

The second main finding was the remarkable contrast between the 'objecrive' figures at the aggregate level and what caregivers themselves perceived as important. Participants said that normative obligations of reciprocity towards parents motivated 
them to provide support, as well. as love and affection for the parent. Relatively little importance was attached to practical and situational factors such as geographical proximity, being the only child or having the least compering commitments. Allan (1988) has suggested that this emphasis on affection is a coping mechanism for adult children to reconcile the contradictory notions of autonomy and debt that is inherent in parent-child relationships. On the one hand, adult children are expected to be independent from parents and to lead their own lives. On the other, they are brought up with the social value of owing a debt to parents, because parents had done so much for them when they were younger. The emphasis on the help to parents being the result of their love, and hence their own free choice, is the way adult children dress up normative obligations to reciprocate to parents.

Other reasons reported by respondents for helping the parent were rather implicit, such as helping parents being a matter of course to them. Finch (1993) has referred to this process as 'non-decisions': someone in the family just assumes the caregiver role without having thought about it; the help is just given. A slightly different process is referred to when caregivers said that 'it happened gradually'. Sometimes care demands build up so slowly and they are fit piecemeal in to the caregiver's daily routine such that caregivers may not be able to discern in retrospect how and why they got involved.

The remarkable but distinct contrast between the top-down and the bottom-up perspective suggests that these perspectives need to be considered as two layers of the day-to-day reality of caregivers. Situational factors might lead individuals almost indiscernibly into the rolle of either the primary or the secondary caregiver, whereas individuals themselves may not experience it as being forced by the circumstances and probably perceive their involvement as being the result of their own free choice.

In addition to our research questions, we examined the validity of our measurement of caregiver responsibility. One can argue wherher the self-identified labels reflected real differences in the burden of care, assuming that these assessments may not represent factual variations in care because caregivers might tend to overestimate their own share. The latrer assumprion was not confirmed. Our findings showed that the self-assessed classification in three levels of responsibiliry, i.e. primary, shared and secondary caregiver involvement, reflected relative and absolute differences in the-objective- burden of care in terms of the amount of help and the number of care tasks that the helper is involved in. Part of our findings were consistent with Tennstedt's (1989) finding that secondary caregivers collectively provide much less care than primary caregivers. However, we did not find, as Tennstedt et al. (1989) did, that primary and secondary caregivers are involved in different types of help; in our sample, primary helpers were more likely to be involved in almost any type of help with secondary caregivers in particular doing less. This difference in findings might be due to differences in samples of caregivers: Tennstedt et al. (1989) included both spouses and adult children, whereas in our study only adult daughters had been selected. 
Our study has several limitations. First, we examined primary and secondary caregivers from different families; hence we could not explore how shared caregiving takes place within the same family. Second, the causal relation between competing roles and caregiver responsibility may run both ways, with levels of caregiver responsibility also derermining the number of hours one is able to work. Women might have already adjusted their work in the course of the caregiving process. Third, we used terms as 'helpers' and 'caregivers" as if it concerns a homogeneous group providing one specific amount and one type of help. However, we do realize that the opposite is true and that they are umbrella terms that cover a wide and diverse range of activities. Another umbrella term was 'parents', referring to parents as well as to parents-in-law. Although the so-called 'externals' of the burden of care will be similar for daughters and daughters-in-law, the so-called 'inner experience' of daughters and daughters-in-law might be different (Brody, 1990). In particular the motives and the relationship with the care recipient, and perhaps also what they are willing to give up to continue providing help is experienced differently. Finally, we cannot know to what extent our findings can be generalized to other countries, for example the US. Major differences between the Netherlands and the US, for example, lie in the size of the country and the greater geographical mobility of the US population. Differences with regard to labor force participation of women are smaller $(68 \%$ in the US as compared to $51 \%$ in the Netherlands, $\mathrm{OECD}, 1993$ ) and, from the literature on intergenerational support, we have found no indication that norms of familism are very different in both countries. Probably, differences within the US itself are large as well.

Despite its limitations, our study showed that practical and situational factors determining the degree of involvement in parent care. Individuals attach more weight to filial obligation, love and affection, indicating how strongly caregiving is interconnected with the moral identity of individuals. It is this moral identity which is at stake when caregivers persevere in their caregiving task even at times when this care forces them to balance on the edge of their own physical and psychological limits.

Future research should include longitudinal research in order to see how caregiving careers develop and changes in the course of the caregiving process. In addition, more attention should be paid to the positive aspects of parent care for the individuals involved and the society as a whole, in order to counterbalance the one-sided stress on the strains of parent care and the elderly being a burden to the society. Policy measures should not be directed at taking over an important part of elder care, but should support caregivers and helpers to carry on with the caregiving task, in particular caregivers that work full-time and that have relatively few siblings. It cannor be emphasized enough that employed caregivers need flexibility in work hours and need the understanding and support of co-workers and managers at the workplace. Special leaves or the opportunity to work part-time for a limited period of time, i.e. when a parent needs more extensive help, enables employed caregivers to provide care for sick or disabled relatives without jeopardizing their job and hence their social security. 


\section{REFERENCES}

Allan, G. (1988). Kinship, responsibility and care for eldetly people. Aging and Society, 8 , $249-268$

Brody, E.M. (1990). Women in the Middle: Their Parent-Care Years. New York: Springer.

Brody, E.M., Litvin, S.L., Hoffman, C. Kleban, M.H. 1995). Marital Status of caregiving daugh. ters and comesidence with dependent parents. The Cerontologist, 35, 75-85.

Central Bureau of Statistics (Netherlands Statistics). (1994). Fifty-nine years of statistics in time series (Viffennegentig jaren statistiek in tijdreeksen). The Hague: CBS-publications.

Ciciralli, V.G. (1993). Attachment and obligation as daughters" motives for caregiving behavior and subsequent effect on subjective burden. Psychology and Aging, 8, 144-155.

Finch, 1. \& Mason, 1. (1993). Negotiating family responsibilities. London: Routledge.

Given, B.A., \& Given, C.W. (1991). Family caregiving for the elderly. In Werley, H. (Ed.), Annual Review of Nursing Research, 77-101. New York: Springer.

Janssen, T. Woldringh, C. (1991). Primary caregivers of elderly people (De centrale verzorg(st)ers van ouderen). Nijmegen (Netherlands): Institute of Applied Social Sciences.

Mangen, D.J., Landry, P.H., and Bengtson, V.L. (1987). The measurement or intergenerational relations. Newbury Park CA, US: Sage Publications.

Merrill, D.M. (1997). Caring for elderly parents; Juggling work, fiamily, and caregiving in middle and working class families. London: Auburn House.

OECD 1 Organization for Economic Co-operation and Development). (1993). OECD Systems: the socio-economic environment statistical references, Health Policy Studies 3. Paris: OECD.

Penrod, J.D., Kane, R.A., Kane, R.L., \& Finch M.D. (1995). Who cares? The size, scope and composition of the caregiver support system. The Cerontologist, 35, 489-497.

Pfuhl, E.H. \& Henry, S. (1993). The devance process. New York: Aldine de Gruyter.

Silverstein, M. Parrot, T.M. \& Bengtson, V.L. (1995). Factors that predispose middle-aged sons and daughters to provide social support to olcler parents. fournal of Marriage and the Family, 57 , $465-475$.

Stoller, E.P., Forster, L.E., \& Duniho, T.S. (1992). Systems of parent care within sibling netwarks. Research on Aging, 14, 28-49.

Stommel, M. Given, B.A. Given, C.W.\& Collins, C. (1995). The impact of the frequency of care activities on the division of labor between primary caregivers and other care providers. Research on Aging, 17, 412-433.

Stone, R. Cafferata, G.L., \& Sangl, J. (1987). Caregivers of the fraill elderly: a national profile. The Gerontologist, $27,616-626$.

Tennstedt, S.L., McKinlay, J.B., \& Sullivan, L.M. (1989). Informal care for frail elders: the role of secondary caregivers. The Gerontologist, 29, 677-683. 


$$
\text { CHAPTER } 6
$$

Stability and change in caregiving; A longitudinal study on the impact of women's multiple roles on continuation and cessation of caregiving

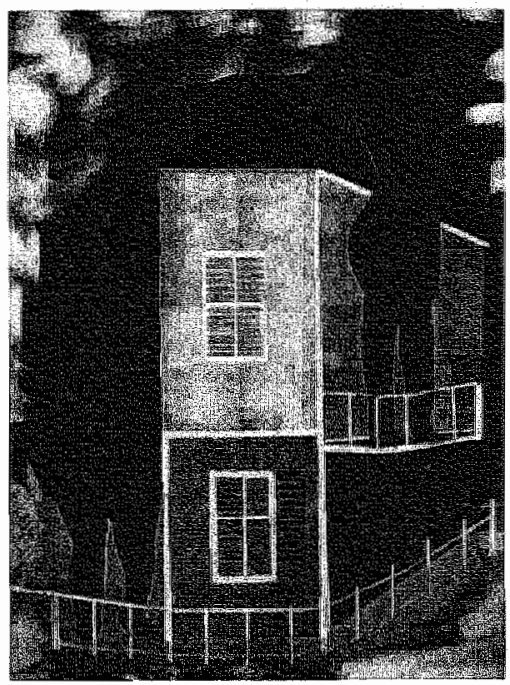


110|Chapter 6

Je hand in de vensterbank, je band in je schoot, die banden die liggen alsof ze een brief hebben gekregen.

matr die niet hebben opengemalkt, en dat ook niet zullen doen.

Rutger Kopland 


\section{ABSTRACT}

This article examines whether women's multiple roles determine decisions regarding the acquisition, continuation and the cessation of caregiving for an elderly parent. Use was made of a telephone survey with measurements at two waves with an interval of two years $\left(\mathrm{N}_{\mathrm{T} 1}=934 ; \mathrm{N}_{\mathrm{T} 2}=743\right)$. Quantitative analyses on determinants of the acquisition, continuation and cessation of caregiving showed that only employment reduces the likelihood to become and remain a caregiver. Additional factors affecting decisions on caregiving were geographical proximity, the age of the parent and being the only child. Other care roles, such as the spousal and parental role, or a combination of those, had no impact. Consistent with these 'objective' findings, women reported on work, geographical proximity, and the presence of siblings as the main reason for not helping parents. A poor relationship with the parent or not feeling obliged to help a parent were mentioned rarely. We concluded that structural and social factors rather than personal and idiosyncratic factors determine who becomes a caregiver, who remains in that role and who withdraws from caregiving.

\section{INTRODUCTION}

Change has been reported as the quintessence of caregiving (Aneshensel, Pearlin, Mullan, Zarit \& Witlach, 1995). The caregiving role may expand or decrease in size and responsibility; it may be prolonged for a considerable period of time or interrupted with intervals. Continuity and discontinuities in caregiving are dependent on the need for care by the care recipient, but have also been associated with the context of caregiving. For most women, and in particular adult daughters, the role of caregiving for an elderly parent is acquired within a panoply of other social roles. They might be involved in paid work, have the responsibility for teenage children or might be pursuing other social acrivities or interests outside their homes. The caregiving role is 'the new kid on the block' and its integration into the role-ser might create conflicts and strains in other areas of life. As a consequence, women with multiple roles might be less likely to get involved in caregiving, for example because they themselves are relucant to take the responsibility for a frail parent or because they might be excused by others from doing so. This article examines whether the involvement in other social roles affects affect the decisions of middle-aged women regarding the assumption and cessation of caregiving. 


\section{Conceptual issues}

Two theoretical perspectives are instrumental in describing and explaining continuity and change in the caregiver role and the impact of women's multiple roles therein: the life course approach and the caregiving career perspective. Both perspectives stress the importance of contextual factors of caregiving.

The life course approach considers caregiving for elderly parents as one of the life trajectories women go through at a certain stage of their life (Robison et al., 1995; Moen et al., 1994). Caregiving is not considered as an isolated episode in life but as a trajectory that is contingent on other pathways (Moen, Robison and Fields, 1994; Robison, Moen and Dempster-McClain, 1995). Hence, the acquisition of and withdrawal from the caregiving role is dependent on transitions and trajectories that occur at that specific point of time in women's lives, such as work, other care roles and the health status of the caregiver.

The career perspective examines the dynamics within the caregiving role (Aneshensel, Pearlin, Zarit and Witlach, 1995). Analogous to the occuparional career, caregiving can be regarded as a multistage trajectory, in which individuals pass through specific stages and transitions (Aneshensel et al., 1995). The three major stages and transitions that occur in the caregiving career are (1) role acquisition, (2) role enactment and (3) role disengagement. Aneshensel et al. (1995) have suggested that multiple roles of women play a part particularly in the first two stages. They postulate that social and structural factors, such as social roles, determine who becomes a caregiver of a frail elderly person. This contrasts with what commonly is postulated, attributing the acquisition of the caregiving role to personal affinity between the caregiver and the care recipient because of the incimacy and primacy of family relations (Aneshensel er al., 1995). During the second stage of caregiving, role enactment, Aneshensel et al. (1995) have stressed that women's multiple roles are a source of additional strain for caregivers, labeled as "secondary stressors", in addirion to the primary stressors that emanate from care demands themselves. A process of stress proliferation may take place in which stressors precipirate other stressors, i.e. the stress from primary care demands may exacerbate because of the friction it creates in other domains of women's lives.

Empirical studies, however, have not been able to demonstrate the often assumed causal relation between women's multiple roles and changes in the caregiving role. Relatively few studies have attempted to examine the factors leading to the caregiving role with the help of quantitative data. In most of those srudies, only cross-sectional data have been used. Three factors have been reported as determining the onset of caregiving (Given and Given, 1991): situational factors (i.e., having the least valued competing commitments), geographical proximity and demographic imperatives (i.e., being the only child or being the only fermale child and feelings of familial obligation). When longirudinal data were used, the focus has been on paid work reducing the likeli- 
hood to start with caregiving, or the passible effect of caregiving on negative work decisions such as quitting jobs. In a sample of married women, Robinson, Moen and Dempster-MacClain (1995) did not find any negative relation between the two. In other studies similar conclusions have been drawn. Women seemed to add on caregiving responsibilities to their role-set rather than making a choice between either of the two roles (Moen, Robison and Field, 1994). Work adaptations are usually done successfully, suggesting that in most cases caregiving is integrated in the role-set of employees after an inirial period of adjustments (Franklin,. Ames and King, 1994).

Our study extends the scope of previous studies by making use of longitudinal data and by examining not only paid work as a determinant of starting or the cessation of caregiving. We also examined the impact of other social roles and structural factors affecting the three stages of caregiving, i.e. the acquisition, the continuation and the cessation of caregiving for an elderly parent. The objectives were to examine in a sample of middle-aged women (1) whether changes had taken place in the caregiving role over a period of two years, (2) whether women's multiple roles are among the factors determining the acquisition, continuation and cessation of caregiving, and (3) whether women themselves felt that their involvement in other roles has forced them to withdraw from caregiving for an elderly parent.

In line with the life course and career perspective we assumed that the acquisition, continuation and cessation of caregiving are contingent on other life trajectories such as the involvement in paid work, or responsibilities as a mother. Hence, we hypothesized, first, that women who are involved in paid work or other care roles are less likely to acquire the caregiving role or to continue with caregiving, and are more likely to withdraw from that role or not to assume that role at all. Second, we hypothesized that continuity and change in the parent care role would not only depend on women's involvement in other multiple roles, but also on other contextual factors. We examined the impact of the social and cultural norm of filial obligation on what adult children should do for elderly parents, the demographic factor of having siblings and the practical factor of proximity to the parent.

\section{METHOD}

Data were obtained through a telephone survey in two municipalities, consisting of one medium-sized town ( 80,000 inhabitants) and three smaller towns (in total 40,000 inhabitants) in the south of the Netherlands. The research area included an urbanized city center, as well as suburbs and village neighborhoods. 


\section{Sample}

At Time 1 (1994), a random sample was drawn among women of the birth cohort 1940-1954 from the registration offices of the two municipalities. The birth cohort 1940-1954 was selected because the women of that age group of ( 40 to 54 years at Time 1) were most likely to perform simultaneously the roles of mother, employee, spouse and caregiver. Participants were interviewed by telephone in two waves, with an interval of 25 months. The first wave (Time 1) took place in 1994; 1206 respondents were approached by telephone and 934 agreed to participate, resulting in a response rate of $79 \%$. At Time 1 we only had information available on the age and marital status of non-responders. Comparing tesponders at Time $1(\mathrm{n}=934)$ with non-responders ar Time $1(1206-934=272)$ showed that in particular widowed and unmarried women were less likely to participate ( $\mathrm{p}<.05)$. The second wave (Time 2$)$ took place in 1996; 854 respondents could be contacted again of whom 743 agreed to participate, resulting in a response rate of $80 \%(743 / 934)$. The overall response rate at Time 2 was $62 \%$ (743/1206). At both waves, the most frequently mentioned reasons for not co-operating were lack of interest, lack of time, privacy considerations or being tired of telephone surveys. A non-response analysis compared the 743 responders of Time 2 with the 191 non-responders at Time 2 (934 minus 743) on several social demographic characteristics such as age, education and variables relevant for the study, such as help to parents, number of living parents, age and health of parents, employment and children. Variables that appeared significant at the bivariate level were examined with the help of logistic regressions. Only a higher education and having children significantly increased the odds for response.

At Time 2,77\% (n=574) had at least one parent/parent-in-law and $51 \%$ were actually helping a parent. Of these 574 participants, the mean age was 48.1 years (range 42.56). Three-quarters were living with a partner, $85 \%$ had children (2.0 on average; range 1-7) and $34 \%$ had ar least one minor child (below 18 years). Half of them were employed ( $49 \%$ ), working on average 25.5 hours per week (SD 13.3; range: $2-70$ hours). On average, they had 3.4 siblings (SD 2.4). Only $2 \%$ were living with a parent or parent-in-law. The mean age of the father was 75.5 years, of the mother 75.8 , of the father-in-law 77.0 and of the mother-in-law 76.4 ; the age of all parents ranged between 53 and 95 years.

In the remainder of this article, "parents" will refer to both parents and parentsin-law.

\section{Measurements}

Respondent characteristics. Educational level was assessed by the highest level of education finished by respondents, varying between primary school (1) and university (7); it 
was only measured at Time 1 . Health status of the respondent was self-assessed by one item (5-point Likert scale, very good-very poor). A change in health status was computed by comparing the self-assessed status at Time 2 with the self-assessed starus at Time 1 . We examined wherher the subjective healch status remained the same, was assessed worse or better at Time 2 .

Demographic factor. Respondents were asked how many living brothers and sisters they had; this item was only asked at Time 2. Geographical distance was measured by the minutes of traveling time needed to reach each of the living parents. In the analyses, three coding categories were made: 0-15 minures, $15-30$ minutes and more than 30 minutes. This variable was only measured at Time 2 .

Competing roles. Child-rearing responsibilities was indicated by having minor children (below 18 years). The spousal role was indicated by living with a partner at Time 1 and work hours by the numbers of hours per week worked in paid employment or a family enterprise. Other care roles were, dichotomous items on whether they shared residence with a chronically ill or handicapped person, wherher they had been helping non-resident children regularly in the past weeks, and whether they had been looking after grandchildren regularly in the past weeks.

Filial obligation. Filial obligation and normative obligations towards parents were indicated by a filial obligation scale, developed in the US and rranslated into Dutch. In the US it proved to have a good reliability and stability over time (Mangen er al., 1988). It consists of six items (5-point Likert scalle) on the responsibility participants believe that adult children should have for elderly parents in (1) providing companionship, (2) helping and supporting them with household chores and transportation, (3) providing advice and guidance, (4) providing personal and health care, (5) providing financial support, and (6) providing housing. Possible scores could vary between 6 and 30 . In our sample the Cronbach's alpha of the scale was .81. Filial obligation was only measured at "Time 2 ,

Care characteristics. Caregiver responsibility was self-assessed by the item with three coding categories: "Are you the one who is doing most (1), do you share tasks equally with others (2) or is someone else doing most (3)?". It resulted in the three levels of responsibility, i.e. caregivers with primary, equally shared and secondary responsibility in care. In our analyses, we distinguished two groups, i.e. caregivers with primary (category 1) and caregivers not having the primary responsibility (categories 2 and 3 ). The difference in levels of responsibility corresponded with differences in the amount of help and the complexity of care tasks. Assistance to parents referred to any instrumental or emotional support given to parents in the past weeks, such as shopping, transportation, cleaning the house, personal care, finances, preparing meals, gardening and house repairs. Interviewers were instructed to state explicitly that the ordinary social visits to the parent were not considered as help. 


\section{Statistical analyses}

Bivariate differences in means were tested by one-way ANOVA $t$ tests of means for multiple comparisons when continuous variables were used, with Scheffé's rests indicating between which groups the significant differences were lying. Nonparametric tests (Mann-Whitney) were used to test differences in ordinal variables and chi-square tests to assess differences in dichotomous variables or nominal variables.

\section{RESULTS}

\section{Continuty and change in the caregiving role}

The first objective of our study was to examine the changes that had take place in the caregiving role over a period of two years. Table 1 presents stability and change in the amount of caregiver responsibility. A distinction was made between two levels of responsibility, i.e. caregivers having the primary responsibility, on the one hand, and those who shared tasks equally or were only involved at a secondary level, on the other hand. A higher level of responsibility corresponded with a larger amount of help. Primary helpers provided assistance for on average 11.9 hours per week whereas other helpers helped on average 5.9 hours per week $(p<.001)$. In addition, primary helpers provided assistance that was more complex: on average they provided 5 different types of help, whereas orhers were involved in 3-4 different types ( $p<.001)$.

Two conclusions can be drawn from table 1 . First, it appeared that stability, and not change, is the major characteristic of caregiver responsibility during a period of rwo years. Once women have assumed a certain responsibilicy in parent care, the greatest like lihood is that they have a similar level of responsibility a few years later; and those who have not been involved at all in parent care will probably still not be helping parents in subsequent years. Second, women tend to have reduced rather than to have increased their involvement in parent care after two years.

Table 2 presents figures for each of the parents separately. Assuming that blood is thicker than water, women might be more likely to be helping their own parents than their parents-in-law. This appeared to be the case to some extent. At first sight, the differences in helping patrers for each of the four parents are small. When analyzed per parent, caregivers are not more likely to have increased their involvement for their own parents as compared to the parents-in-laws. However, a closer look shows that the percentage of 'no care' is smallest for elderly mothers, i.e. $29 \%$ as compared to percentages varying between $37 \%$ and $40 \%$ for the other parents. This pattern comes out even nore clearly when absolute numbers are considered. Table 2 shows that 421 respondents had been giving help to their mothers, whereas only 215 respondents had been 
TAELE 1. Transition matrixiprobability of stabiliy and change n caregiving responsibility al T2 gvon the caregiving responsibility at $T 1$ respondents with at lesst one living parent at $T$ t and $T 2$ (n-580)

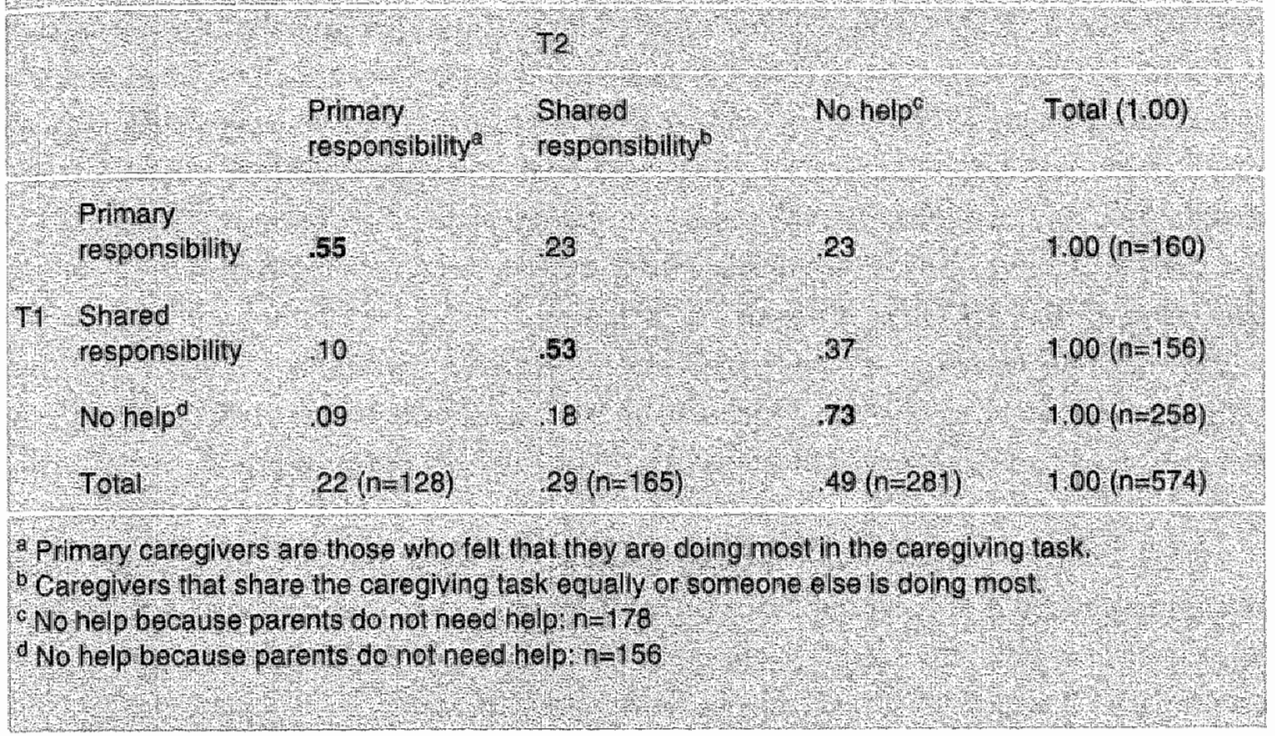

TABLE 2 Stability and chango In careguvingresponsibility at TI end T 2 tor eachparent when at least one pare tis stillalive at 11 and 12

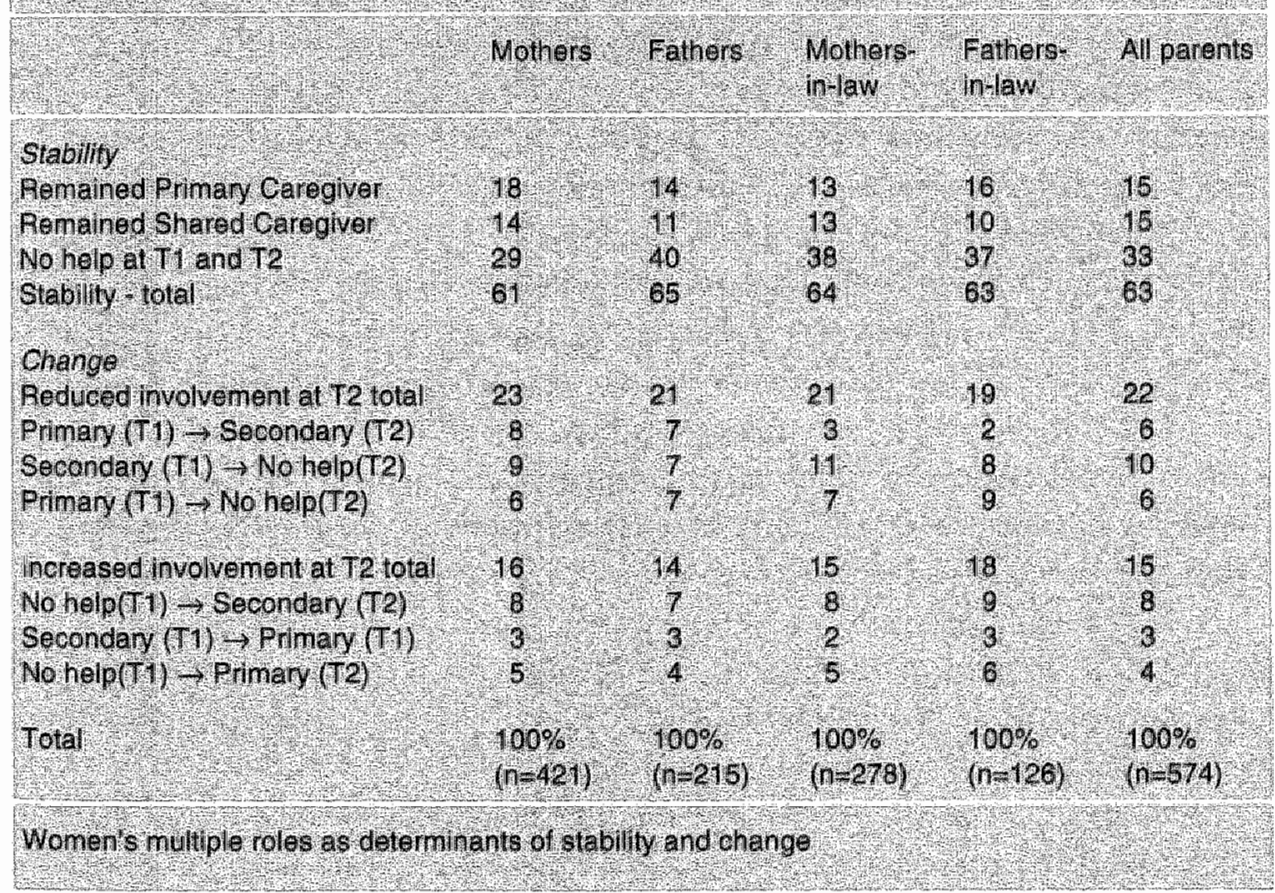


helping fathers, 278 their mothers-in-law and only 126 respondents their fathers-in-law. Hence, mothers are most likely to be helped, followed by mothers-in-law, with those having a specific level of responsibility being most likely to be in a similar position two years later. Fathers and fathers-in-law probably are helped to a lesser extent because they are likely to be survived by their wives who will take care of them when they need help. In addition, both daughters and their elderly mothers tend to marry men that are older than themselves, together with the fact that women live longer than men. Thus, the own mother rather than the parents-in-law is most likely to survive and be cared for by a daughter.

The second objective of our study was to determine whether women's multiple roles predicr the acquisition, continuation and cessation of caregiving for elderly parents. This objective was examined with the help of bivariate and multivariate analyses.

Table 3 shows the results of bivariate analyses. For these analyses, we included only respondents who had reported that one or more of their parents were in moderate or poor health and who had not reported that their parents didn't need any help. We examined the impact of several respondent characteristics, i.e. age, education and self-rated health and distress levels at Time 1 and Time 2, the demographic factor of siblings, the practical factor of geographical distance, competing roles and filial obligation. Competing roles referred to out-of-home employment, living with a spouse, having minor children, co-residing with a chronically ill person, looking after grandchildren and the total number of roles, including the major social roles of women, i.e. the role of employee, of mother of minor children and the spousal role. We also examined the following changes that had taken place at Time 2: changes in self-rated health, in work hours, in having acquired or quitted employment, having lost the spouse, no minor children anymore, got a chronically ill person in household, and had started looking after grandchildren. Table 3 presents the predictors that showed significant differences on the cited variables among the four groups, i.e. women who had at Time 2 acquired the caregiving role, withdratun from caregiving, continued-perhaps againwith caregiving and women who were not caregivers at both points of time. Since we assumed a causal relationship between the predictors and change and continuity in the caregiving role, percentages of table 3 are run horizontally. Table 3 only presents the figures on the variables that have been examined at the multivariate level as well.

As indicated in table 3 , five factors appeared statistically significant $(p<.05)$. First, geographical distance to the parents was strongly associated with continuity and change in the caregiving role. Women that live near a parent are more likely to become the caregiver of a frail parent and to remain in that role.

Second, employment appeared as a role that competed with the caregiving role. Employed women were more likely to have withdrawn from caregiving or not to have 
TABLE3. Percentage distribution ol competing roles and other taclors detemining change and contl nuity in the caregiving role $(n=497)^{\mathrm{a}}$

\begin{tabular}{|c|c|c|c|c|}
\hline (2) & 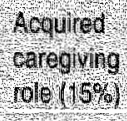 & $\begin{array}{l}\text { Whatrawn } \\
\text { hron croghng } \\
(136)\end{array}$ & 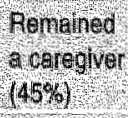 & $\begin{array}{l}\text { Nol garegluer } \\
\text { a } 71 \text { and } T \text { ? } \\
(27 \%)\end{array}$ \\
\hline Resiondert characternstics & & & & \\
\hline e(T) & & & & \\
\hline 4246 yrs $(1-199)$ & 16 & 12 & 44 & 29 \\
\hline 4751 ys $(1=170)$ & tis & 16. & 43 & 28 \\
\hline 5256 yrs $(n-120)$ & 13 & 13 & 52 & 23 \\
\hline Educalion [1] & (1) & & (1) & \\
\hline lower $100 \%=100 \mathrm{~J}$ & 20 & 14 & $44^{2}$ & 22 \\
\hline $00 \%,=214$ & 14 & 12 & 46 & 28 \\
\hline $0 \% 7=80$ & 4. & 15 & 81 & 30 \\
\hline Saffrated fealhat? & Wet & mi & & 3 \\
\hline 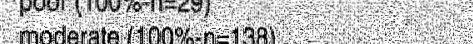 & 3 & 2 & 15 & 13 \\
\hline good $(100 \%=317)$ & 12 & 12 & 48 & 20 \\
\hline Bemographic factor (T2) & & & & \\
\hline Sibilings: & & & & \\
\hline beng an only chill $(n-24)$ & 25 & B & 54 & 3 \\
\hline 1-2 s bings $(n=185)$ & 15 & 13 & 47 & 25 \\
\hline ( 3 sibings bn 282 ) & 18 & 14 & 44 & 29 \\
\hline Geograplival proxming (1)2) & & & & \\
\hline Bestance o peren ts inavel tine) & 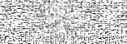 & & & \\
\hline 0.15 nin $100 \%$ - $1=207$ & 17 & 12 & 54 & 17 \\
\hline $4080 \mathrm{~min}(100 \% \mathrm{r}=\mathrm{V} 26)$ & 16 & 18 & 48 & $88^{2}$ \\
\hline$=30$ nil. $(100 \% n-76)$ & 12 & 12 & 26 & 50 \\
\hline Gonpetho cles(T2) & & (1) & & \\
\hline Employment & & & & \\
\hline Errployed $(100 \%$ n=225) & 12 & 15 & 40 & 3 \\
\hline Not enployed $(100 \%$ - h=259) & 17 & 12 & 5 & 20 \\
\hline Number of fadolionall, roles of $T^{6}$ & & & & \\
\hline (no role $(100 \%=0.56)$ & 9 & 16. & 59 & 46 \\
\hline 1 role $(1007 \cdot n-19)$ & 15 & 16 & 4 & 26 \\
\hline 2 roles $(100 \% \mathrm{n}=162)$ & 11 & 15 & 46 & 28 \\
\hline Broles $(100 \%=78)$ & 18 & 12 & a2 & 36 \\
\hline Marredining with partner $(100 \%=344)$ & 18 & 14 & 46 & 26 \\
\hline nol marned wing with partiner $(100 \%$ on-140) & 19 & 41 & 48. & 22 \\
\hline Minor chidien $(100 \%-10-168)$ & 10 & 17 & 39 & 30 \\
\hline 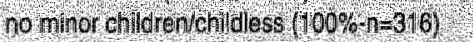 & 14 & 13 & 150 & 24 \\
\hline Parent characteristic(T2) & & & & \\
\hline 21 parent $>75$ years $(100 \% \mathrm{n}=375$ & 14 & 12 & 49 & 26 \\
\hline no parent $\rightarrow 75$ years ol age $(100 \%$ r $n=109)$ & $\sqrt{16}$ & 10 & 36 & by \\
\hline Filla obilgation (T2) & & 10 & & \\
\hline $233 \%$ of respoidents $(100 \%-h-128)$ & 13 & 12 & 62 & 23 \\
\hline $38.67 \%$ ol respondenis $(100 \% \cap=178$ ) & 12 & 11 & 46 & 29 \\
\hline$>67 \%$ of igsponiden's $(100 \%$ on 161$)$ & 18 & 17 & 38 & 27 \\
\hline
\end{tabular}

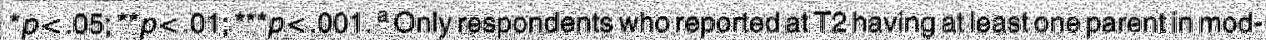
erate health and who did not report that their barents did not ineed help, b Referring to the roles of em ployee, nother and spouse. Whe noomparing the mean no ol addlifonal roies for each of the four groups (ANOVAt tests ot means) differences appeared significant for those wio remained caregivers (on av: erage 1.4 roles) and those who were not careguers at Time 1 and 7 ine 2 (on average 17 roles) 
got involved in caregiving at all. Other roles, such as having minor children and other care roles, did not affect changes in the caregiver role.

Third, having siblings was an important predicror. Women who were the only child of their parents were particularly more likely to acquire the caregiver role or to remain a caregiver. The number of siblings had no impact.

Fourth, having a parent above 75 years of age predicted in particular whether women remained caregivers. Those who did not have a parent older than 75 were more likely to have withdrawn from helping parents in the past two years.

Fifth, the educational level of women appeared significant, with lower educated women being more likely to acquire the caregiving role and higher educated women being more likely not to be caregivers at Time 1 and Time 2. Views regarding what should be done for parents (filial obligation) did not affect continuity and change in the caregiving role neither did self-rated health or distress levels. None of the 'change-factors', such as having entered or quitted a job, were associated with change and continuity in caregiving.

The bivariate findings were confirmed ar the multivariate level. A discriminant analysis showed that distance to the parent, employment, having multiple roles, and siblings were significant variables predicring women having the same caregiver status. At the multivariate level, the factor "educational level of the respondent" lost its significance, probably because of its correlation with employment: higher educated women are significantly more likely to be employed and to work more hours per week.

However, the factors of roles, distance and siblings predicted in particular stability in the caregiver role, i.e. women that either remained a caregiver or did not provide care at all. The discriminant functions were not significant for the groups that changed in caregiver status, i.e. became a caregiver or stopped helping a parent. In sum, we concluded from the analyses that structural factors rather than personal factors may determine who remains a caregiver of an elderly parent or who does not become a helper at all.

\section{Multiple roles and the cessation of caregiving}

Women were also probed on the reasons for not helping parents. We selected the respondents who were helping parents at T1 but had stopped doing so at Time 2 despite them having at least one parent in moderate or poor health at Time 2.

Table 4 indicates that the most frequently reported reason for withdrawal of the caregiving role was that parents did not need help anymore ( $44 \%$ of the responses) or that other resources of help were available, such as professional care, siblings or the elder's spouse ( $30 \%$ of the responses).

Among the women that most probably had parents needing help, $11 \%$ reported that they did not help because other relatives were doing so, because of the geographical distance to the parent $(7 \%)$, or because their job or other responsibilities did not allow 
TABLE 4. Percontage distribution (multiplo responso) of reasons reponted by non caregivers with at Teast one living parent for hot providing help to pairemts at T2 when thelp was given at $T 1$ and one or mare parents ijad a moderate or poor health (n-93)

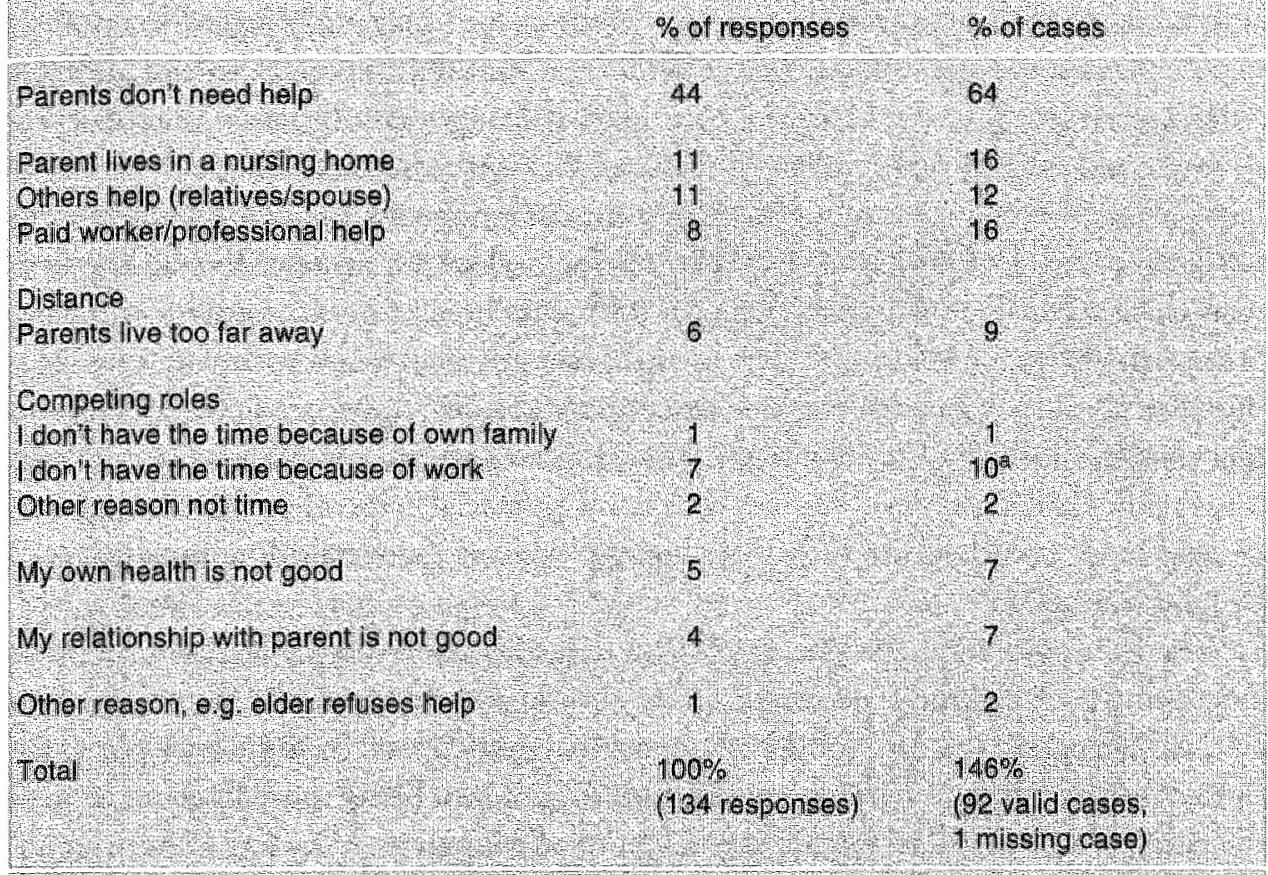

a $17 \%$ of tha employed respondents reported that they did nat help parents because of their obs

them to $(10 \%)$. Few respondents reported that they had withdrawn from helping because their own health was not good enough $(5 \%)$ or because they had a poor relationship with the parent $(5 \%)$.

\section{DISCUSSION}

This arricle described changes in caregiving that had taken place over a period of two years and examined whether multiple roles of women affected decisions regarding the acquisition and continuation of caregiving. Women's multiple roles included paid work and various care roles. Our main findings were, first, that over a period of two years stability, and not change, was the dominant pattern. Women who have started to help parents are most likely to be doing so a few years later and to have a similar level of responsibility. In addition to stability, we found that women are more likely to have reduced their share in the caregiving task than to have become involved to a larger 
extent. Thus, the commonly postulated statement that the need for care increases with women's age is not valid for the wornen of this age group (40-54 years).

Our second main finding was that multiple roles do affect women's decisions on starting or continuing caregiving for an elderly parent only with regard to employment. Other care roles, including child-rearing responsibilities and the care for a disabled co-residing relative, had hardly any effect. Changes in roles, such as a reduction of work hours or having become widowed, had no impact as well. The relative importance of employment as a competing commitment is not consistent with a study in the US by Moen et al. (1994) finding that employment does not decrease the likelihood of women becoming a caregiver. Perhaps the difference in our findings with Moen's work is due to a difference in samples. Moen examined only married women that were helping not only elderly parents, but also other disabled relatives. Moreover, the women of our sample originated from relatively large families and had more than three siblings on average. Perhaps in those families with many potential helpers of parents, employed daughters are excused from the caregiving task because there are other, nonemployed daughters available.

Besides employment, practicalities seem to lead women to become caregivers or to stop doing so. Our study indicated that structural and demographic factors are decisive, with geographical proximity having the strongest impact. In addition, siblings appeared as a demographic imperative, with only children being more likely to acquire the caregiving role and to remain the helper of a frail parent. Very few of our respondents referred to the relationship with the parent as a reason for not helping him or her anymore. Strong views on whar should be done for elderly parents did not make any involvement in parent care more probable as well. In that respect our findings confirmed the assumption of Aneshensel et al. (1995) about the importance of social and structural factors. The impact of proximity, employment and demographics is consistent with a study by Given and Given (1991).

Regarding our hypotheses formulated on the basis of the life course and caregiving career perspecrive, we found that only the occupational career is a life trajectory that may interfere with caregiving for an elderly parent. Other trajectories such as the mother role are less likely to interfere with the provision of assistance to elderly parents. An additional care role might be fitted more easily into the daily routine of other care responsibilities than can employment that is tied to fixed working-hours. However, our findings suggest that situarional factors such as proximity, and other resources, are at least as important.

In line with the quantitative findings on the determinants of caregiving, the reported reasons for not helping a parent referred to distance, the presence of other helpers, being too busy because of a job or a family. These justifications and excuses have been labeled in studies on social deviancy as verbal accounts, or the vocabularies of motives, referring to the explanations that individuals use to justify or neurralize supposedly 
'wrong' behavior (Pfuhl and Henry, 1993). It appeared that women refer to factors that were lying outside their control in explaining why they are not helping a parent.

The design of this study had several limitations. First, we had only two measurements in time and lacked any data on the intervening period, which limired the understanding of the pattern of the changes that had taken place in the period in-berween. Second, in a period of two years only limited changes can take place in major social roles such as the spousal role or work. Therefore, the subgroups that had changed were very small which restricred any possibilities to detect statistically significant changes. Third, since we measured the subjective health status of the parents only at $T 2$, we only could use their age as an indicator of the health status of the parents. Hence, we could not investigate whecher health of parents is a predictor of change and continuity in caregiving. Finally, we regret that we did not have a measurement of the quality of the relationship with the parents at $T 1$, so that we could not include it as a predictor for changes in help.

Despite these limitations, our findings clearly showed that the social, economic and demographic context of caregiving is more important in explaining the diversity among groups of caregivers than idiosyncratic and personality factors.

\section{REFERENCES}

Aneshensel, C.S., Perin, L.I., Mullan, J.T., Zarit, S.H., and Witlach, C.J. (1995). Profiles in caregiving: the unexpected career. San Diego (US): Academic Press inc.

Franklin, S.T., Ames, B.D., and King, S. (1994). Acquiring the family elder care rol es; influence on female employment adaptation. Research on Aging, 16:27-42.

Given B.A., and Given C.W. (1991). Family caregiving for the elderly, in Werley H. (ed.), Annual Review of Nursing Research. 77-101. New York: Springer.

Mangen, D.l., Landry, P.H. and Bengtson, V.L. (1987). The Measurement of Iniergenerational Relations. Newbury Park CA, US: Sage Publications.

Moen, $P$, Robinson, $\mathrm{J}$, and Fields, V. (1994). Women's work and caregiving roles; a life course approach. Journal of Gerontology: Social Sciences, 49, $\$ 176-5186$.

Pfuhl, E.H., and Henry, S. (1993). The Deviance Process. New York: Aldine de Gruyter.

Robinson, 1., Moen, P., and Dempster-McClain, D. (1995). Womer's caregiving: changing profiles and pathways. Journal of Cerontology: Social Sciences, 50B, $5362-5373$.

Stoller, E.P. and Pugliesi K.L. (1989). The transition to the caregiving role. Research on Aging, $3: 312-330$. 



\section{SUMMARY}

This dissertation addresses one of the most prominent social issues of our times - the support that older people receive from younger generations and in particular from the daughters in the family. Demographic trends show that the proportion of elderly people is growing dramatically. Since daughters and daughters-in-law are the main source of help for frail elderly, policy makers have expressed concern that changes in lifestyles of women and the rapid entry of middle-aged women into the labor force, reduce women's availability for parent care. Terms such as 'women-in-the-middle', 'the sandwich generation' and 'the double burden' are used. They suggest that women who are involved in caring for a generation behind as well as a generation ahead of them, face difficulties and might get "caught" or "sandwiched" in the middle of multiple claims on their time and energy.

Relatively few studies have subjected these assumptions to empirical proof. Fundamental questions demand answers. First, is the so-called sandwich generation an issue of major concern? Second, is parent care negatively affected when women have other care responsibilities as well? Third, what are the determinants of the amount of help given to parents? What are women's motives and reasons to continue helping their parents or to stop doing so? Fourth, to what extent does women's involvement in parent care affect their wellbeing? These are the questions that we have focused on in this dissertation.

Data have been collected by telephone interviews with women of the birth cohort 1940-1954, because women aged 40 to 55 are most likely to have an overlap in responsibilities of childcare, employment and parent care. The sample was random and population-based, drawn from the municipal population registration offices of a town, Heerlen, and a cluster of three bordering villages, Landgraaf, in the south of the Netherlands. Data collection took place by telephone interviews in two waves with an interval of 25 months. The first wave was in $1994(\mathrm{~N}=934$, response rate $79 \%)$ and the second wave in $1996(\mathrm{~N}=743$; response rate $80 \%)$.

We examined our data from the theoretical perspective of role theory, based on the general view that societies consist of institutions and that institutions are made up of social roles. Social roles refer to a set of obligations that individuals are expected to fulfil and a common set of values and agreements that usually go with it. In our study, we examined the women's roles of mother, employee, spouse and helper of an elderly parent. The core question was whether multiple roles are beneficial or detrimental for the wellbeing of daughters helping elderly parents.

Three hypotheses of role theory appeared relevant for our study. The first hyporhesis was the role scarcity or role conflict hypothesis, which assumes that multiple roles lead to distress because individuals tend to 'overload' themselves with roles and respon- 
sibilities that eventually conflict in time and place. In contrast, the role accumulation hypothesis assumes an opposite effect, stressing that multiple roles enhance the individual's wellbeing because they provide individuals with multiple sources of status security, support and self-esteem. The third hyporhesis, the role expansion hypothesis, assumes that individuals may add on another role without increasing distress only under one condition, i.e. that she/he is highly committed to that particular role.

With regard to the furst question, the existence and prominence of the phenomenon labeled as the 'sandwich generation', we found that considerable proportions -approximately $30 \%$ - were mothers, paid workers and helpers of their parents. However, only tiny proportions were bighly involved in these roles at the same time. The majority also indicated that the help for their parents was no burden at all to them. Hence, the term 'sandwich generation' is misleading since neither the majority of middle generation women, or the majority of helpers of elderly parents, feel "sandwiched" or "caught" between compering roles and responsibilities.

With regard to the impact on parent care, the second research question, the overall picture was that multiple roles make women somewhat less available for parent care but do not significantly reduce their involvement. The amount of help given to parents was not related to the number of other commitments that women had, such as a family, or a job, or a combination of those responsibilities. The time spent on parent care depended on orher factors, in particular dementia symptoms of the parent and how close to the parent a daughter lived.

Employment appeared to have a specific impact. Employed women were less likely to start helping parents and to assume a primary responsibility in care. In particular full-timers were involved as secondary helpers rather than as primary helpers of their parents. However, once they helped a parent, part-time and full-time employed women provided equal amounts of help to a frail parent. Our findings showed that employed women did not always find it easy to balance work and the help to their parents, but that they managed reasonably well by making use of vacation days. In addition, the consequences of women's involvement in parent care for the workplace in terms of absenteeism at work, reduced hours or quitting jobs, were very limired.

The third question examined the determinants of women's involvement in parent care, and their reasons and motives for starting and ceasing caregiving. The overall conclusion was that structural and practical factors are more significant than personal and idiosyncratic factors. Geographical proximity, the daughter's availability and demographic imperatives determined who became the caregiver. Daughters who live nearby, have no job, have a parent in poor health or are the only child, are the designated caregivers. Feelings of duty and obligation towards parents and a good relation with the parent had no significant impact. Our data suggest that a self-selection process rakes place, with a daughter living nearby who is not too overwhelmed by other responsibilities being most likely to assume the caregiver role. 
The impact of structural and social forces often seems to operate outside the awareness of helpers of frail elderly. When legitimizing and explaining why they helped a parent, caregivers expressed the belief that their involvement in parent care was the result of their artitude of filial obligation and love for the parent, seemingly unaffected by extraneous circumstances. This finding contrasted to explanations of daughters for not helping a parent. Those daughters did refer to situational factors such distance to the parent and having no time because of their jobs, legirimizing their non-involvement by referring to factors lying outside their control.

With regard to impact of women's mulriple roles on distress and the experienced burden of care, we found no such relation. Women with multiple roles and in various role combinations were not more distressed or burdened than women with few other roles. Assuming the role of helper of a parent did not increase women's distress. Probably, in the general population, the majority of middle-aged women are able to integrate the care task into their lives without major frictions and dislocations.

The overall picture was that women with multiple roles generally are less distressed rather than more distressed. Most distressed were women with very few social roles. Although the direction of cause and effect might nor be clear, we hypothesized that being rendered 'roleless' deprives women of a feeling of belonging and meaning in life rather than multiple roles causing them to feel distressed.

The burden of care was determined by factors other than women's social roles. Helpers who provided a large amount of help to a parent in bad health, whose own health was relatively poor, and whose relationship with the parent was nor good, experienced a higher burden of care.

With regard to the theoretical implications of this study and the hyporheses that we tested, the conclusion was that most support was found for either the role accumularion or the role expansion hypothesis of role theory. Both hypotheses stress the porentially beneficial impacr of multiple roles and responsibilities rather than its stressful effects. Hence, only limited support was found for the role scarcicy hypothesis, stressing the negative and conflicting impact of multiple roles on individuals.

On the basis of out findings, we recommend that supportive and facilitating policy measures should be taken. However difficult it is for some caregivers, our findings suggest that daughters want to continue helping frail parents. Policy measures can support them in doing so. In particular, full-time employed women and women who are the only child may receive special attention. Flexibility at the workplace, respite care, professional support during the times that the parent's health deteriorates suddenly, and the active involvement of the broader social nerwork of the frail elderly parent are instrumental in bridging gaps for a primary helper when care demands suddenly go up. A new and relatively unexplored area is the involvement of telecommunication and com. puter technology to support daughters who live farther away from a parent that needs help. 
$1 2 8 \longdiv { \text { Summary } }$

The overall picture was that help to parents is still very common among middle-aged women. Nor only were a considerable number helping the parent regularly and had been doing so for many years, they considered this help as being a matter of course. Apparently, the institution of family care still exists and seems to have strong foundations. It is our conwiction that the notion of alienation and abandonment of elderly parents by their children is a very persistent myth. We hope that this srudy has been a contribution to challenging this myth. 


\section{SAMENVATTING}

Dit onderzoek gaat over familiezorg voor ouderen en in het bijzonder de rol van dochters en schoondochters daarin. Het aantal ouderen in de samenleving neemt sterk toe en daarmee ook de behoefte aan familiezorg. Aangezien het de vrouwen in de familie zijn die her leeuwendeel in de zorg voor ouders en schoonouders leveren, vragen beleidsmakers zich bezorgd af of zij overbelast kunnen raken. Dir geldt wooral wanneer deze dochters de zorg voor de oudere combineren mer de verantwoordelijkheid voor her eigen gezin of een baan. De Nederlandse terminologie die in dit verband wordt gebruikt is 'dubbele taken" en "dubbele belasting'; in de Angelsaksische literatuur spreekt men over "women in the middle" of de 'sandwich generation'. Zij maken melding van een middengeneratie vrouwen -meestal van middelbare leeftijd-die klem kunnen komen te zitten tussen zorgvraag vanuit de generatie zowel boven als onder hen.

In ons onderzoek hebben we allereerst een indruk proberen te krijgen van de omvang van dit fenomeen. In hoeverre komt het voor dat vrouwen dubbele taken en verantwoordelijkheden hebben? Ten tweede hebben we onderzocht in hoeverre vrouwen daardoor belemmerd worden om hulp te geven aan hun ouders of schoonouders. Ten derde hebben we onderzocht welke factoren bepalen hoeveel hulp dochters geven aan hun ouders. Is de situatie waarin iemand zit doorslaggevend, zoals afstand en her beschikken over voldoende tijd, of gaar het vooral om de liefde voor de ouder en plichtsbesef? Bij het beantwoorden van deze vraag hebben we zowel de redenen onderzocht waarom sommige dochters wel en anderen geen hulp geven. Ten vierde hebben we onderzocht in hoeverre de combinatie van dubbele taken het welzijn negatief beïnvloedt en het gevoel van belasting verhoogt.

Her theoretisch perspectief dat we gehanteerd hebben is de zogeheten toltheorie, die er vanuit gaat dat de samenleving bestaat uit sociale structuren met darin diverse instituties waarin individuen sociale rollen vervullen. Rollen verwijzen nat verplichtingen, verwachtingen en opvattingen rondom de vervulling van die plichten en taken. In dit onderzoek hebben we ons gericht op de rol van moeder, werknemer, echtgenote en van hulpgevende dochter. In de kern kwam her er op neer dat we wilden weren of de combinatie van al deze rollen goed is voor vrouwen of juist niet. Het begrip dat in dit verband wordt gebruikt is 'distress', het werwijst naar her welzijn en geluk van personen. Hoe meer distress iemand ervaart, des te lager het welzijn.

De roltheorie had drie hypotheses die bruikbaar waren voor her onderzoek. De eerste hypothese wordt de schaarste- of conflicr-hypothese genoemd. Deze gaat ervan uit dat meerdere taken en rollen er toe leiden dat mensen distressed en overbelast raken ondat ze van nature geneigd zijn te veel taken op zich te nemen. De tweede hyporhese daarentegen, de rol accumulatiehypothese, gaat er van uit dat mensen meerdere rollen 
aannemen omdat ze zich er goed bij voelen. Hoe meer rollen, des te meer bronnen van zekerheid en status, en des te meer mogelijkheden woor persoonlijke groei en zelfbevestiging. De derde hypothese, de expansiehypothese, neemt een middenpositie in omdat deze stelt dat het distressverhogend effect athangt van de mate waarin iemand zich gecommitteerd voelt aan bepaalde rollen. Een extra taak of rol veroorzaakt geen distress als men zich erg gecommitteerd voelt aan die taak. De drie hypotheses (conflict, accumulatie en expansie) hebben we empirisch getoetst in ons onderzoek.

De bevindingen hebben we gebaseerd op een bevolkingssteekproef van 934 vrouwen uit het geboortecohort 1940-54, omdat bij deze leeftijdsgroep (40-54 jaar) de kans het grootst was dat ze een gezin hadden, een baan en ouders die hulp nodig hadden. Deze steekproef wetd in 1994 getrokken uir de bevolkingsregisters van de gemeentes Heerlen en Landgraaf. In 1994 zijn 934 vrouwen telefonisch geinterviewd waarvan er in 1996743 opnieuw bevraagd. De medewerking was erg groot met een respons van $75-80 \%$.

Met betrekking tor de eerste onderzoeksvraag, de omvang van het fenomeen wan de sandwichgeneratie, viel op dat het regelmatig woorkwam dat vrouwen de hulp aan ouders of schoonouders combineerden met een eigen gezin of een baan. Circa 30\% van de vrouwen zat in die situatie. Echter, de combinatie van intensieve zorg voor ouders (minimal 3-4 dagdelen per week) met een eigen gezin en/of een fulltime baan was heel uitzonderlijk (minder dan 1\%). Bovendien vonden de meeste dochters die hulp gaven her niet belastend en juist wel prettig om te doen. Het leek er op dat rollen van hulpgever aan een oudere, moeder en werknemer eerder opeenvolgend worden vervuld en niet zozeer regelijkertijd. Onze conclusie is daarom dat de term sandwichgeneratie schromelijk overtrokken is, aangezien de meeste vrouwen zich niet klem ("sandwiched') voelen zitten en het zeker nier een hele generatie betreft.

De tweede onderzoeksvraag betrof de invloed van andere taken, zoals de zorg voor her eigen gezin of een baan, op de hulp aan ouders. Deze bleek zeer beperkt te zijn. Vrouwen met een gezin namen even goed de hulp voor de ouder erbij. Geen van de andere taken of combinaties ervan, had invloed op de omvang van de hulp die aan een ouder werd gegeven

Werk nam wel een bijzondere positie in. Vrouwen met een baan begonnen niet zo snel hulp te geven, met name fulltime werkende vrouwen werden niet zo gauw de centrale verzorger wan een ouder. Als ze echter eenmaal hulp gaven, deden ze dit ongeacht het aantal uren dat ze buitenshuis werkten. En hoewel ongeveer énderde van werkende verzorgsters aangaf dat ze zich regelmatig klem voelde zirten tussen werk en zorg, mer name de fulltimers, losten ze dat meestal toch wel op door bijvoorbeeld snipperdagen op re nemen. De hulp aan de ouders had geen negatieve invloed op hun loopbaan gehad of een reden geweest voor bijvoorbeeld ziekteverzuim en het opgeven van hun baan. 
Als derde hebben we onderzocht welke factoren bepalen of en hoeveel hulp er werd gegeven. We kwamen tot de conclusie dat her vooral strucrurele en situationele factoren zijn en niet persoonlijke, meer individueel bepaalde factoren. Afstand tot de ouder, beschikbaarheid van een verzorger (geen werk), het ontbreken van alternatieven (enig kind) en de zorgbehoefte van de oudere bleken significant te zijn. Niet doorslaggevend waren de relatie met de ouder of gevoelens van plichrsbesef. Op basis van onze bevindingen kregen we de indruk dat er in zekere zin een zelfselectieproces plaatsvindr; in eerste instantie zal de dichtst bij wonende dochter mer de minste andere verplichtingen hulp gaan geven en de rol van centrale verzorger op zich nemen.

Opvallend was dat de verzorgers zelf zich niet altijd van bewust waren van de mate waarin praktische factoren hun inzer bepaalden. Als redenen om hulp te geven noemden zij, behalve de vanzelfsprekendheid, 'edele motieven' zoals 'uit liefde voor de ouder' en 'iets terug te willen doen' of plichtsbesef. Al eerder hebben we ook aangegeven dat de meeste dochters de hulp aan de ouders of schoonouders in het algemeen als een positieve ervaring beschouwen, of dat zo willen beschouwen. Sommige onderzoekers hebben in dit verband wel beweerd dat de belangrijkste reden om ouders hulp te geven 'gegeneraliseerde wederkerigheid' is. Dit is het plichtsgevoel om iets 'terug te doen" voor de zorg die men zelf als kind heeft ontvangen. Voor zichzelf en naar buiten toe wordt het meestal zo gebracht als zou her (alleen) om liefde en affectie gaan.

Opvallend was wel het contrast met de redenen van degenen die geen hulp gaven. Dan werd wel verwezen naar structurele factoren van overmacht, zoals de afstand tot de ouder of een drukke baan. Dit laatste was dus conform de eerder genoemde analyses waaruit bleek dat de praktische situatie vooral bepalend is.

De vierde onderzoeksvraag betrof de disstress van vrouwen en de ervaring belasting. In tegenstelling tot onze verwachting, bleek er geen systematisch werband te bestaan russen de hoeveetheid - of diverse combinaties- van andere taken en verplichringen die hulpgevers van ouderen hadden en de hoeveelheid stress of belasting in de zorg die zij ervoeren. In meer algemene zin bleek zelfs dat vrouwen die meerdere rollen en taken hadden, juist minder distressed waren en dat degenen die het minst omhanden hadden zich het minst gelukkig voelden. Hoewel oorzaak en gevolg niet altijd duidelijk zijn omdat het wellicht juist de 'sterkste' vrouwen zijn die de meeste taken op zich nemen, maken onze onderzoeksbevindingen het aannemelijk dat het leven als meer zinvol wordt ervaren wanneer vrouwen meerdere, en niet minder, rollen en taken hebben.

Soortgelijke conclusies gelden voor de ervaren belasting in de zorg. We vonden geen enkele aanwijzing dat andere taken, naast die van de zorg voor de ouder, de ervaren belasting verhoogde. Er lijkt dus geen sprake te zijn van 'dubbele belasting' als gevolg van de zorg voor her eigen gezin of een baan. Belasting werd bepaald door andere factoren, zoals her aanta! uren hulp, de eigen fysieke gezondheid van de verzorgster, de gezondheid van de ouder en de relatie mer de ouder. Belangrijk was de mate waarin de zorg doordrong in alle aspecten van haar leven en de privacy aantastte. 
Theoretisch bexien en wooral in relatie tot de drie hypotheses uit de roltheorie, vonden we steun voor de rolaccumularie en rolexpansie hypothese, die stellen dat meerdere rollen en taken her welzijn kunnen bevorderen. De rolconflicr leek nauwelijks van toepassing als het gaat om hulp aan ouders door dochters van middelbare leeftijd.

Het overheidsbeleid zou ons inziens faciliterend en aanvullend moeten zijn. Want hoe moeilijk ze het ook af en toe vinden, wij kregen sterk de indruk dar vrouwen graag een aandeel in de zorg voor hun ouders willen blijven houden. Ze moeten echter daartoe wel in staat gesteld worden. Vooral fulltime werkende hulpgevers verdienen extra aandacht. Flexibele werktijiden, zorgverlof, professionele hulp voor het opvangen van pieken in de zorg, en het betrekken van de familie en andere porenriële hulpgevers wanneer professionele hulp wordt ingeschakeld, is belangrijk. Een nieuw en relatief onontgonnen gebied is ondersteuning van zorg door moderne communicatietechnologie, wat belangrijk kan zijn vooral wanneer een dochter wat verder weg woont en enig kind is.

Wellicht de meest opvallende waarneming in dit onderzoek was hoe gewoon en vanzelfsprekend het nog steeds wordt gevonden om hulp te geven aan ouders. Wij concludeerden dan ook, conform vele andere studies, dat familiezorg als institutie nog steeds bestaat en stevig verankerd lijkt in de samenleving. De idee dat familiewaarden vervagen en dat ouderen door hun kinderen in de steek worden gelaten berust ons inziens dan ook op een mythe. De hardnekkigheid van deze mythe wordt wel eens wergeleken met her zevenkoppige monster uit de Griekse mythologie: voor elk hoofd dat wordt afgekapt groeit het dubbele aantal er opnieuw aan. Desalniettemin hebben wij met dit onderzoek een hernieuwde poging ondernomen om tegenwicht te bieden aan deze mythe. 


\section{ACKNOWLEDGEMENTS}

First of all, I like to thank the women in Landgraaf en Heerlen who participated as respondents in this study. We are grateful for their willingness ro cooperate and to share with us their personal views about the experiences with helping parents. Those who received me at home, I thank them for their kindness, their openness and the time spent on explaining me their situation.

I also like to thank the interviewers of MEMIC who are so skillful in persuading the respondents to cooperate and share their views. Robert Klinkenberg, thanks for your patience and the technical support and Gregor Franssen, thanks for the organization of the telephone survey. The project assistant Vonca Schaeffer did some excellent in-depth interviews providing us with the complementary background information on the caregving situation of the respondents.

Jos, you have been a great supervisor, giving room for new ideas and supporting this study with your keen-wirted analytical mind. The image of you leaning behind in your chair and smoking your pipe while ventilating all kinds of hypotheses, is ineffaceable.

Hans, you have been very much at a distance for several years, but compensated this at the end of our study when you shared with us your keen 'helicoprer views'. Having reached the age of retirement, you perhaps will be soon a test case of what we postulated in this study: that family support for a frail parent is still very common and a matter of course.

I felt lucky to be part of the department of Medical Sociology for five years, as you, 'medsoc' colleagues, have provided me with a very sociable working environment. The tea breaks at the secretarial office and the many chats at the printer's room helped me through uninspired hours. Regien, Silvia and Bert have been great office "roommates" for me and I am happy that we became friends. Bert, thanks for your support and the fun we made about our co-workers and about ourselves. Jeanine, thanks for your support at the background. Rutger, you have been my 'sounding-board' for so many issues in life and I enjoyed the endless gossips we shared. Paul, our chats while having coffee helped me through the many weekends that I had to spend on writing final versions of chapters. At least I knew I was not the only one struggling at the office. And, last but not least, Rudi, would you please save your last dance for me?

My job as a researcher enabled me to rravel all over the world and meet many interesting colleagues. One of those, Dorly Deeg, aired the view that it often happens to researchers that they suffer from their own object of study. That's what occurred to me. By the time that I was about to funish the last chapter on daughters caring for elderly mothers, my mother fell ill. It provided me with the real life experience of the employed daughter rushing berween the office, hospital and home. Just like my respondents, I did it without thinking and as a matter of course. 
134 Acknowledgements

Mum, you have been a wonderful and joyful mother to me. Your disease has brought the two of us, as well as our family, so much closer. I earnestly hope that we still have some time ahead together. And my brothers, as my family, you are simply there. But I would have chosen you, too, as my friends. 


\section{CURRICULUM VITAE}

Being conceived in 1959 on a boat sailing the Adantic Ocean and born on the Caribbean island Bonaire (Dutch Antilles) has perhaps laid the foundation for the international and almost nomadic life style that I have adopted as an adult. In 1963 , when I was three years old, my parents returned from the Dutch Antilles to their home village Nieuwenhagen in Parkstad Limburg, Netherlands. I grew up as a real village Limburg girl and finished primary school at the Catholic Maria School in Nieuwenhagen. Nuns and the Catholic traditions in general have be an ineradicable part of memories of my youth.

At the age of rwelve, I went to the Coriovallium College, finishing High School ('Gymnasium') with a specialization in languages in 1978. In 1981, I graduared from Tilburg University with a Bachelor's degree ('kandidaars') in Sociology; in 1987, I received my Masters ('doctoraal'), with non-western Sociology as a major (Tilburg University) and three minors, i.e. Medical Anthropology (University of Amsterdam), Education (Tilburg University) and Indian Languages and Culture (University of Groningen). As part of my studies, I researched local health care systems in Indian villages near Calcutta from 1985 to 1986.

International cooperation was indeed my calling. From 1987-1988, I worked part-time as the coordinator of education at the Center for Development Cooperation (COS) in Groningen, and part-time as a research fellow at the Institute for Development Cooperation (IVO) at Tilburg University on a project on women's labor in the Pakistani carpet industry. From 1988 to 1990 , I did a srudy of the mental health of Dutch immigrants in the Netherlands at the Faculty of Economics at Tilburg University.

When the Royal Tropical Instirute in Amsterdam approached for a research project in Tanzania, $I$ accepted the challenge and worked for three years as the head of a research department doing research on AIDS and HIV transmission in Mwanza, Tanzania. From 1993 onwards, I decided to stay in The Netherlands. During my appointment as coordinator of a center organizing courses for Durch expatriates in 1993-1994, I thought that a Ph.D. was the most logical next step in my career. Hence, in 19941 joined the Maastricht University and wrote this $\mathrm{Ph}$. D. thesis on women's involvement in parent care at the Department of Medical Sociology of the Faculty of Medicine.

From May 1999 onwards, I have again been working in international cooperation, but now in a different field: international education. As a Deputy Director of the Center for European Studies at Maastricht University, I am responsible for the day-to-day management of the Center and the organization of international educational programs for university students from all corners of the globe.

Maaike Dautzenberg 
Weggaan kun je beschrijwen als een soort van blijuen. Niemand wacht want je bent er nog. Niemand neemt aficheid want je gaat niet weg.

Rutger Kopland 